S=HE ¿lgualdad de oportunidades?

\title{
DESARROLLO PROFESIONAL de hombres y mujeres en España
}

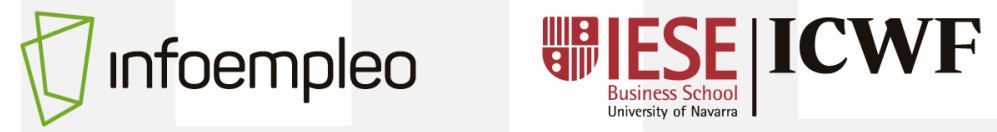


1 
INDICE 


\section{Introducción \\ Prólogos}

Marco Previo

Evolución 1987-2017

Desigualdad de oportunidades:

Brecha salarial

Segregación vertical

Segregación horizontal

Evolución del contexto social

16 Objetivos y metodología

18 Glosario

20 Muestra
26 Modelo S=HE de Igualdad de Oportunidades ¿Qué son los entornos S=HE?

$\mathrm{S}=\mathrm{HE}$ en Empresa

Políticas y prácticas

Liderazgo

Cultura inclusiva

$\mathrm{S}=\mathrm{HE}$ Personales

Prácticas de organización

Toma de decisiones

Creencias personales

$\mathrm{S}=\mathrm{HE}$ en Familia

Prácticas de organización

Toma de decisiones

Creencias en el entorno 
38 Resultados del estudio S=HE en España

$\mathrm{S}=\mathrm{HE}$ : Políticas y Prácticas

Políticas y prácticas en las Empresas

Prácticas de organización personal eficaz

Prácticas de organización familiar

S=HE Liderazgo y Toma de Decisiones:

Liderazgo en las Empresas

Toma de decisiones - búsqueda de apoyo

externo

Toma de decisiones en familia

$\mathrm{S}=\mathrm{HE}$ Cultura y Creencias:

Cultura inclusiva en la Empresas

Creencias personales - autoestima

Creencias en el entorno familiar
54 Consecuencias

Entorno S=HE en la empresa

Horas de trabajo

Compromiso con la misión

Satisfacción con el trabajo

Entorno S=HE en la familia

Conflictos en la familia debido al trabajo Tiempo dedicado a la familia

Entorno S=HE en la persona

Satisfacción con áreas vitales

Calidad del sueño

Colapso

4 


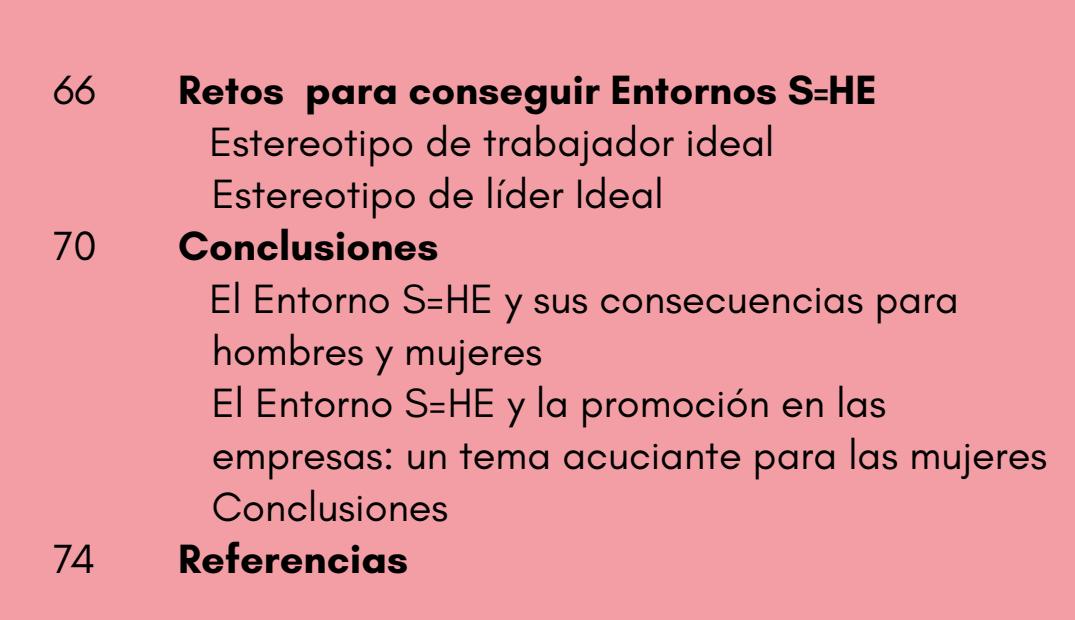




\section{INTRODUCCIÓN}

\section{Querido lector:}

Tienes en tus manos el informe "S=HE ¿lgualdad de Oportunidades? Desarrollo Profesional de Hombres y Mujeres en España." Corresponde al estudio dirigido desde el Centro Internacional Trabajo y Familia del IESE (ICWF en sus siglas en inglés) con la colaboración de Infoempleo y Gas Natural Fenosa, realizado en el año 2017.

Te animo que al leer este informe, encuentres en él algo que en tu labor profesional diaria, en tu comportamiento social, o en tu quehacer dentro de tu familia pueda ayudarte: como directivo, emprendedor o empleado. No importa cuál sea tu rol social tú puedes ser un agente de cambio, puesto como iras descubriendo en este informe, con tu modo de hacer, de decidir, de tomas decisiones, influencias el entorno en el que desarrollan su trayectoria otros cerca de ti.

Seguro que hay algo que puedes hacer para que más personas se beneficien de entornos Satisfactorios, frente a desarrollar sus vidas, y sus trayectorias profesionales, en entornos Hostiles o Escluyentes. Si tienes responsabilidades políticas o directivas, aún mejor, en ese caso no dejes de pensar en los cambios legislativos que podrían fomentar que más y más personas desarrollen sus tareas en empresas que fomentan la igualdad de oportunidades para hombres y mujeres.

Todos nos beneficiaríamos de tener una sociedad en la que desarrollar una vida más sana, más productiva, y en la que la dedicación a la familia (hijos, mayores, dependientes y otros seres queridos) no sea excluyente con una aportación profesional relevante. Por ello mi agradecimiento va hacia los que han participado en este estudio haciendo posible llegar a conocer mejor los entornos en nuestro país, así como las consecuencias de dichos entornos. Mi agradecimiento se dirige también hacia Infoempleo, por hacer posible este estudio así como a Gas Natural Fenosa, que ha apoyado nuestro esfuerzo investigador. $Y$ no puedo dejar de agradecer a mis queridas colegas de IESE, Esther Jiménez, quien participó en la concepción del marco del estudio, así como a Gemma Palet, que ha ayudado a facilitar su lanzamiento. También a Gemma Riera y Julia Sierra, que con su cuidado trabajo de análisis han ayudado a destilar los resultados.

Tenemos la confianza de que el camino que comenzamos a recorrer con este informe seguirá discurriendo por veredas que harán de esta sociedad un lugar mejor para el desarrollo de las empresas, los ciudadanos en su conjunto y las familias. Contamos contigo. 


\section{Mireia Las Heras \\ Directora de investigación del ICWF IESE Business School}

Se incorporó a IESE en 2009 después de graduarse de su Doctorado en Boston University School of Management. Anteriormente había estudiado su MBA en IESE, graduándose en la promoción del 2003. Es además Ingeniera Industrial por la Universidad Politécnica de Cataluña.

Fruto de su investigación, ha publicado en revistas de impacto académico en temas relacionados con la integración trabajo-familia alrededor del mundo, sobre mujer y liderazgo, sobre desarrollo de trayectorias profesionales, así como sobre Talento y Generaciones. Mireia es la directora del proyecto de investigación IFREI, que reúne a investigadores de más de diez países. Junto a la Prof. Chinchilla, dirige la Conferencia Internacional Trabajo Familia, que ha celebrado ya su $7^{a}$ edición. Es además la directora de la Conferencia Internacional de IESE de Mujer y Liderazgo, que celebró su primera edición en Julio 2017.

Le encantan las manualidades, la fotografía y el baloncesto - ya no lo practica. Es muy activa y le encantan las Redes Sociales emireialasheras. 


$$
\text { PRÓLOGOS }
$$




\section{Jorge Guelbenzu Lapresta Director General Infoempleo}

Este informe que tienes ante ti es, ante todo, una llamada a la acción. Parece, cuando menos, anacrónico que en pleno siglo XXI vivamos en un mundo en el que las mujeres, por el mero hecho de serlo, partan de una posición más desfavorable que los hombres a la hora de conseguir un empleo, un ascenso o un salario igual al de su compañero varón, por mencionar solo algunas de las discriminaciones que más se denuncian en el ámbito laboral.

Sí, la igualdad de oportunidades entre hombres y mujeres es importante. A estas alturas, nadie debería poner en duda esta afirmación. Pero, como podrás descubrir a lo largo de este estudio, todavía nos queda un largo camino por recorrer.

No hay ninguna razón creíble que avale que las mujeres no deban estar al mismo nivel que los hombres en el desarrollo de su vida profesional, familiar y personal. Más bien todo lo contrario: la igualdad de oportunidades se traduce en mejoras para toda la sociedad.

Un ejemplo: en 2016 murieron más personas de las que nacieron por segundo año consecutivo en nuestro país. Además de todas las implicaciones que este hecho conlleva en materia de sostenibilidad del Estado de bienestar, el argumento económico para la igualdad de género que se esconde detrás es claro. La plena participación de las mujeres en la fuerza de trabajo contribuye de forma determinante a la economía de un país, además de favorecer un crecimiento y un desarrollo sostenibles.

Es más, eliminar las desigualdades entre hombres y mujeres en el ámbito laboral se traduciría en un aumento del $26 \%$ del PIB mundial para el año 2025, una información publicada por el Instituto McKinsey y respaldada por la ONU, el FMI o la OCDE, entre otros organismos internacionales.

La igualdad de oportunidades entre mujeres y hombres no es solo un derecho fundamental amparado y protegido por ley. Es una piedra angular para cualquier economía que quiera ser próspera y que persiga un crecimiento sostenible.

No más brecha de género, no más techo de cristal, no más desigualdad salarial. Gobierno, empresas, instituciones educativas, familias... Todos somos responsables, y en cierto modo culpables, de una discriminación a la que deberíamos haber puesto freno hace mucho. Nuestra obligación ahora es trabajar unidos para que el reparto de derechos, oportunidades y responsabilidades no dependan del sexo con el que nacemos, sino de nuestra propia capacidad. 


\section{Cristina Escribano Subdirectora de Talento Gas Natural Fenosa}

La incorporación del concepto y las prácticas de diversidad en las organizaciones, concretamente la diversidad de género, es algo que arranca en el marco de un gran cambio social ocurrido a finales del siglo $X X$, pero que ya en el XXI se ha convertido en uno de los pilares de la sostenibilidad de nuestras organizaciones.

La gestión de la igualdad de género, y la gestión de la diversidad en su conjunto, se convierte así en un rasgo cultural de una organización si esta lleva a cabo una serie de políticas y beneficios orientados a la integración de dicha diversidad, hablando entonces de una cultura inclusiva: una cultura donde existe conciencia y participación para integrar a aquellos que, de una u otra forma, son distintos entre sí.

La correcta gestión de la diversidad de género en el seno de una compañía, es decir, la existencia de una cultura corporativa inclusiva adaptada a la realidad social y empresarial, es fuente de oportunidades de crecimiento en términos de:

- incremento en las oportunidades del mercado,

- avance en innovación y transversalidad,

- reconocimiento externo e imagen corporativa y

- desarrollo del capital humano como fuente de ventaja competitiva
Por eso, la gestión de la diversidad es una apuesta decidida de Gas Natural Fenosa, especialmente desde 2011, cuando comienzan a producirse varios hechos claves que lo ponen de manifiesto:

- La publicación de nuestro Plan de Desarrollo Humano y Social, en el que se dota de protagonismo a la igualdad de género y discapacidad

- Inclusión del principio de Interés por las Personas como uno de los compromisos principales de la Política de Responsabilidad Corporativa de Gas Natural Fenosa.

- Formalización del Plan Integral de Diversidad estructurado sobre tres ejes de actuación: Edad, Discapacidad y Género

Conocer cómo es el entramado social en que se desenvuelven nuestras compañías en términos de diversidad de género, cómo son los comportamientos individuales y de dirección de equipos y cuáles son los estereotipos que los pueden estar determinando, además de, y sobre todo, entender la barreras psico-sociales que debemos afrontar, son elementos fundamentales que cada compañía debe tener en cuenta a la hora de revisar sus políticas, normativas y procedimientos. 
Todo ello permitirá facilitar la cultura inclusiva que nos debe mantener competitivos y nos contribuirá a reforzar nuestra presencia en el mercado.

Por ello, este riguroso trabajo, centrado en aspectos tan significativos como una revisión profunda de las políticas y prácticas sociales, empresariales e individuales en materia de igualdad, un análisis del líder como responsable y gestor de la inclusión y una visión de la cultura empresarial inclusiva, es una inestimable ayuda para las empresas en la gestión de la igualdad en términos de oportunidades de desarrollo. 


\section{MARCO PREVIO}

\section{Evolución de tasa de actividad femenina, formación académica femenina y natalidad en España 1987-2017}

Desde el final de la década de los 80 hasta nuestros días, muchos han sido los avances efectuados por la mujer española a nivel social y laboral. La tasa de actividad femenina hace tan solo 30 años, en 1987, se hallaba en el $32.4 \%$; la de los hombres era del $67,1 \%$. Sin embargo, en el primer trimestre del 2017 la tasa de actividad femenina estaba en el $53,24 \%{ }^{2}$, frente a la de los hombres, que en el mismo periodo se situaba en el $64,62 \%$. Por lo tanto, mientras el gap de actividad en el año 1987 se situaba en 37 puntos porcentuales, en 2017 lo hace en tan solo 11,38 puntos. Aunque dicho gap no es ni mucho menos negligible, sí que ha experimentado una evolución claramente positiva.

Los cambios más importantes acaecidos en la economía española, durante los últimos 30 años, se pueden resumir en tres ${ }^{3}$. Primero, en el mercado laboral español se ha incrementado la tasa de actividad femenina en más de 21 puntos en tres décadas; segundo, en el sistema educativo la tasa de escolaridad de la mujer es superior en casi todas las edades a la de los varones, incluida la educación universitaria, excepto en las carreras técnicas; tercero, la disminución de la tasa de natalidad, de 18,7 nacidos por cada mil habitantes en el año 1977 (y 9,5 en 2002) a 8,8 en 2017.

Aunque desde 1910 las mujeres en España han podido matricularse de modo oficial en las universidades, no representaban más que el $12,6 \%$ de los estudiantes en 1940 o el 31\% en 1970; en el año 2000, sin embargo, ya suponían el $53 \%$, y el $54 \%$ en 2010 . En la actualidad, su tasa de éxito es mayor que la de los varones. Por ejemplo, según datos del INE ${ }^{4}$, en el curso terminado en 2015 , las mujeres matriculadas en grados de ciencias sociales y jurídicas eran el $59 \%$; las que se graduaron ese mismo año fueron el $65 \%$ del total de nuevos titulados.

Sin embargo, es aún desproporcionadamente masculina la población que se decanta por estudios científicotécnicos. En el año 2015 las mujeres matriculadas en enseñanzas de grado de ingeniería y arquitectura eran tan solo el $25 \%$; las que se graduaron ese mismo año fueron el $28 \%$ del total de los graduados.

\section{Evolución del contexto económico 1987-2017}

Paralelamente a la incorporación de la mujer a los estudios universitarios y al mercado laboral, el contexto 
económico en España ha sufrido grandes cambios en las últimas décadas. Nuestro país ha conseguido en treinta años transformarse política, social y económicamente ${ }^{5}$. El rápido crecimiento del turismo, la industria de la construcción, así como la automovilística, hicieron de la economía española una de las de mayor crecimiento de Europa durante tres décadas.

Sin embargo, en estas tres décadas la economía ha pasado por un fuerte bache a raíz de la crisis financiera que se desencadenó a nivel mundial en el año 20082009, y de la que todavía estamos recuperándonos en la actualidad.

\section{Aspectos en que se manifiesta la desigualdad de oportunidades de hombres y mujeres}

En el mercado laboral español hay tres dimensiones en las que hombres y mujeres difieren de modo sustancial:

\section{- Brecha salarial}

Por brecha salarial se entiende que los varones obtienen mayores salarios que las mujeres al desempeñar el mismo trabajo.

Si bien en España sigue existiendo una brecha entre el salario medio de las mujeres y el de los varones, se constata una tendencia general hacia su reducción ${ }^{6}$. El acercamiento entre ambos salarios medios se ha debido, fundamentalmente, a la mejora de las cualificaciones relativas de las mujeres, al menos hasta el inicio de la última crisis económica que ha sufrido el país.

La brecha salarial ha afectado históricamente de mayor modo a las personas de mayor edad. Así pues, en el año $2014^{7}$ (último del que se disponen datos al respecto del INE) la brecha seguía siendo del $45 \%$ entre personas de más de 65 años, 
mientras que dicha ratio disminuye hasta el 5,7\% en los menores de 25 años.

\section{- Segregación vertical}

La segregación vertical se refiere a que la presencia de mujeres desciende a medida que se asciende en las escalas jerárquicas de las empresas, así como en los puestos de responsabilidad social. Igual que en otros indicadores, dicha segregación ha disminuido en las últimas décadas, y de modo más intenso en los últimos años.

Sin ir más lejos, en febrero del 2017 las mujeres ocupaban un 20,3\% de los puestos en los Consejos de Administración del IBEX-35. Si bien es cierto que la presencia de mujeres consejeras ha experimentado un mayor aumento en las empresas del IBEX-35 que en el resto de empresas ${ }^{8}$, su evolución muestra un cambio notorio del rol de

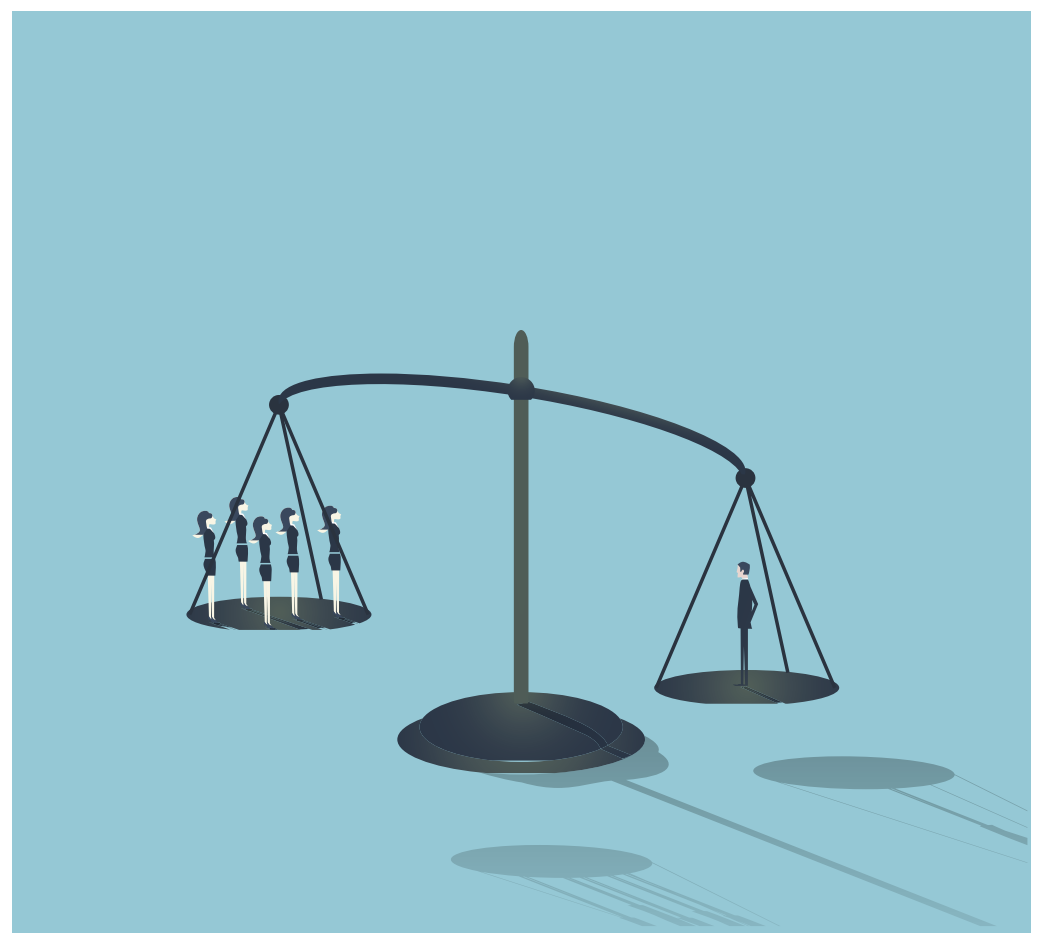

responsabilidad que desempeñan las mujeres en el ámbito corporativo.

Para alcanzar el éxito empresarial, el reto de atraer y fomentar el desarrollo profesional de las mujeres, aprovechar su talento y complementarlo con el liderazgo masculino es una tarea esencial en las organizaciones. Asimismo, estas deben ajustarse a la realidad social cambiante y crear entornos laborales propicios para hacer compatible el equilibrio entre la familia y el trabajo de sus trabajadores.

\section{- Segregación horizontal}

La segregación horizontal se refiere a la presencia fememina en los distintos ámbitos de actividad económica, e incluso en los distintos departamentos dentro de las empresas.

En gran medida dicha segregación horizontal viene explicada, como se ha mencionada anteriormente, por las distintas elecciones de estudio que realizan hombres y mujeres. Mientras que los primeros se decantan más por carreras científico-técnicas, las mujeres optan mayoritariamente por estudios del ámbito de las ciencias sociales, humanidades y ciencias de la salud.

Además, existen algunas ocupaciones con un grado muy elevado de representación feminina, como "empleados domésticos" y "otros trabajadores de los cuidados a las personas". Se observan también porcentajes muy altos de mujeres en algunas ocupaciones relacionadas con la educación, la sanidad o con las tareas de carácter administrativo y de atención al público.

Por su parte, algunas de las ocupaciones más masculinizadas son las relacionadas con la 
construcción, la mecánica o la conducción de vehículos y los servicios de protección.

\section{En concreto, hay 35 ocupaciones feminizadas/} masculinizadas y 20 ocupaciones integradas en términos de género. De entre las primeras, 22 están masculinizadas y 13 feminizas. Muchas de las ocupaciones más feminizadas o masculinizadas están muy ligadas a los estereotipos y creencias sobre lo que son actividades "femeninas" o "masculinas".

\section{Evolución del contexto social}

Hasta hace tan solo dos o tres décadas, las roles y responsabilidades sociales y familiares estaban claramente repartidos entre hombres y mujeres. Aunque con excepciones, era mayoritariamente aceptado que las mujeres debían encargarse del cuidado del hogar y de los miembros de la familia, mientras a los hombres

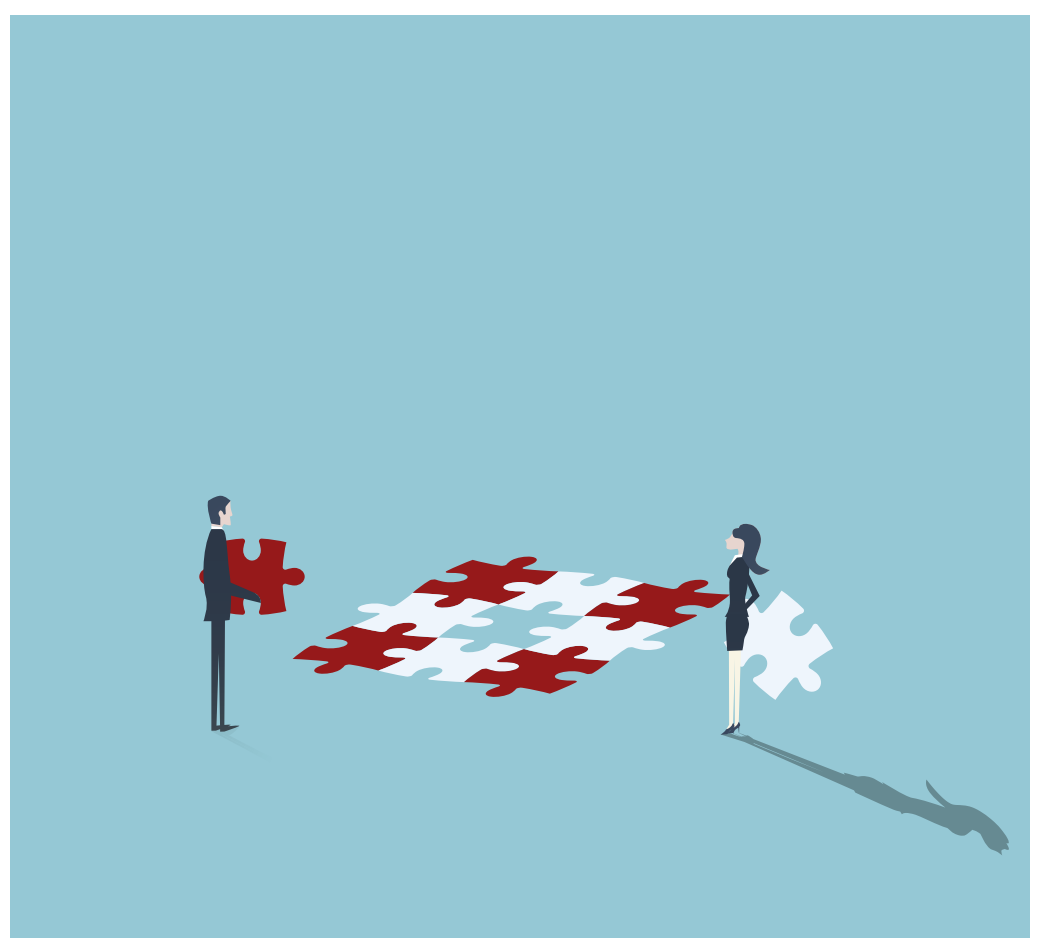

les correspondía obtener los recursos económicos realizando un trabajo fuera de casa. Este reparto de tareas comenzó a cambiar notablemente en España durante la década de los 90.

A día de hoy sigue resultando imprescindible que en nuestro país se avance en la corresponsabilidad de hombres y mujeres en las tareas domésticas, en los poderes públicos y en las universidades. En el ámbito del hogar, por ejemplo, la mujer sigue realizando las tareas más rutinarias y físicas con sus hijos. Son ellas las que, cuando trabajan a tiempo completo, indican que les visten el $96 \%$ de las veces, o preparan la comida el $89 \%$ de las ocasiones; mientras que ellos afirman que lo hacen el $67 \%$ y el $57 \%$ de las ocasiones 9 , respectivamente.

La responsabilidad compartida en las tareas domésticas y de cuidado de los hijos es imprescindible para que la maternidad no se convierta en una limitación en la carrera profesional de las mujeres; o, dicho de otro modo, que el estar en el mundo laboral no dificulte o llegue a impedir la maternidad.

La igualdad de oportunidades entre mujeres y hombres es un componente fundamental en el progreso de una sociedad, especialmente en una como la nuestra, donde, como se ha dicho anteriormente, la tasa de natalidad disminuye y se registra una tendencia demográfica hacia el envejecimiento ${ }^{10}$. Se prevé que el porcentaje de población mayor de 65 años, que en el año 2017 se sitúa en el 18,2\%, pasará a ser del 24,9\% en 2029 y del $38,7 \%$ en 2064 , con los consiguientes problemas que esto genera para el sistema de pensiones, el mercado laboral y el cuidado de mayores, entre otros. 


\section{OBJETIVOS Y METODOLOGÍA}

Las personas desarrollan sus trayectorias profesionales en entornos organizativos, sociales y familiares. Esta realidad puede conducir a que aporten el máximo en cada uno de dichos ámbitos o, por el contrario, que su contribución se vea mermada.

El objetivo de este estudio es realizar un diagnóstico de los entornos en los que se desarrollan estas trayectorias profesionales de hombres y mujeres, así como sus preferencias profesionales y vitales.

En base a la teoría antropológica del Prof. Juan Antonio Pérez Lopez, se desarrolla el concepto S=HE, basado en tres entornos distintos (entorno Satisfactorio, entorno Hostil y entorno Excluyente), a través de los cuales se puede medir el nivel de liderazgo femenino y masculino.

En el modelo S=HE distinguimos tres dimensiones que determinan el tipo de entorno en el que la persona desarrolla su trayectoria. Estas tres dimensiones se refieren siempre a:
- Políticas y prácticas habituales

- Estilos de decisión y de liderazgo

- Cultura y valores en la toma de decisiones

El estudio S=HE es un modelo antropológico y holístico. Es antropológico porque se basa en el paradigma antropológico de persona, a la que sitúa como centro y pilar de la empresa, de la familia y de la sociedad. Y es holístico porque comprende a la empresa, la familia y la sociedad en sus diversas dimensiones.

En concreto el modelo S=HE trata a la empresa como un conjunto de personas que desean generar riqueza y repartirla del modo más equitativo posible, produciendo un bien o servicio. La producción de dicho bien o servicio debe, por una parte, satisfacer necesidades reales de los clientes $y$, por otra, conseguir que quienes componen la empresa desarrollen sus capacidades y satisfagan sus necesidades personales y profesionales.

El modelo S=HE comprende a la familia como el lugar en el que, por naturaleza, se desarrolla primeramente toda persona, ya que es el principio y el fin de toda 
existencia humana. Es la familia, por tanto, la base de toda sociedad y fuente de la felicidad a la que todos aspiramos.

Con este estudio buscamos conocer en qué entornos se mueven los hombres y las mujeres en España, y cómo los distintos entornos repercuten en variables de interés a nivel empresarial, personal-familiar y social. Es decir: en la presente investigación estudiamos hasta qué punto los distintos entornos favorecen a las organizaciones, a los individuos y la sociedad en su conjunto.

Para llevar a cabo este estudio, el Centro Internacional de Trabajo y Familia del IESE Business School ha elaborado un cuestionario cuantitativo que ha sido distribuido a nivel español por Infoempleo y contestado por 2.138 participantes durante el 2017. Dicho cuestionario recoge preguntas de los propios investigadores del centro junto con otras elaboradas a partir de cuestionarios existentes, todas ellas debidamente validadas mediante rigurosos métodos cuantitativos.

Más relevante si cabe, el estudio S=HE es el primero que se realiza en España en el que se distinguen los entornos a nivel empresarial, familiar y social, combinándolos de modo que podemos conocer el entorno "global" en el que se mueven las personas en nuestro país, además de relacionalo estadísticamente con las consecutivas que dicho entorno genera.

Como sociedad, debemos dar máxima trascendencia al bienestar de las personas. Por lo tanto, los resultados que este estudio son de la mayor relevancia para todos nosotros, como ciudadanos, como empleados y como miembros de una familia.

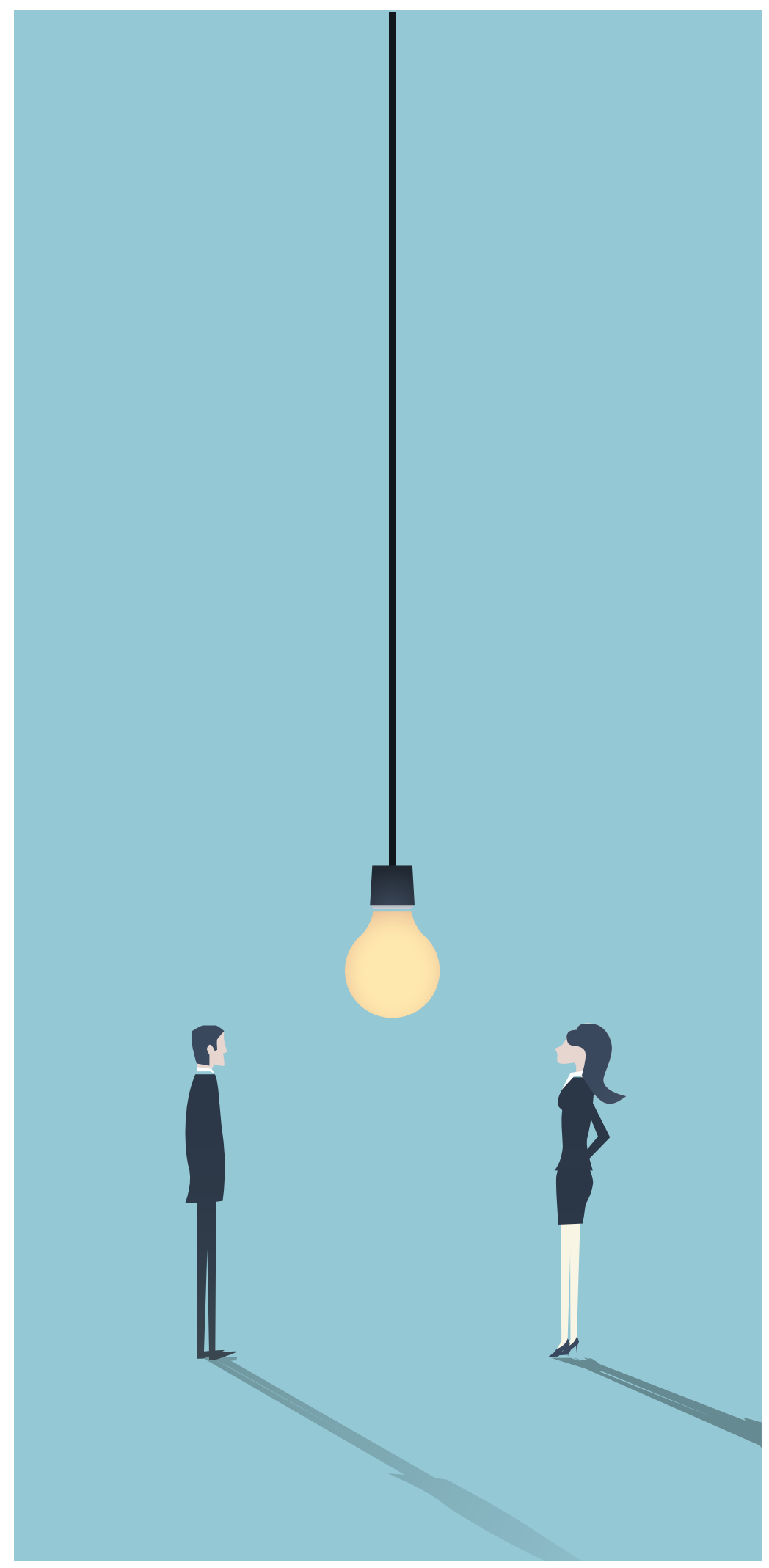




\section{GLOSARIO}

Calidad del sueño: sueño que tiene una duración suficiente. Es continuo y profundo, y por ello reparador.

Colapso: incapacidad de desarrollar una actividad normal de modo operativo. Se manifiesta en la sensación de incapacidad de realizar aquello a lo que uno se ha comprometido y conduce a pensar constantemente en lo que todavía queda por hacer.

Compromiso con la misión de la empresa: deseo que tienen los empleados de contribuir a la consecución de la misión de la empresa por el mero hecho de pensar que ésta es relevante.

Conflicto trabajo-familia: situaciones en las que las demandas del trabajo o la sobrecarga del mismo dificultan o imposibilitan tener una relación satisfactoria con el cónyuge, los hijos u otros familiares dependientes, así como dedicar tiempo a desarrollar otros aspectos relevantes de la vida personal (voluntariado, formación continua, deporte, ocio, etc.).

\section{Cultura inclusiva en la empresa: conjunto de} supuestos, creencias y valores compartidos por los miembros de la organización en función del grado de apoyo de ésta a los empleados.

Creencias en el entorno familiar: quién debería ser el responsable de realizar las tareas de cuidado, tanto del espacio físico en el que se cohabita como de las personas que conviven en el núcleo familiar - hijos, dependientes $\mathrm{y} / \mathrm{o}$ personas mayores.

Creencias personales: valoración positiva o negativa que una persona hace de sí misma y que le llevará a proyectar una imagen concreta, a presentarse ante los demás y a reconocer los aciertos y errores propios.

Entorno: espacio en el que las personas toman sus decisiones y desarrollan su vida. por ello en el estudio $\mathrm{S}=\mathrm{HE}$ definimos tres tipos de entornos:

- Entorno organizativo o de empresa: definido en función de las políticas en la empresa y del liderazgo y la cultura que se ejercen en ella.

- Entorno familiar: determinado por las prácticas en el entorno familiar, la toma de decisiones conjunta y las creencias respecto al cuidado de dependientes y de tareas del hogar.

- Entorno personal: prácticas de organización personal, toma de decisiones y búsqueda de apoyo externo, además de creencias respecto a capacidad propia y motivación.

Estereotipo de líder ideal: imagen estructurada y aceptada por la mayoría de lo que es representativo y necesario para ser un buen líder en una empresa.

El estereotipo de líder ideal influencia las expectativas que se tienen de las características necesarias para poder ejercer un rol directivo. 
Estereotipo de trabajador ideal: imagen estructurada y aceptada por la mayoría de lo que es representativo y necesario para ser un buen trabajador. Formada a partir de una concepción estática sobre las características generalizadas de los empleados con éxito en la época post-revolución industrial y que no responde a las características del entorno de trabajo actual.

\section{Políticas que facilitan igualdad de oportunidades:}

prácticas establecidas en las organizaciones destinadas a que se favorezca el talento y no haya discriminación.

Prácticas en el entorno familiar: responsabilidades que cada miembro de la pareja asume en los trabajos del hogar y el cuidado de otros miembros de la familia (en concreto, padres, suegros y/o hijos).

Prácticas de gestión personal: hábitos que tienen los individuos en términos de organización y delegación de obligaciones.

S=HE: modelo de estudio de los entornos en los que las personas toman sus decisiones personales $y$ profesionales. Estos entornos se clasifican como:

- Entorno S (Satisfactorio): se fomenta la igualdad de oportunidades. Políticas de empresa que facilitan que no haya sesgos por razón de sexo. Cultura inclusiva de la empresa. Toma de decisiones consensuada en el ambiente familiar.

- Entorno H (Hostil): el entorno dificulta ocasionalmente la igualdad de oportunidades entre hombres y mujeres.

- Entorno E (Excluyente): el entorno dificulta sistemáticamente la igualdad de oportunidades entre hombres y mujeres.

\section{Toma de decisiones en la empresa - Liderazgo} inclusivo: cuatro tipos de conductas que los líderes pueden mostrar y que facilitan la diversidad de necesidades y aportaciones entre sus empleados. Son: apoyo emocional, apoyo instrumental, manager como modelo a seguir y gestión de las políticas de balance trabajo-familia.

Toma de decisiones en gestión de personas: en el contexto de estrategias de modelos de dirección, se refiere a la empatía, o soporte social mutuo, que las personas buscan en los demás, ya sea en individuos de ambientes y marcos diferentes al suyo o en individuos más familiarizados con el problema cuestión.

Toma de decisiones en el entorno familiar: búsqueda de apoyo en la pareja cuando el individuo tiene problemas o conflictos en el trabajo.

Satisfacción en el trabajo: actitud positiva de la persona hacia su trabajo. 


\section{MUESTRA}

Total: 2.138 participantes

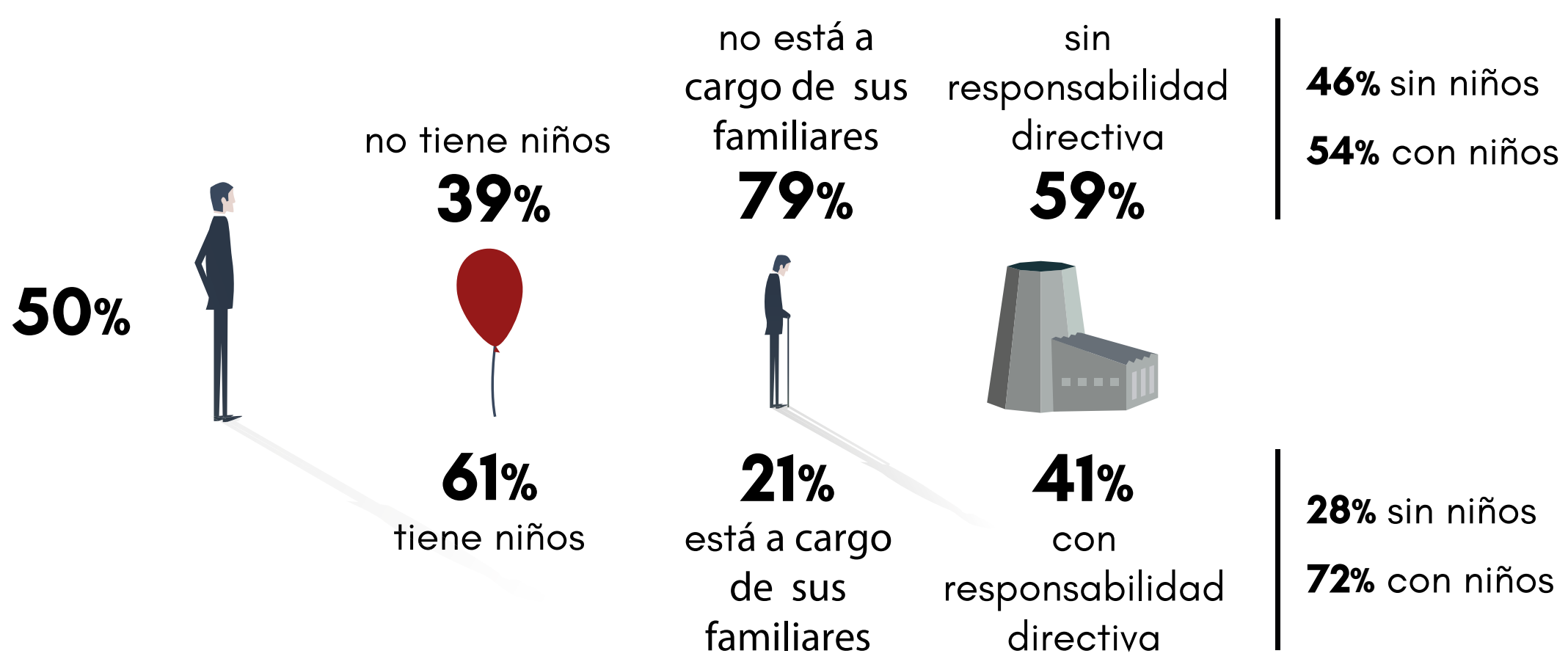




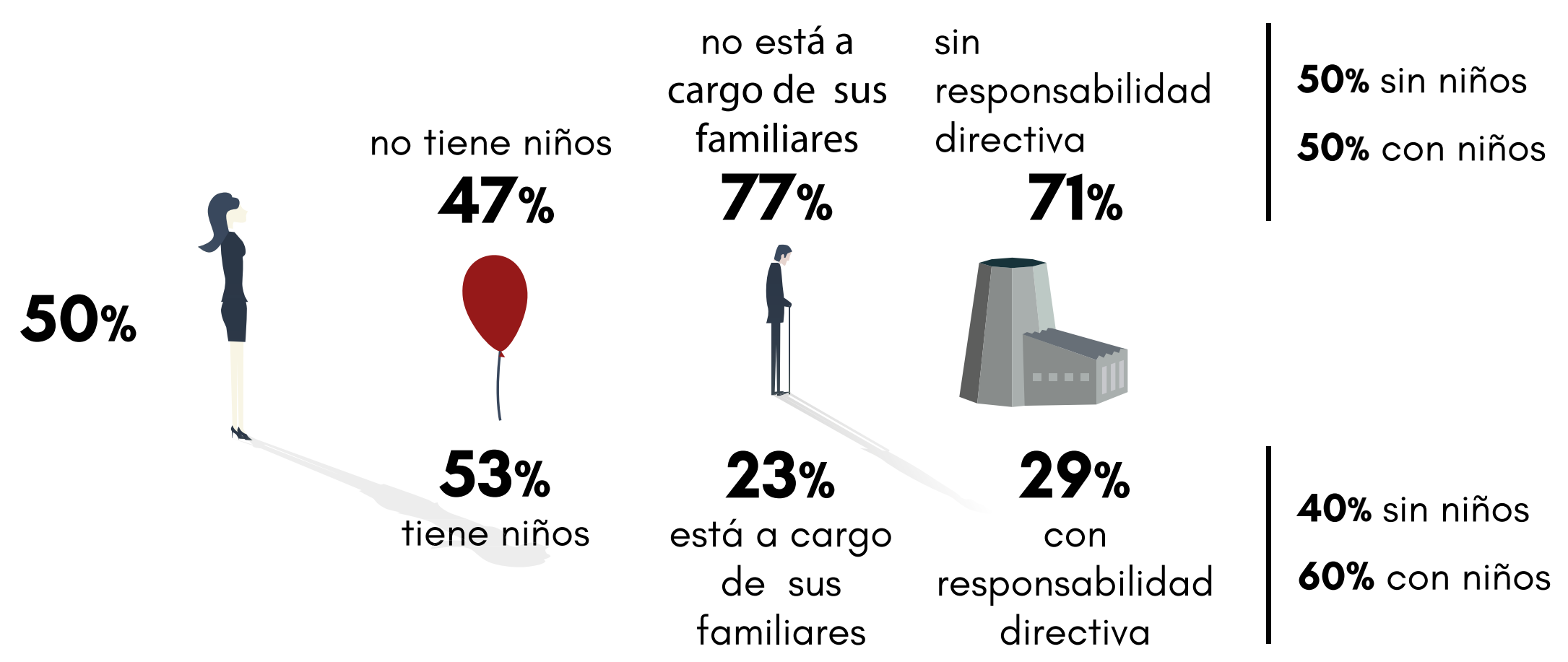




\section{ESTADO CIVIL}

MUJER

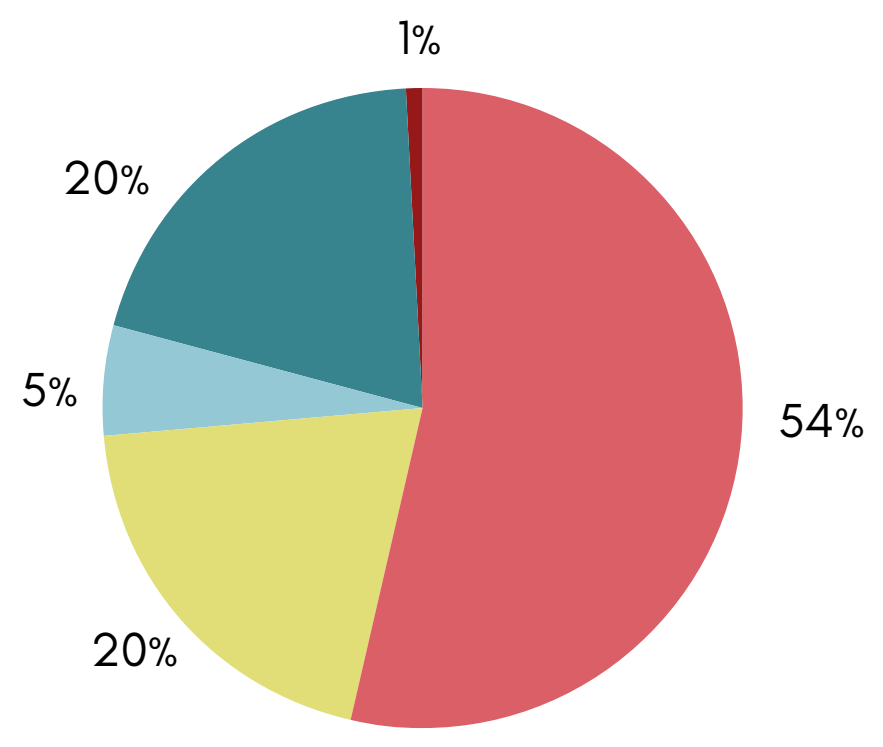

Casado/a

Con pareja estable

Separado/a - Divorciado/a y sin pareja estable

\section{HOMBRE}

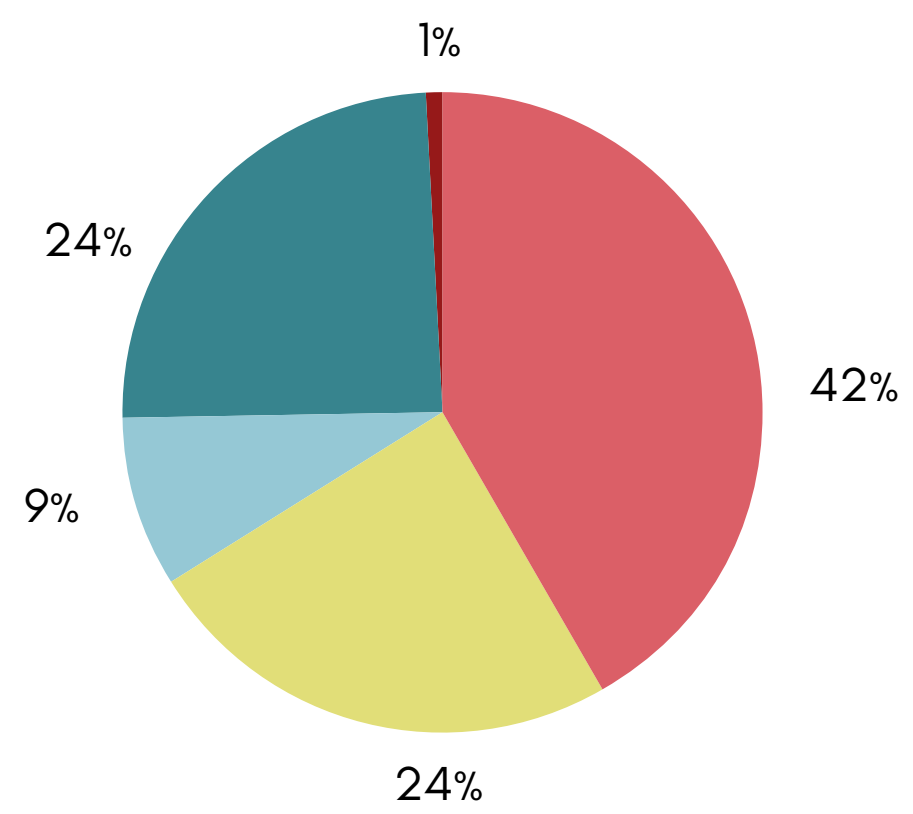

Soltero/a

Viudo/a 


\section{ESTUDIOS}

MUJER

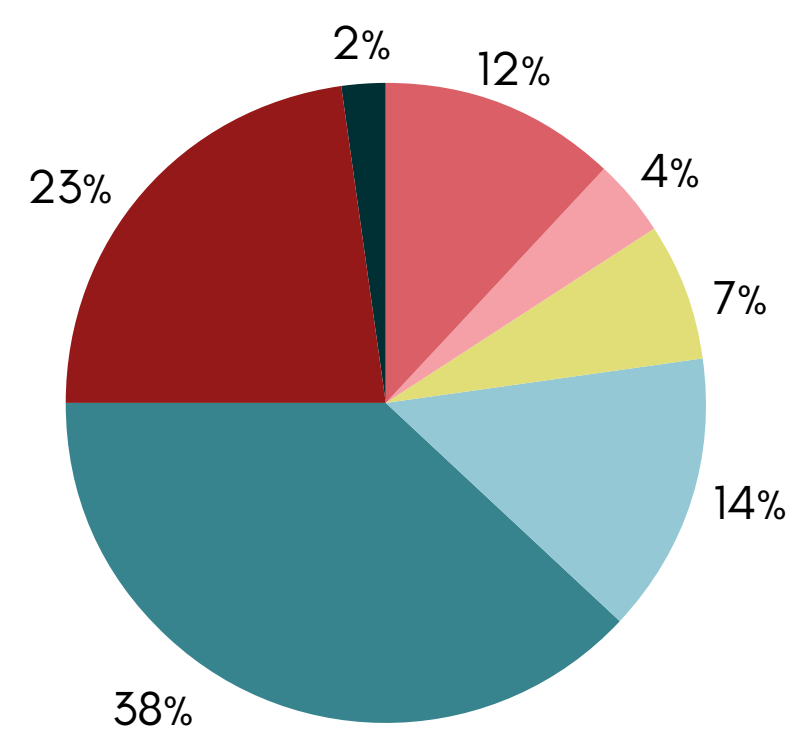

HOMBRE

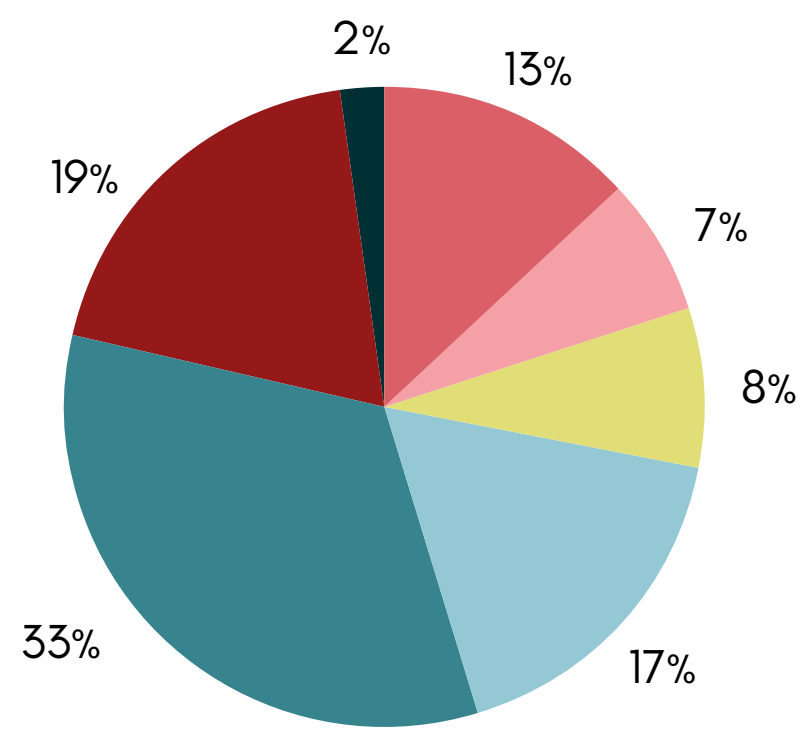

Graduado / Licenciado / Diplomado Universitario Máster / Posgrado

Doctorado
Bachillerato, COU o equivalente

ESO, Graduado escolar o equivalente

FPI / Técnico Medio

FP II / Técnico Superior 


\section{SECTOR}

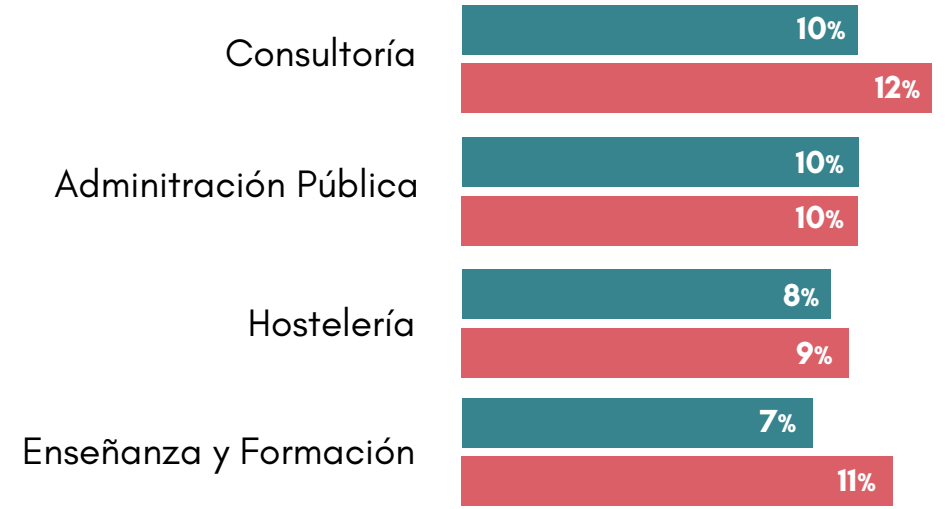

Alimentación, bebidas y tabaco

$5 \%$

\section{Banca y seguros \\ Telecomunicaciones \\ Salud \\ Publicidad y medios \\ Construcción \\ Distribución y Logística}

Otros 


\section{TAMAÑO DE LAS EMPRESAS}

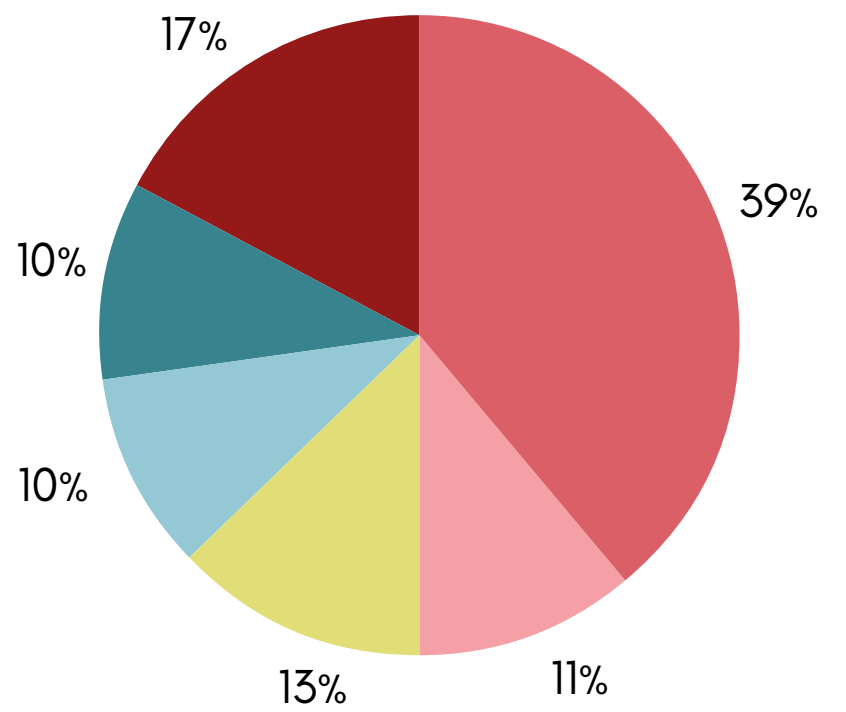

50 empleados o menos

Entre 51 y 100 empleados

Entre 101 y 250 empleados

Entre 251 y 500 empleados

Entre 501 y 2.500 empleados

2.500 o más empleados 


\section{ENTORNOS S=HE}

\section{¿Qué son los entornos S=HE?}

Cada persona se mueve en distintos entornos; es decir, en espacios que facilitan o dificultan la igualdad de oportunidades. Esos entornos no son exclusivamente externos a la persona, sino que también vienen determinados por la propia persona y su modo de pensar, decidir y organizarse.

La igualdad de oportunidades (o la falta de igualdad de oportunidades) que una persona disfruta (o sufre) viene mayormente determinada por lo que sucede en el marco de su empresa o lugar de desarrollo profesional, en su ámbito familiar y en su modo de afrontar personalmente la vida.

Dentro de la empresa, en función del número de políticas a las que la persona tiene acceso en su puesto de trabajo, y muy especialmente en función de los comportamientos de su supervisor/líder y de la cultura en la que trabaja, el entorno $\mathrm{S}=\mathrm{HE}$ se clasifica como $\mathrm{S}=$ Satisfactorio; $\mathrm{H}=$ Hostil;o $\mathrm{E}=$ Excluyente.

De modo análogo sucede en la familia, en la que en función de prácticas familiares, la toma de decisiones y las creencias respecto a la distribución de roles y tareas, volverá a clasificarse el entorno como S= Satisfactorio; $\mathrm{H}=$ Hostil; o $\mathrm{E}=$ Excluyente.
Y lo mismo sucede con el entorno personal, entendido como prácticas de organización personal, toma de decisiones efectiva y creencias personales. En este caso, el entorno también volverá a clasificarse como $\mathrm{S}=$ Satisfactorio; $\mathrm{H}=$ Hostil; o $\mathrm{E}=$ Excluyente.

A partir de la puntuación obtenida en cada una de estas tres dimensiones se alcanza una puntuación global.

En cuanto a la igualdad de oportunidades, estos entornos están dentro de un continuo en el que el extremo izquierdo representa el mejor de los entornos (Satisfactorio) y el extremo derecho, el peor entorno (Excluyente).

La capacidad de mejorar un entorno es gradual, y debe llevarse a cabo de modo sistemático en cada uno de los distintos ámbitos -organizativo, familiar, personal. $\mathrm{Si}$ bien es más difícil tener capacidad de influencia sobre el ámbito organizativo, sí que es más factible actuar sobre el ámbito familiar y personal.

Es importante subrayar que el modelo S=HE habla de entornos, y que existen tantos entornos como personas debido a que cada una de las personas que desarrollan su actividad en la empresa tendrá acceso a unas políticas específicas, desarrollará su trabajo 
con un supervisor/líder concreto y percibirá la cultura corporativa de un modo u otro. De modo análogo, cada persona tiene también un ámbito familiar en el que las prácticas de organización, la toma de decisiones y las creencias son distintas. Y otro entorno configurado por las propias decisiones, valores y modos de organización personal que variará de una persona a otra, dependiendo posiblemente de su educación, sus creencias y sus libres elecciones.

Sin embargo, mientras en algunas empresas -o paísesuna gran mayoría de personas desarrollan su labor en un entorno satisfactorio (S); en otras, la mayoría de personas reportan hallarse en un entorno hostil $(\mathrm{H}) \mathrm{O}$ excluyente (E). A lo largo de estas páginas veremos las consecuencias que esto comporta a nivel individual y agregado.

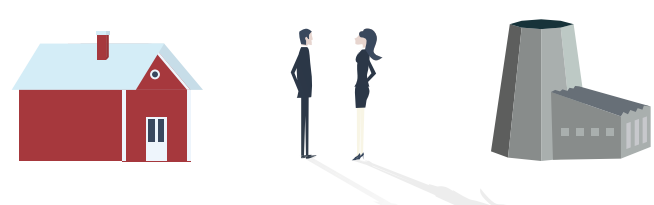

FAMILIA PERSONAL EMPRESA

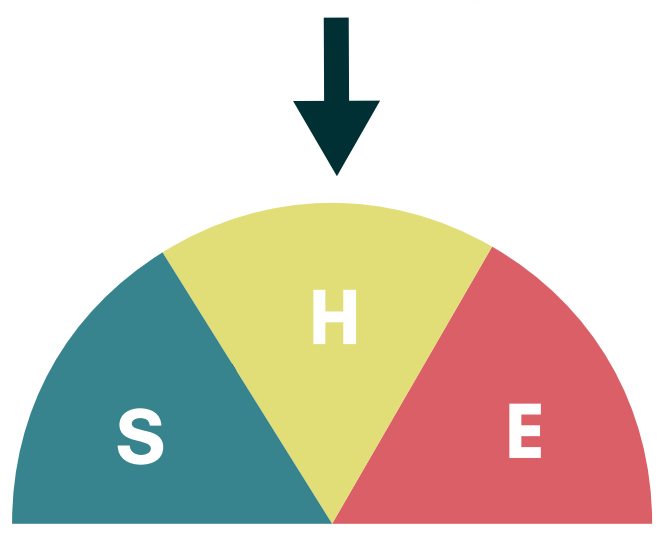

ENTORNOS

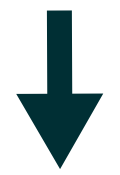

RESULTADOS

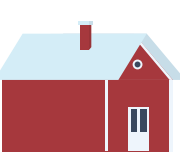

$1^{2}$

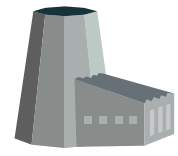

FAMILIA PERSONAL EMPRESA 


\section{ENTORNOS EN LA EMPRESA}

\section{Políticas y prácticas en las empresas}

Las políticas y prácticas que tienen mayor relevancia a la hora de crear entornos de igualdad de oportunidades son las que se refieren a los siguientes ámbitos, establecidos de acuerdo a criterios académicos validados":

- Selección: procesos de selección justos, con procedimientos establecidos acorde a unas normas y criterios objetivos, que se ajustan a las competencias necesarias para el puesto y no a las características de la persona.

- Formación: el acceso a la formación se establece en base a criterios conocidos y justos, y por ello las personas de una misma categoría profesional tienen acceso a ellos.

- Promoción: los criterios y procesos de promoción se establecen con criterios equitativos y transparentes.

- Evaluación: los procesos de evaluación son justos y conocidos por las personas afectadas por ellos.

- Retribución: no hay diferencia salarial entre hombres y mujeres por cuestión de sexo.

- Conciliación: existe la oportunidad de acceso a algunas medidas de flexibilidad que fomentan la conciliación trabajo-familia (horarios flexibles, trabajo desde casa, reducción de jornada, etc.).

\section{Liderazgo en las empresas}

Las políticas de conciliación son necesarias para fomentar la conciliación trabajo-familia. Sin embargo, no son suficientes para lograrlo. Un entorno de igualdad de oportunidades (Entorno S=HE) es aquel en el que el líder, el superior jerárquico que toma las decisiones que atañen al empleado, muestra comportamientos que fomentan que este comparta sus necesidades, genera alternativas en caso de que sea necesario, las prueba, las evalúa y las ajusta.

Los supervisores juegan un papel primordial a la hora de decidir asignación de proyectos, de horarios o de cargas de trabajo, entre otras cosas. Por ello, sus decisiones influyen de modo esencial en la capacidad de los empleados de conciliar trabajo y familia.

Hay cuatro tipos de conductas que los líderes pueden mostrar para facilitar la conciliación de sus empleados:

- Apoyo emocional. El supervisor que da apoyo emocional manifiesta conductas tales como interesarse por las circunstancias familiares y personales de sus colaboradores, mostrar interés por la forma en la que el trabajo afecta a las responsabilidades familiares, y manifiesta respeto, comprensión y sensibilidad hacia estos aspectos.

- Apoyo instrumental. El soporte instrumental implica la interpretación y aplicación de políticas formales o el ajuste de horarios con el fin de 
que los colaboradores puedan cumplir con las responsabilidades propias de su vida personal y familiar.

- Manager como modelo a seguir. Consiste en la adopción de estrategias y buenas conductas en materia de conciliación por parte del supervisor. De este modo el supervisor actúa como ejemplo a seguir por sus colaboradores.

\section{- Gestión de las políticas de equilibrio trabajo-} familia. Es una conducta de carácter proactivo, estratégico e innovador. Está orientada a generar condiciones favorables a la conciliación.

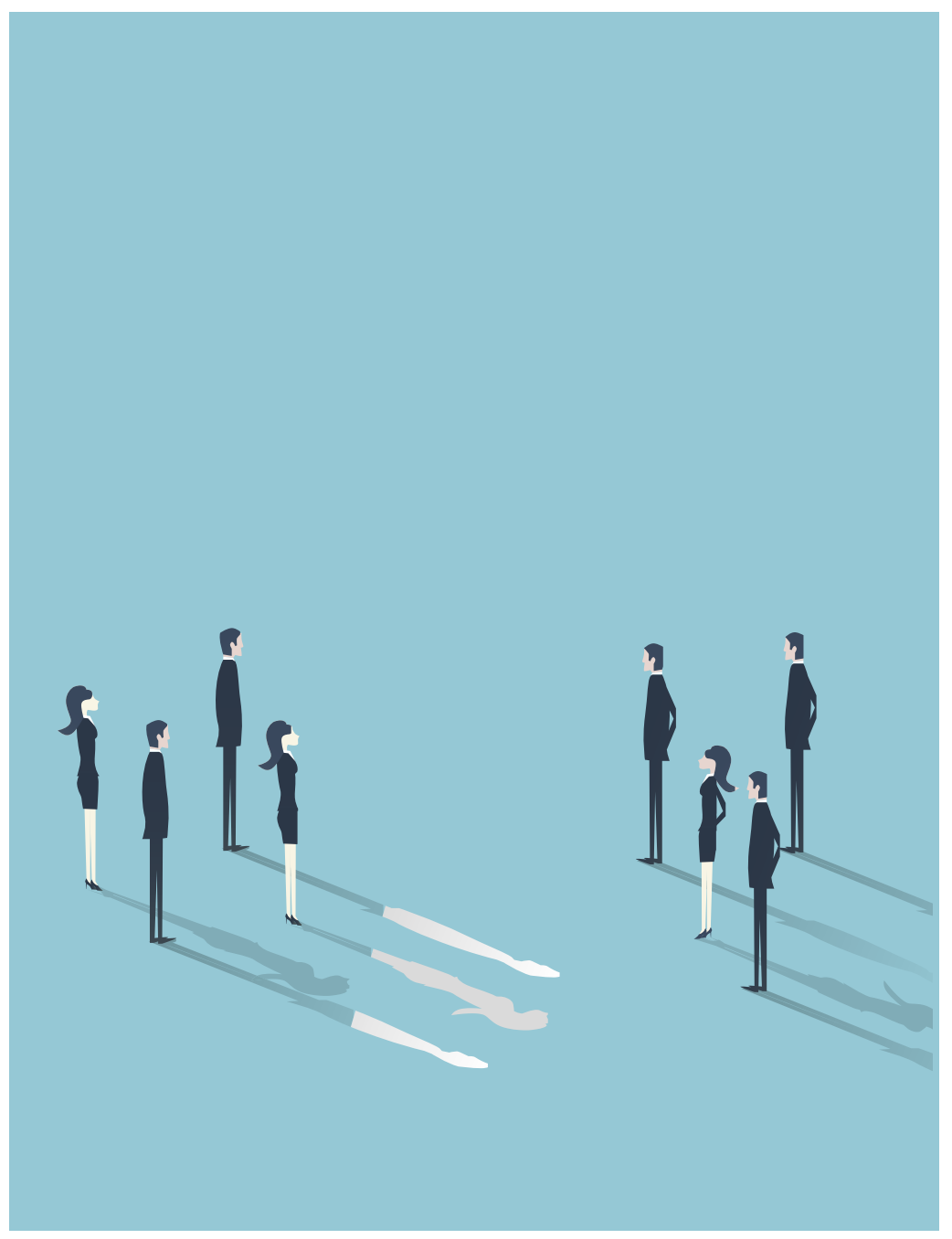

Este constructo en su modo original se llama FSSB (Family Suportive Supervisor Behavior). En él, para medir sus cuatro dimensiones, Hammer y otros ${ }^{12}$ desarrollaron y validaron una escala de catorce ítems. El S=HE utiliza una escala abreviada de siete de esos ítems. Cada una de las preguntas se mide con escala de Likert de 1 a 7.

\section{Cultura inclusiva en la empresa}

Definimos la cultura inclusiva, siguiendo a Nishi et al $^{13}$, como el conjunto de supuestos, creencias y valores compartidos por los miembros de la organización en relación con el grado en que esta apoya y valora la diversidad y los distintas aportaciones de sus empleados.

Como hemos justificado anteriormente, las políticas son necesarias y convenientes, pero no suficientes para constituir entornos de igualdad de oportunidades $\mathrm{S}=\mathrm{HE}$. Para ello se requieren unos comportamientos adecuados del líder, así como una cultura favorable a la igualdad de oportunidades en la que se dé una creencia hondamente arraigada que respeta y fomenta la diversidad y lo que esta aporta.

Específicamente una cultura inclusiva es aquella que:

- Proactivamente recaba información de los miembros de la organización para mejorar los procesos, servicios, productos $y$, específicamente, las condiciones de trabajo.

- Reacciona de modo positivo, aceptando las propuestas que los distintos miembros de la empresa aportan para mejorar en diversas facetas del negocio, del clima laboral o de las condiciones de trabajo. 


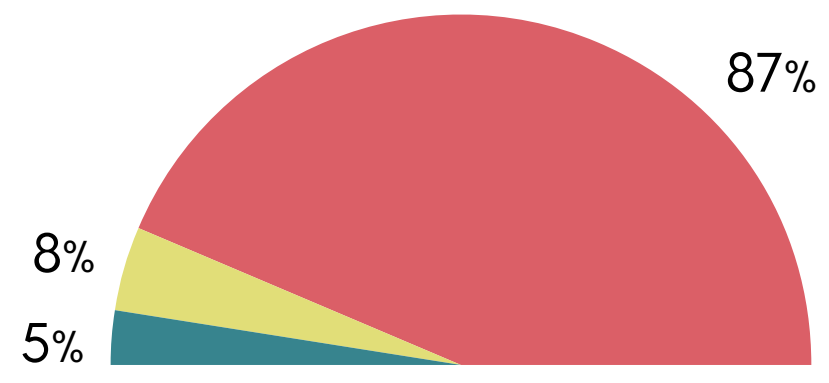

\section{HOMBRES}

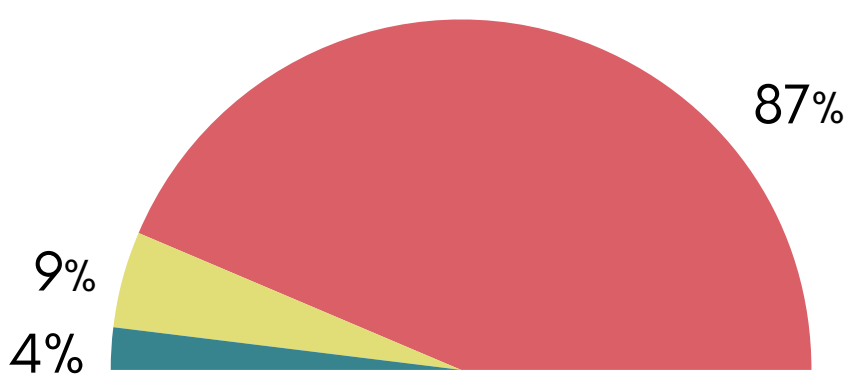

TOTAL

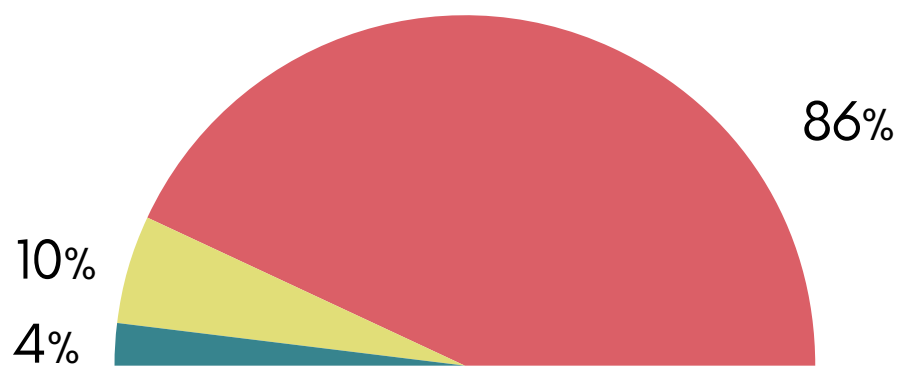

\section{MUJERES}

Como se puede observar en los gráficos, tan solo el $4 \%$ de hombres y el $5 \%$ de mujeres se encuentran en un entorno satisfactorio; y el $13 \%$ y el $14 \%$, respectivamente, muestran estar en entornos organizativos que de algún modo fomentan dicha igualdad (entornos $\mathrm{S} \circ \mathrm{H}$ ). Esto significa que el $87 \%$ de hombres y el $86 \%$ de mujeres se encuentran en el peor de los escenarios: un entorno excluyente.

En capítulos posteriores se verán ampliaciones de estos resultados; sin embargo, podemos adelantar que las opciones de mejora de las empresas son muy grandes, y que el daño que genera el no tener entornos satisfactorios pesa sobre los empleados y la sociedad en su conjunto, pero también sobre la propia empresa.

SATISFACTORIO: se fomenta la igualdad de oportunidades. La empresa cuenta con políticas que facilitan que no haya sesgos por razón de sexo. La cultura de la empresa es inclusiva y se tienen en cuenta las aportaciones de los trabajadores para generar valor. La toma de decisiones en el ambiente familiar es consensuada.

HOSTIL: el entorno dificulta ocasionalmente la igualdad de oportunidades para hombres y mujeres.

EXCLUYENTE: el entorno dificulta sistemáticamente la igualdad de oportunidades para hombres y mujeres. 


\section{ENTORNOS DIMENSIÓN PERSONAL}

\section{Prácticas de organización personal}

Hay una serie de prácticas individuales que ayudan a ser más efectivo y eficiente en la gestión del tiempo personal, y facilitan la asunción de retos y la consecución de objetivos. Entre ellos, según los académicos Bird et al ${ }^{14}$, distinguimos dos "hábitos ancla" que ayudan a desarrollar otros:

\section{- Hábito de priorización efectiva: se trata} de organizar las tareas a realizar por orden de importancia y no de urgencia ni de aparición en la agenda. Este hábito es de gran importancia en un entorno de trabajo como el actual, en el que las tecnologías de la información hacen que la urgencia de las tareas se haga más evidente a través de los medios de comunicación asíncrona, como el correo electrónico o las aplicaciones de mensajería instantánea, que exigen del receptor respuestas rápidas y priorización desmedida.

- Concentración en el trabajo: se trata de realizar las tareas sin dejar que la multitarea (multitasking) conduzca a una disminución de nuestra capacidad de atención y deteriore nuestro rendimiento.

\section{Toma de decisiones}

Basado en los estudios originalmente realizados por Hall ${ }^{15}$, la investigación S=HE mide el modo en el que la toma de decisiones de las personas se basa en criterios objetivos, análisis profundo y estudio de las posibles consecuencias de las distintas acciones. Distinguimos tres dimensiones:

- Búsqueda proactiva de feedback: se trata de buscar información que lleve a comprender mejor los sentimientos, necesidades e intereses propios en personas no directamente involucradas en la situación a analizar-decidir. Mediante esta

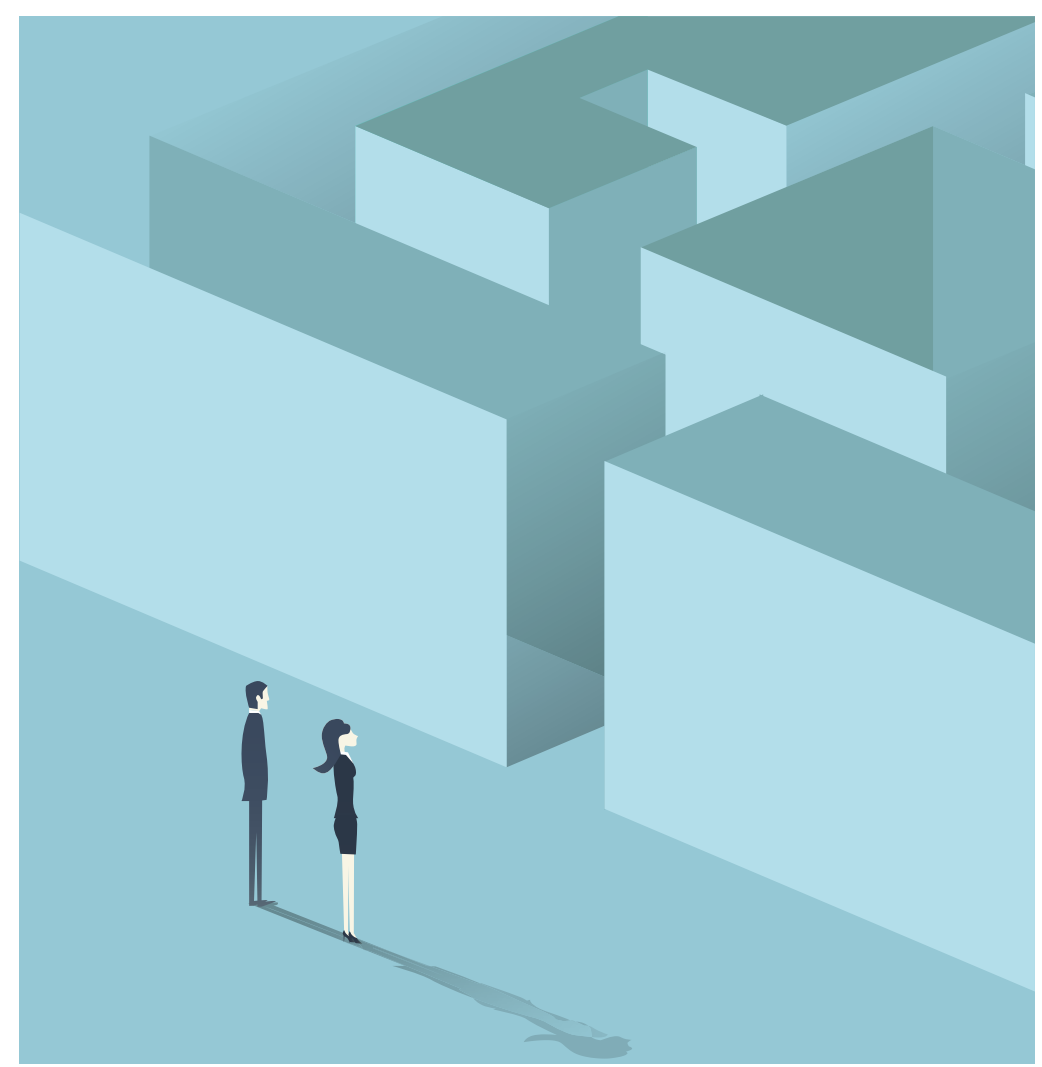


práctica la persona se siente más capaz de tomar decisiones correctas sin el sesgo excesivo de la subjetividad y de la emocionalidad.

- Solicitud de apoyo emocional-afectivo: se trata de cultivar la cercanía y el trato con personas que muestran inclinación a ayudar e interés por el propio bienestar. Cultivando estas relaciones, estas personas ofrecen un apoyo afectivo que ayude a sostener el esfuerzo y afrontar situaciones complejas

- Exploración de información y alternativas: se trata de cultivar la cercanía y el trato con personas que muestran capacidad de explorar alternativas y ofrecer consejos útiles.

\section{Creencias personales}

En el modelo $\mathrm{S}=\mathrm{HE}$, las creencias personales se refieren a la autoestima, al convencimiento de que uno es capaz de ser efectivo, de estar motivado y de realizar un buen trabajo.

Las creencias personales son muy relevantes. En función de pensamientos, sentimientos y experiencias propias, la valoración que una persona hace de sí misma le llevará a proyectar una imagen concreta, a presentarse ante los demás y a reconocer sus propios aciertos y errores.

La forma en que una persona se valora está influida en muchas ocasiones por agentes externos y puede cambiar a lo largo del tiempo. En concreto, en el modelo S=HE tenemos en cuenta las siguientes dimensiones de las creencias personales:

\section{- Capacidad de automotivación: es la} capacidad de encontrar motivos para realizar un buen trabajo, ya sea por lo que se recibirá como fruto de dicha labor, por el placer de realizar el trabajo en sí y las relaciones que se desarrollarán en el trabajo, o por lo que la contribución de dicho trabajo hará en la vida de otros, tanto la propia familia como los compañeros, los clientes o la sociedad en su conjunto.

- Competencia laboral: es la creencia de que uno tiene la capacidad, la formación y las habilidades necesarias para realizar un buen trabajo en lo que se refiere a sus aspectos técnicos y relacionales.

- Capacidad de aceptar responsabilidades: es el convencimiento de que si a uno se le ofrece una oportunidad o se le presenta una ocasión propicia, podría realizar un trabajo adecuado, válido, de calidad y, por lo tanto, podría sacarle partido a dicha oportunidad.

- Actitud: es la actitud positiva ante el trabajo y la vida que ayuda a afrontar retos, a sobrellevar dificultades y a sostener el esfuerzo que la realización de cualquier trabajo conlleva. 


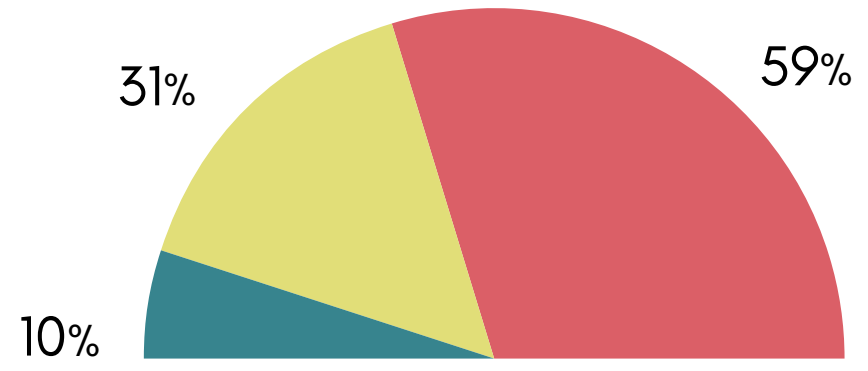

\section{HOMBRES}

$13 \%$

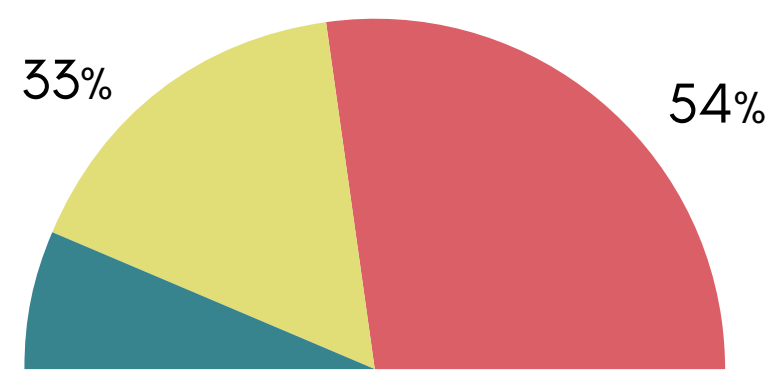

\section{TOTAL}

$15 \%$

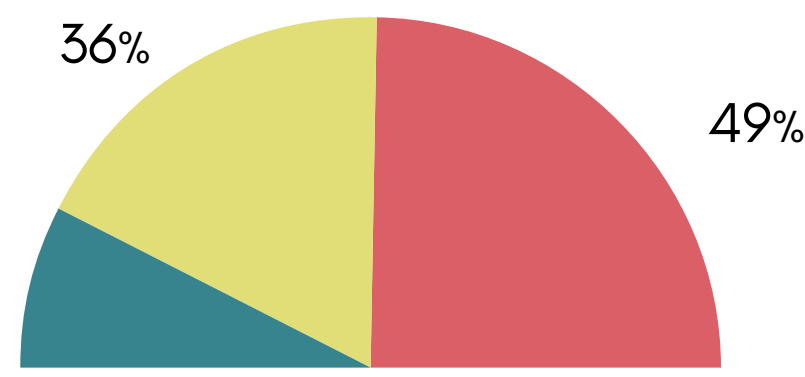

\section{MUJERES}

El $41 \%$ de hombres y el $51 \%$ de mujeres se hallan en un entorno personal que fomenta la igualdad de oportunidades entre hombres y mujeres; es decir, en entornos $\mathrm{S}$ o H. Si bien aún queda un espacio de mejora, a nivel personal, y especialimente las mujeres, tienen hábitos organizativos, modos de decidir y creencias que en cierta medida favorecen la igualdad de oportunidades.

En comparación con el ámbito empresarial, en el que el $87 \%$ de hombres y el $86 \%$ de mujeres se encuentran en el peor de los escenarios -un entorno Excluyente-, a nivel personal encontramos entornos mucho más positivos: un $59 \%$ de hombres y un $49 \%$ de mujeres se encuentran en dichos entornos.
SATISFACTORIO: se fomenta la igualdad de oportunidades. La empresa cuenta con políticas que facilitan que no haya sesgos por razón de sexo. La cultura de la empresa es inclusiva y se tienen en cuenta las aportaciones de los trabajadores para generar valor. La toma de decisiones en el ambiente familiar es consensuada.

HOSTIL: el entorno dificulta ocasionalmente la igualdad de oportunidades para hombres y mujeres.

EXCLUYENTE: el entorno dificulta sistemáticamente la igualdad de oportunidades para hombres y mujeres. 


\section{ENTORNO FAMILIAR}

Este entorno solo se ha calculado para las personas que o bien están en pareja estable, o cuidan de hijos y/o de mayores, o cualquier combinación de las anteriores situaciones; es decir: no se considera que afecte (positiva o negativamente) la igualdad de oportunidades a aquellos que ni viven en pareja estable, ni tienen hijos o mayores dependientes. Por ello, las prácticas familiares, toma de decisión en familia y creencias en los entornos familia se refieren siempre a alguna de las situaciones mencionadas (pareja-hijospadres).

\section{Prácticas de organización familiar}

Hay una serie de prácticas a nivel familiar que llevan a organizar y distribuir las tareas entre los distintos miembros de la unidad familiar. Las más relevantes se refieren al cuidado del propio hogar, el cuidado de los hijos y el cuidado de dependientes (personas mayores o con discapacidad).

\footnotetext{
- Cuidado de personas mayores (dependientes) - con discapacidad: el cuidado es exigente a nivel físico y psíquico, por lo que una equilibrada distribución de la tarea que impida que el peso del cuidado recaiga desproporcionadamente en la persona que ya tiene una dedicación laboral a tiempo completo es absolutamente necesaria para fomentar la igualdad de oportunidades.
}

- Cuidado de hijos (menores de 18): el cuidado, la dedicación al correcto desarrollo académico y el acompañamiento en actividades lúdicas son exigentes para quien las desarrolla. Para fomentar la igualdad de oportunidades resulta clave el equilibrio en la dedicación a dichas tareas, de tal modo que su peso no recaiga de forma desproporcionada en la persona que laboralmente ya tiene una dedicación profesional a tiempo completo.

- Cuidado del hogar: el cuidado material del hogar es exigente en tiempo y energía. Por ello es crucial, para que haya una efectiva igualdad de oportunidades, que no recaiga desproporcionadamente sobre la persona que tiene una dedicación laboral a tiempo completo.

\section{Toma de decisiones en familia}

En base a los estudios de Caplan ${ }^{16}$ sabemos que hay heurísticas de decisión que permiten ser más efectivos y eficientes. Caplan ${ }^{17}$ relaciona también estos modos de decisión con problemas como la salud coronaria y el estrés. En el modelo S=HE captamos los modos de decisión en pareja que se refieren a:

- La confianza: confianza en la pareja para sostenerle anímicamente y recibir apoyo emocional y comprensión en épocas de trabajo duro/intenso. 
Entornos $\mathrm{S}=\mathrm{HE}$

- La benevolencia: la persona espera de su pareja un trato benevolente y esforzado para hacer su vida más agradable, fácil y provechosa.

Creencias en el entorno familiar

Basado en Ripley et al. ${ }^{18}$, el modelo S=HE estudia cómo las creencias referentes a la vida en pareja/matrimonio funcionan como un continuo entre los que lo perciben como un contrato frente a los que lo perciben como una alianza:

- Vida en pareja/matrimonio como transacción: perciben las decisiones como negociaciones de "suma cero" en las que el mayor beneficio de uno repercute en el menor beneficio del otro.

- Vida en pareja/matrimonio como alianza: perciben las decisiones como oportunidades de crear mayores beneficios. Habitualmente, las decisiones se basan en la expectativa de que estas serán repetitivas y los beneficios se conseguirán en el largo plazo, no inmediatamente.

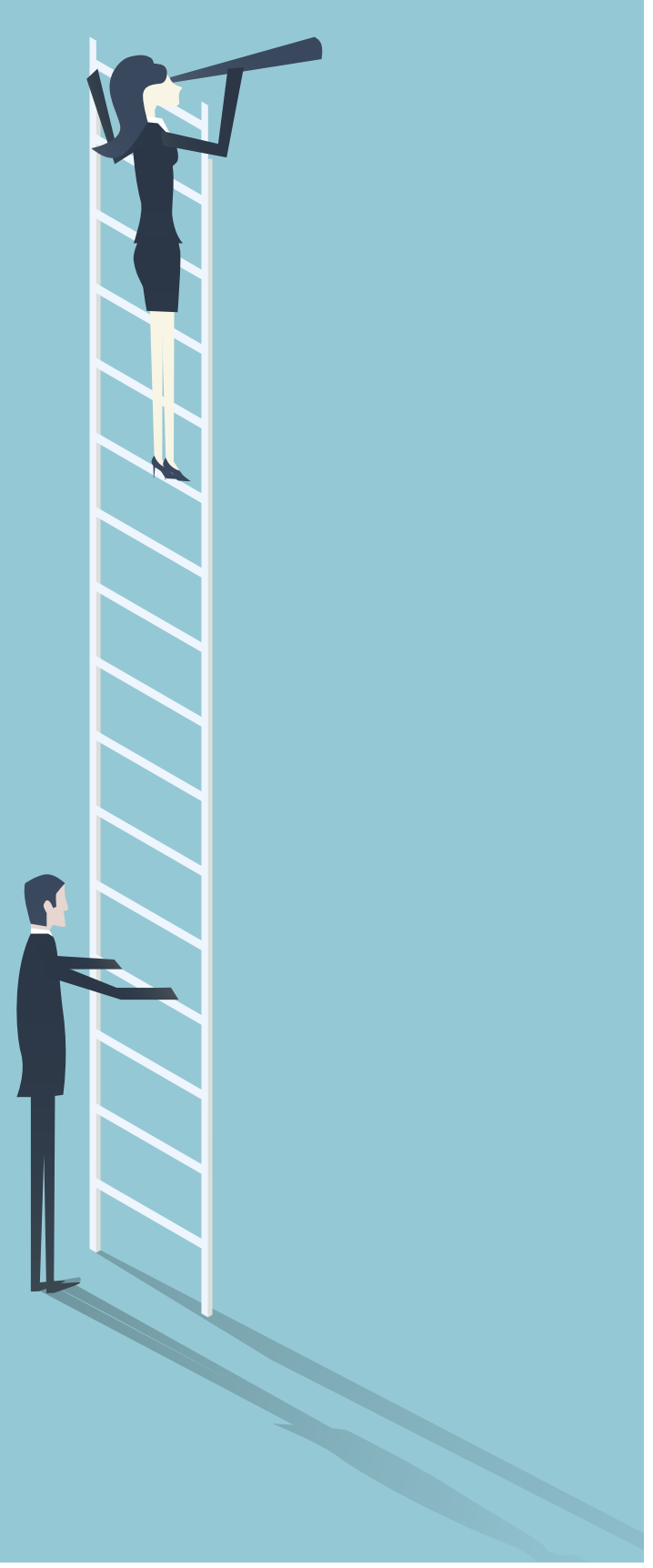

35 


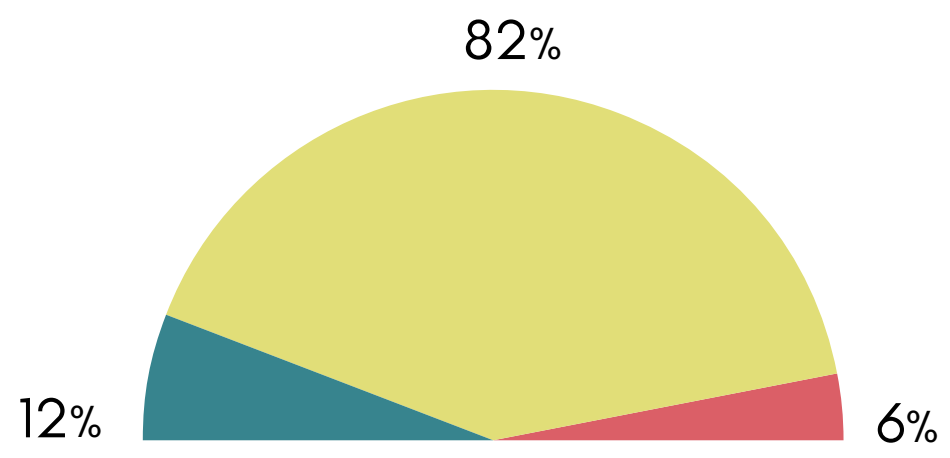

\section{HOMBRES}

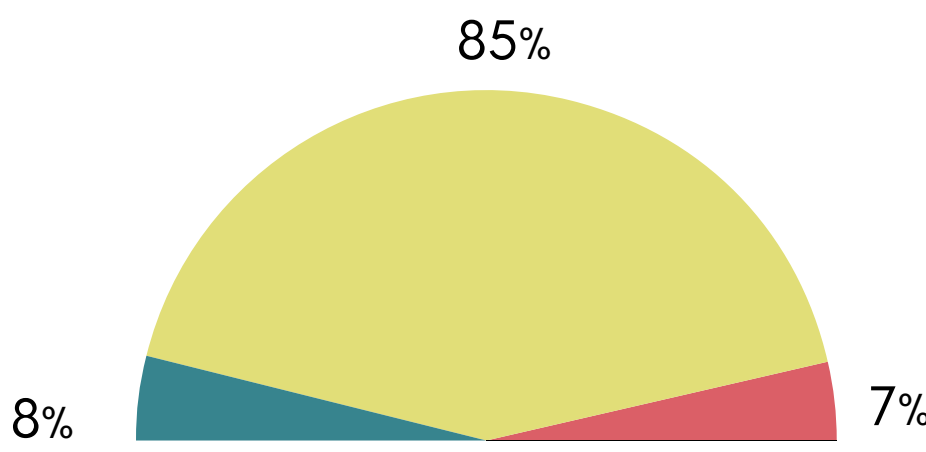

\section{TOTAL}

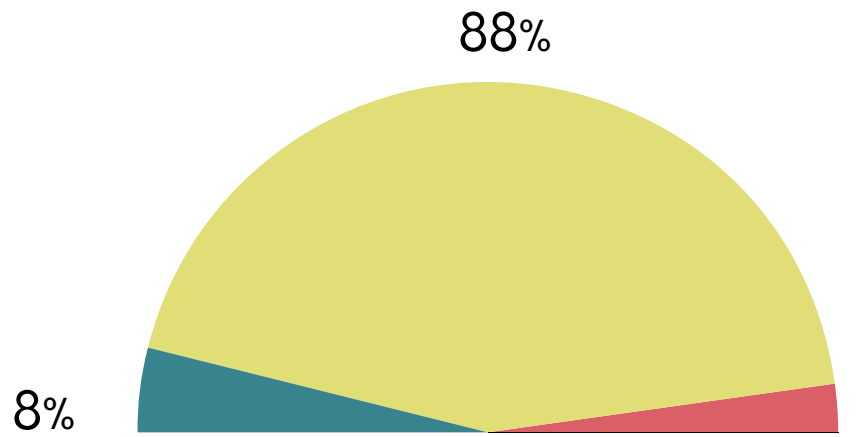

$4 \%$

\section{MUJERES}

Dentro del modelo S=HE, el entorno familiar es el que reporta resultados más positivos tanto para los hombres como para las mujeres. Si bien solo el $12 \%$ de los hombres y el $8 \%$ de las mujeres se encuentran en entorno $\mathrm{S}$ (satisfactorio), el $94 \%$ y el $92 \%$, respectivamente, se encuentran en entornos $\mathrm{S}$ y $\mathrm{H}$.

Esto significa que tan solo el $6 \%$ de varones y el $8 \%$ de mujeres se encuentran en entornos familiares $E$ (excluyentes). Un dato que contrasta de forma especial con los entornos de empresa u organizativos, donde el $87 \%$ de hombres y el $86 \%$ de mujeres afirman estar en el peor de los escenarios: un entorno excluyente.

SATISFACTORIO: se fomenta la igualdad de oportunidades. La empresa cuenta con políticas que facilitan que no haya sesgos por razón de sexo. La cultura de la empresa es inclusiva y se tienen en cuenta las aportaciones de los trabajadores para generar valor. La toma de decisiones en el ambiente familiar es consensuada.

HOSTIL: el entorno dificulta ocasionalmente la igualdad de oportunidades para hombres y mujeres.

EXCLUYENTE: el entorno dificulta sistemáticamente la igualdad de oportunidades para hombres y mujeres. 


\section{Entorno Global}

Si bien hemos visto que hay signos de esperanza, especialmente en el entorno familiar y también el personal, es preocupante el bajo porcentaje de personas que se encuentran en entornos $S$ (satisfactorios) a nivel organizativo.

Más preocupante si cabe es el resultado cuando agregamos los datos para observar el porcentaje de personas que se hallan en un entorno S (satisfactorio) global; es decir, tanto a nivel organizativo como familiar y personal. Tan solo un $1 \%$ de hombres y un $1 \%$ de mujeres reportan encontrarse en dicha situación de igualdad de oportunidades "global".

La otra cara de la moneda nos la ofrece el entorno $E$ (el peor de todos: excluyente), que pasa a ser de $33 \%$ para los hombres y $34 \%$ para las mujeres. Es decir, un tercio de la población en España se encuentra en un entorno global (empresarial-familiar-personal) que dificulta activamente la igualdad de oportunidades. En las siguientes páginas podrás descubrir lo que esto significa a nivel de resultados.

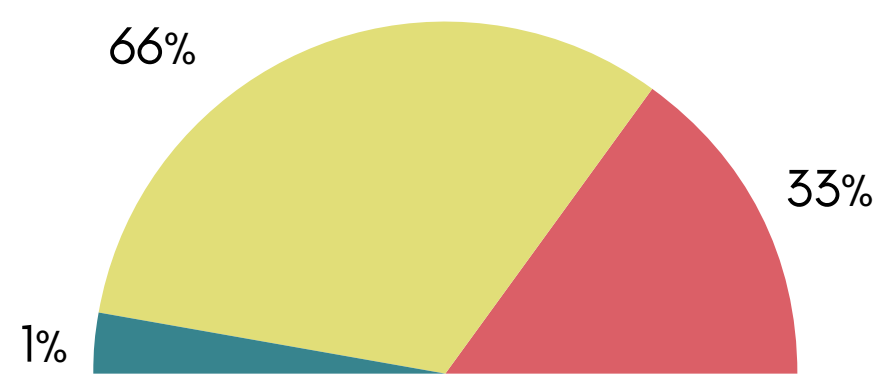

\section{HOMBRES}

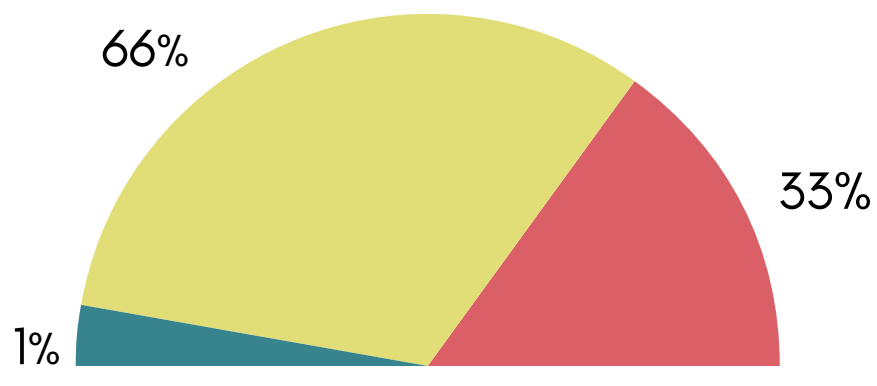

TOTAL

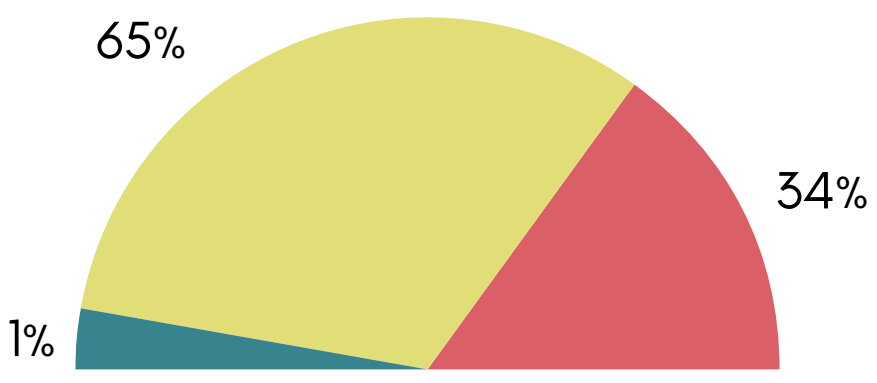

MUJERES
EXCLUYENTE: el entorno dificulta sistemáticamente la

igualdad de oportunidades para hombres y mujeres.

SATISFACTORIO: se fomenta la igualdad de oportunidades. La empresa cuenta con políticas que facilitan que no haya sesgos por razón de sexo. La cultura de la empresa es inclusiva y se tienen en cuenta las aportaciones de los trabajadores para generar valor. La toma de decisiones en el ambiente familiar es consensuada.

HOSTIL: el entorno dificulta ocasionalmente la igualdad de oportunidades para hombres y mujeres. 


\section{RESULTADOS}

\section{Entorno S=HE de igualdad de oportunidades: políticas en la empresa}

A pesar de que cada vez son más las mujeres que acceden al mercado laboral y que alcanzan puestos directivos, siguen existiendo situaciones de falta de igualdad de oportunidades para hombres y mujeres dentro de las organizaciones en cuestión de contratación, remuneración y promoción.

Ante esta situación, en 2007 se aprobó la Ley Orgánica 3/2007 para la igualdad efectiva de mujeres y hombres que establece la obligación de respetar la igualdad de trato y oportunidad en el ámbito laboral. Pero hacer efectiva esta igualdad en las empresas no es solo una obligación legal, sino que también se ha demostrado que mejora la imagen de la empresa, el clima laboral, la productividad y los resultados.

La siguiente tabla muestra la percepción que hombres y mujeres tienen de las políticas que ofrecen sus empresas, y que son las que la investigación ha detectado que favorecen la igualdad de oportunidades entre hombres y mujeres: selección, formación, promoción, evaluación, retribución y conciliación.

En cuanto al proceso de selección, tanto hombres como mujeres opinan que no está totalmente estructurado (hombres $\mathbf{4 5 \%}$; mujeres $43 \%$ ). Un dato negativo ya que implica un sesgo de la persona -o comité- a cargo de la selección, y que posiblemente conduce a desigualdades y resultados sub-óptimos.

La formación en la empresa se considera una práctica fundamental en la gestión de personas. Además, es un derecho que tienen todas las personas trabajadoras, y una necesidad para las empresas en un entorno laboral tan cambiante como el actual. Se trata, asimismo, de un mecanismo clave que permite el desarrollo de la carrera profesional y la promoción profesional del personal de una empresa.

En este nivel, los resultados nos muestran que ni hombres ni mujeres consideran que haya igualdad de oportunidades para acceder a la formación en la empresa. Solo un tercio de los encuestados $(36 \%$ de hombres y $32 \%$ de mujeres) piensan que el acceso a la formación en su empresa se decide con criterios equitativos.

Los procesos de promoción son aquellos que se siguen para decidir quién pasa a ocupar puestos de mayor responsabilidad. Esta práctica es la menos valorada dentro de las políticas de igualdad de oportunidades. Menos de un tercio de los encuestados (un $\mathbf{2 5 \%}$ de mujeres y un $\mathbf{2 9}$ \% de hombres) creen que su empresa cumple con criterios de promoción justos y transparentes. Cuando no hay criterios justos $y$ 
transparentes, los sesgos de similitud y los estereotipos benefician fácilmente a los hombres (caucásicos) contra las mujeres.

Los procesos de evaluación en las empresas sirven para estimar cuantitativa y cualitativamente el grado de eficacia y eficiencia de los trabajadores. Se pretende detectar los puntos fuertes y débiles con el fin de ayudar a mejorar estos últimos. En el estudio, solo un $33 \%$ de los hombres y un $28 \%$ de las mujeres están de acuerdo en que los procesos de evaluación en su empresa son justos. Sin criterios justos de evaluación, la subjetividad, el presentismo y la similitud entre el evaluador y el evaluado pasan a ser cruciales, beneficiando de nuevo a los hombres (caucasianos) por encima de las mujeres (y personas de raza no caucásica).

Las diferencias salariales entre hombres y mujeres es uno de los principales problemas de nuestro mercado laboral. Las causas de esta brecha son varias: más mujeres que trabajan a tiempo parcial, baja presencia de mujeres directivas, hombres que trabajan en empleos mejor remunerados. Sin embargo, en este estudio se ha preguntado a los profesionales con empleo por su percepción acerca de si en su empresa existen diferencias salariales por razón de sexo (no de formación, responsabilidad u otras causas). Sorprendentemente, solo el $62 \%$ de los hombres y el $54 \%$ de mujeres dicen que NO existen diferencias salariales por razón de sexo. Es decir, que el $38 \%$ de hombres y el $46 \%$ de mujeres asumen que Sí hay diferencias salariales en función del género.

Aunque la ley es clara, puede que su aplicación todavía esté lejos de ser óptima, o puede que haya que hacer hincapié en una política de trasparencia que muestre que esas percepciones de discriminación salarial por razón de sexo no responden a una realidad.

\section{Solo el $62 \%$ de hombres y el $54 \%$ de mujeres consideran que NO hay discriminación salarial por razón de} sexo en su empresa

Las medidas para conciliar trabajo y familia permiten a los trabajadores responder a las necesidades de su vida familiar, laboral y personal. De este modo, la conciliación es una estrategia global que permite a las empresas favorecer la participación de las personas con responsabilidades familiares, fundamentalmente a las mujeres, y por tanto aprovechar el potencial de todo el capital humano disponible ${ }^{19}$. Los datos obtenidos muestran que las políticas de conciliación no están plenamente implantadas en las organizaciones. 
La formación en mi empresa es

$36 \%$ igual para todas las personas de mi categoría profesional

$32 \%$

$25 \%$

$29 \%$

$\left\{\begin{array}{l}\text { En mi empresa los criterios de } \\ \text { promoción son justos y } \\ \text { transparentes }\end{array}\right.$

$\left\{\begin{array}{l}\text { En mi empresa los criterios de } \\ \text { promoción son justos y } \\ \text { transparentes }\end{array}\right.$

$\left\{\begin{array}{l}\text { En mi empresa los criterios de } \\ \text { promoción son justos y } \\ \text { transparentes }\end{array}\right.$

$28 \%$

$33 \%$

El proceso de evaluación es justo

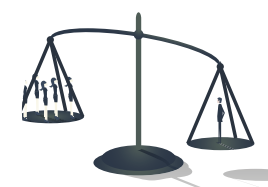

$54 \%$

$62 \%$

No hay diferencias salariales entre

hombres y mujeres

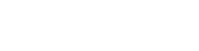

$44 \%$

Puedo acceder a algunas medidas de flexibilidad que me facilitan la conciliación

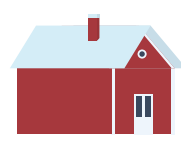

$43 \%$ trabajo-familiar 


\section{Entorno S=HE de igualdad de oportunidades: prácticas en la familia}

\section{Cuidado del hogar}

Lo más relevante en lo que se refiere al cuidado del hogar es que ambos reportan que son las mujeres las que toman una mayor carga en el cuidado del hogar. Tanto hombres como mujeres coinciden en que ellas hacen el $50 \%$ más que los hombres (los hombres dicen que ellos hacen el $37 \%$ de las tareas frente al $55 \%$ que realizan sus parejas; las mujeres dicen que sus parejas hacen el $38 \%$ frente al $53 \%$ de ellas).

\section{Hombres y mujeres reconocen que son ellas las que hacen la mayor parte de las tareas del hogar}

\section{Cuidado de mayores}

De nuevo lo más relevante es que tanto hombres como mujeres coinciden en que, una vez más, son ellas las que asumen un mayor porcentaje del cuidado que requieren los mayores, que en este caso supera al de los varones entre un $30 \%$ y un $40 \%$. Mientras ellos reportan que se encargan del $32 \%$ de las tareas y sus parejas del $41 \%$; ellas dicen realizar el $42 \%$ y que sus parejas se ocupan del $23 \%$.

\section{Cuidado de niños}

Tanto hombres como mujeres vuelven a coincidir en que recae un mayor peso del cuidado que requieren los hijos menores en las mujeres. En este caso ellos dicen hacer menos de un $10 \%$ de las tareas, mientras sus parejas realizan el $57 \%$. Ellas reportan ocuparse del $52 \%$ de las tareas y sus parejas, del 10\%. Este porcentaje no incluye actividades lúdico-deportivas, solo actividades de cuidado stricto sensu.

\section{Los hombres realizan una mínima parte del trabajo de cuidado de los hijos}




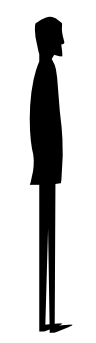

$\mathbf{3 7 \%}$ del trabajo realizan ellos

$\mathbf{5 5 \%}$ del trabajo lo realizan sus parejas

$\mathbf{8} \%$ del trabajo lo realiza una persona externa

$\mathbf{3 2} \%$ del trabajo realizan ellos

$\mathbf{4 1 \%}$ del trabajo lo realizan sus parejas

$\mathbf{2 7} \%$ del trabajo lo realiza una persona externa

$6 \%$ del trabajo realizan ellos

$\mathbf{5 7 \%}$ del trabajo lo realizan sus parejas

$\mathbf{3 7 \%}$ del trabajo lo realiza una persona externa $\mathbf{5 2} \%$ del trabajo realizan ellas

$\mathbf{3 8} \%$ del trabajo lo realizan sus parejas

$10 \%$ del trabajo lo realiza una persona externa

42\% del trabajo realizan ellos

$\mathbf{3 3} \%$ del trabajo lo realizan sus parejas

$\mathbf{2 5} \%$ del trabajo lo realiza una persona externa

$\mathbf{5 2} \%$ del trabajo realizan ellos

$10 \%$ del trabajo lo realizan sus parejas

$\mathbf{3 8 \%}$ del trabajo lo realiza una persona externa 


\section{Entorno S=HE de igualdad de oportunidades: prácticas personales}

Hay una serie de prácticas individuales que ayudan a ser más efectivo y eficiente en la gestión del tiempo personal, y que facilitan la asunción de retos y la consecución de objetivos. Entre ellos, según los académicos Bird et al. ${ }^{20}$ distinguimos dos dimensiones "hábitos ancla" que ayudan a desarrollar otros hábitos que permiten fomentar dicha eficiencia personal:

- Hábito de priorización efectiva: se trata de organizar las tareas a realizar por orden de importancia y no de urgencia ni de aparición en la agenda. Este hábito es de gran importancia en un entorno de trabajo como el actual, en el que las tecnologías de la información hacen que la urgencia de las tareas se haga más evidente a través de los medios de comunicación asíncrona, como el correo electrónico o las aplicaciones de mensajería instantánea, que exigen del receptor respuestas rápidas y priorización desmedida.
Solo el $18 \%$ de hombres y el $23 \%$ de mujeres afirman priorizar su trabajo por nivel de importancia de forma habitual.

- Concentración en el trabajo: se trata de realizar las tareas sin dejar que la multitarea (multitasking) conduzca a una disminución de nuestra capacidad de atención y deteriore nuestro rendimiento.

Solo el $16 \%$ de los hombres y el $20 \%$ de las mujeres reportan trabajar con una intensidad tal que les permita ser efectivos y eficientes. Esto está ligado a un bajo nivel de rendimiento (por hora) en todo el país, así como a jornadas de trabajo muy extensas.

\section{Las mujeres suelen gestionar mejor sus tareas por orden de importancia. Sin embargo, tanto hombres como mujeres muestran un bajo nivel de priorización}

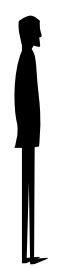

$18 \%$

Afirman que habitualmente priorizan y hacen lo más importante en primer lugar
$23 \%$

$20 \%$
Afirman que habitualmente trabajan de modo eficaz para acabar las tareas 


\section{Entorno S=HE de igualdad de oportunidades: liderazgo inclusivo en} la empresa

Las dimensiones de esta escala miden comportamientos tales como:

\section{El líder asume sus responsabilidades básicas, como conocer las circunstancias familiares y personales del empleado.}

\section{El líder ejemplifica, con la propia vida, la importancia de la conciliación.}

Los encuestados afirman que sus supervisores, en muchos casos, no desarrollan este tipo de liderazgo. La falta de comportamientos inclusivos, con lo que se genera igualdad de oportunidades, tiene un coste enorme para la empresa. Y más si tenemos en cuenta que para su aplicación solo se requiere convencimiento, adquirible mediante formación.

Según se puede observar en el gráfico inferior, la gran mayoría de los encuestados varones tienen líderes que son de su mismo género $(79 \%)$.
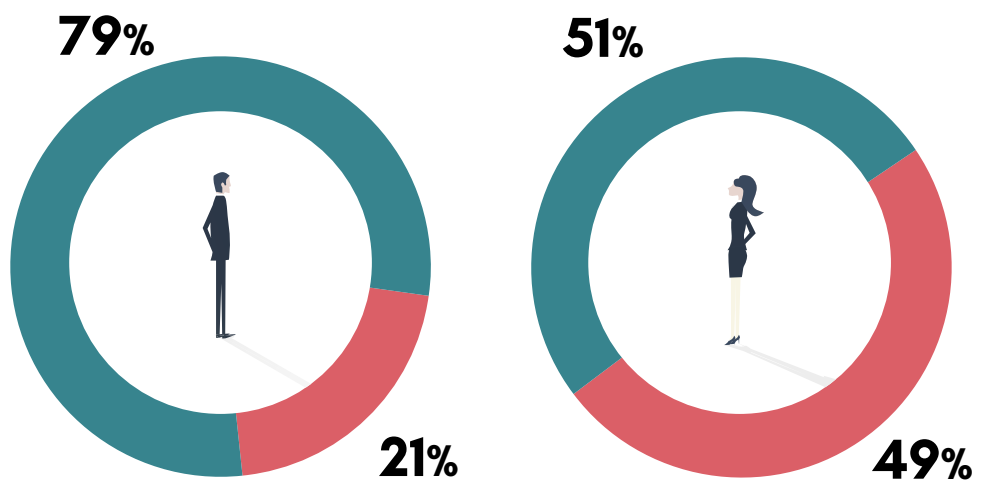

Esto indica que el comportamiento mostrado por los líderes, en cuanto a mostrarse favorables a la igualdad de oportunidades y a la flexibilidad para integrar el talento, está lejos de alcanzar el nivel óptimo. Se trata de un campo en el que las empresas deberán claramente movilizar recursos para formar a sus líderes y ayudarles a cambiar de actitud y de comportamiento. 


\section{Cuando el líder es mujer}

$45 \% \quad$ Sienten el apoyo instrumental de su supervisora

$41 \%$

$43 \% \quad$ Sienten que su supervisora hace una buena gestión de las políticas de la empresa

$41 \%$

$42 \% \quad$ Sienten que su supervisora es un buen modelo a seguir

$45 \%$

$52 \% \quad$ Sienten el apoyo emocional de su supervisora

$47 \%$

\section{Cuando el líder es hombre}

$47 \%$

Sienten el apoyo instrumental de su supervisor

$45 \%$

$38 \%$

Sienten que su supervisor hace una buena gestión de las políticas de la empresa

$42 \% \quad$ Sienten que su supervisor es un buen modelo a seguir 


\section{Entorno S=HE de igualdad de oportunidades: toma de decisiones en la familia*1}

Se miden dos dimensiones:

- La confianza: la persona confía en su pareja para sostenerle anímicamente y recibir su apoyo emocional y comprensión en épocas de trabajo duro e intenso.

- La benevolencia: la persona espera de su pareja un trato benevolente y esforzado para hacer su vida más agradable, fácil y provechosa.

Aunque en ambas dimensiones los hombres dicen sentirse más apoyados por sus parejas de lo que reconocen las mujeres, la diferencia es prácticamente nula. Sí cabe destacar que en ambos casos es muy elevada, por encima del $80 \%$, lo que permite concluir que las personas en pareja estable tienen una ventaja real a la hora de conseguir igualdad de oportunidades, ya que pueden utilizar este recurso, el del apoyo y la comprensión, que les permitirá superar situaciones difíciles y comprometidas en múltiples ocasiones.

\section{Creencias en el entorno familiar}

Basado en Ripley et al. ${ }^{21}$, el modelo S=HE estudia cómo las creencias referentes a la vida en pareja/matrimonio actúan como un continuo entre los que la perciben como un contrato frente a los que la perciben como una alianza.

\section{- Vida en pareja/matrimonio como}

transacción: perciben las decisiones como negociaciones de "suma cero" en las que el mayor beneficio de uno repercute en el menor beneficio del otro.

\begin{abstract}
- Vida en pareja/matrimonio como alianza: perciben las decisiones como oportunidades de crear mayores beneficios. Habitualmente, las decisiones se basan en la expectativa de que esats serán repetitivas $y$, por lo tanto, los beneficios son los que se conseguirán en el largo plazo, no inmediatamente.
\end{abstract}

Estas son dos visiones excluyentes; es decir, la vida en pareja se percibe de uno o de otro modo, y esto afecta a cómo se toman las decisiones laborales $u$ otras cuestiones trascendentales para la vida personal y familiar.

\section{El $58 \%$ de los varones percibe la vida en pareja como una alianza; el $52 \%$ de las mujeres tienen la misma percepción. Los demás la perciben como una transacción}

En comparación con las mujeres, son los varones los que más ven la vida en pareja como una alianza en la que pesan más los resultados conjuntos que el beneficio propio de cada decisión individual.

*1 Esta dimensión solo se refiere a personas con pareja estable 
Puedo confiar en mi pareja/esposo(a) cuando el trabajo es duro

Apoyo nulo

Apoyo pleno

Mi pareja/esposo(a) se esfuerza por hacer mi vida más fácil

Apoyo nulo

Apoyo pleno

Apoyo пulo

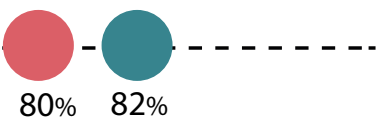

Mi pareja y yo negociamos en beneficio de los dos

Negociación nula

Negociación plena

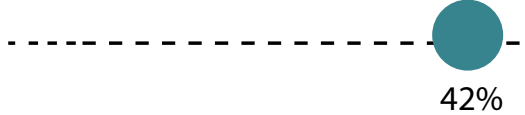

$52 \%$

Mi pareja y yo buscamos lo que sea mejor para el

matrimonio/familia, incluso si ninguno de los dos consigue lo que más le gustaría

Compromiso nulo

Compromiso pleno

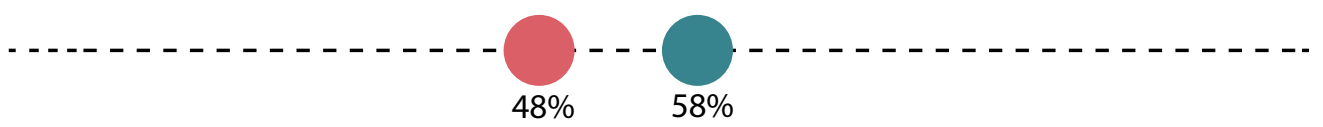




\section{Entorno S=HE de igualdad de oportunidades: toma de decisiones personales}

Hay prácticas de organización personal que ayudan a generar un entorno de igualdad de oportunidades, entre ellas:

\section{- Búsqueda proactiva de feedback}

- Solicitud de apoyo emocional-afectivo

- Exploración de información y alternativas

En nuestra muestra hallamos que las mujeres, y más específicamente aquellas menores de 40 años, sin hijos y con estudios superiores, son las que generan entornos de mayor igualdad de oportunidades a través de su práctica de acceso a feedback, apoyo emocionalafectivo y exploración de alternativas.

\section{Las mujeres menores de $\mathbf{4 0}$ años, sin hijos y con estudios superiores, son las que generan entornos de mayor igualdad de oportunidades a través de su práctica de acceso a feedback, apoyo emocional- afectivo y exploración de alternativas}

En el otro extremo, los hombres con hijos, con menos de 40 años y sin estudios superiores son los que generan un menor entorno de igualdad de oportunidades a través de sus prácticas de acceso a feedback, apoyo emocional-afectivo.

En la exploración de alternativas, el perfil masculino que genera un mejor entorno de igualdad de oportunidades son los que no tienen hijos, son menores de 40 y cuentan con estudios superiores.
Es llamativa la poca búsqueda proactiva de feedback y solicitud de apoyo emocional-afectivo que hacen tanto hombres como mujeres. En cualquier caso, las mujeres superan a los varones en estas prácticas, siendo las menores de 40 años las que mayor feedback reclaman ( $35 \%$ dicen buscarlo con regularidad), frente a los

\section{Busqueda proactiva de feedback}

Sin hijos

\begin{tabular}{|c|c|c|c|}
\hline Mujer & $33 \%$ & $44 \%$ & $24 \%$ \\
\hline Hombre & $22 \%$ & & \\
\hline
\end{tabular}

Con hijos

\begin{tabular}{|c|c|c|c|}
\hline Mujer & $30 \%$ & $1 \%$ & $29 \%$ \\
\hline Hombre & $39 \%$ & $37 \%$ & $24 \%$ \\
\hline
\end{tabular}

Mayores de 40

\begin{tabular}{l|l|l|l|} 
Mujer & $28 \%$ & $44 \%$ & $28 \%$ \\
Hombre & $21 \%$ & $36 \%$ & $42 \%$
\end{tabular}

Menores de 40

\begin{tabular}{|c|c|c|c|}
\hline Mujer & $35 \%$ & $40 \%$ & $25 \%$ \\
\hline Hombre & $26 \%$ & $42 \%$ & $33 \%$ \\
\hline
\end{tabular}

Estudios Superiores

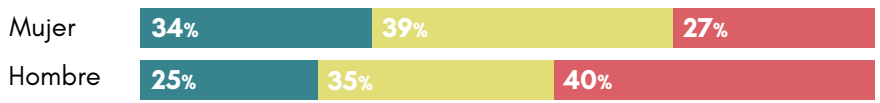

Estudios Medios o Básicos

\begin{tabular}{l|l|l|l} 
Mujer & $27 \%$ & $47 \%$ & $26 \%$ \\
Hombre & $20 \%$ & $43 \%$ & $37 \%$ \\
& & & \\
\multicolumn{2}{l}{ Siempre } & A veces & Nunca
\end{tabular}


hombres mayores de 40 años (solo un $21 \%$ reconocen realizar una búsqueda proactiva de feedback).

La exploración de alternativas conjunta (acceder a otras personas que puedan ayudar en ella) es, dentro de las prácticas de decisión personal, la realizada por

\section{Solicitud de apoyo emocional afectivo}

Sin hijos

\begin{tabular}{|c|c|c|}
\hline Mujer & $59 \%$ & $7 \%$ \\
\hline Hombre & $51 \%$ & $12 \%$ \\
\hline
\end{tabular}

Con hijos

\begin{tabular}{|c|c|c|c|}
\hline Mujer & $50 \%$ & $38 \%$ & $12 \%$ \\
\hline Hombre & $43 \%$ & $3 \%$ & $14 \%$ \\
\hline
\end{tabular}

Mayores de 40

\begin{tabular}{|c|c|c|}
\hline Mujer & $51 \%$ & $11 \%$ \\
\hline Hombre & $43 \%$ & $14 \%$ \\
\hline
\end{tabular}

Menores de 40

Mujer $\quad 58 \%$

Hombre $\quad 50 \%$

Estudios Superiores

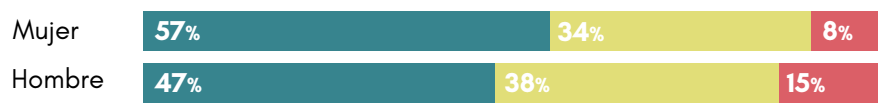

Estudios Medios o Básicos

\begin{tabular}{|c|c|c|c|}
\hline Mujer & $49 \%$ & $39 \%$ & $12 \%$ \\
\hline Hombre & $45 \%$ & $3 \%$ & $12 \%$ \\
\hline
\end{tabular}

\begin{tabular}{l|ll} 
Siempre & A veces & Nunca
\end{tabular} más personas. El $64 \%$ de las mujeres sin hijos y menores de 40 años dicen utilizar este modo de decisión regularmente. Los hombres que más lo utilizan son también los que no tienen hijos y tienen menos de 40 años.

\section{Exploración de información y alternativas}

\section{Sin hijos}

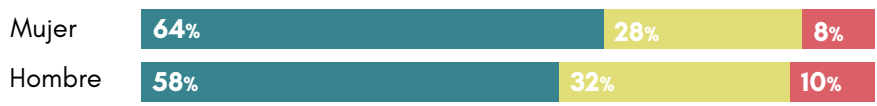

Con hijos

\begin{tabular}{|c|c|c|c|}
\hline Mujer & $53 \%$ & $38 \%$ & $9 \%$ \\
\hline Hombre & $51 \%$ & $38 \%$ & $11 \%$ \\
\hline
\end{tabular}

Mayores de 40

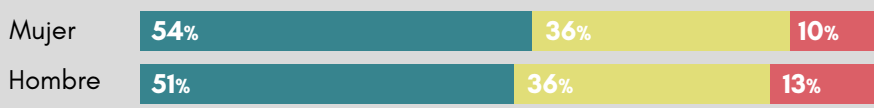

Menores de 40

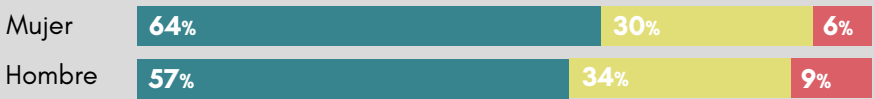

\section{Estudios Superiores}

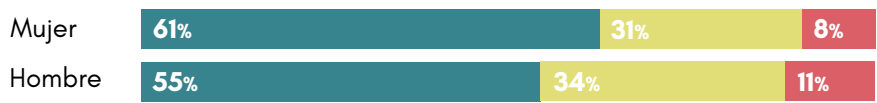

Estudios Medios o Básicos

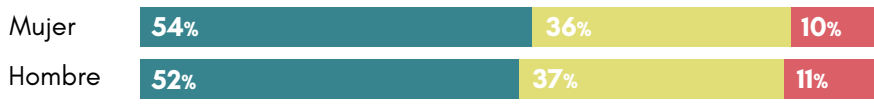

\begin{tabular}{l|l} 
Siempre & A veces \\
\end{tabular} 


\section{Entorno S=HE de igualdad de oportunidades: cultura en la empresa}

Siguiendo a Nishii ${ }^{22}$, en el modelo S=HE definimos la cultura inclusiva como el "conjunto de supuestos, creencias y valores compartidos por los miembros de la organización en relación con el grado en que esta apoya y valora la diversidad y los distintas aportaciones de sus empleados". De forma más específica, una cultura inclusiva es aquella que:

Proactivamente recaba información de los miembros de la organización para mejorar los procesos, servicios, productos $y$, específicamente, las condiciones de trabajo.

Reacciona de modo positivo, aceptando las propuestas que los distintos miembros de la empresa aportan para mejorar en diversas facetas del negocio, del clima laboral o de las condiciones de trabajo.

\section{El $66 \%$ de hombres y el $67 \%$ de mujeres trabajan en entornos cuya cultura no es inclusiva}

Aproximadamente, un tercio de los participantes en la encuesta ( $34 \%$ de hombres y $33 \%$ de mujeres) consideran que la cultura de su empresa es muy discriminante; es decir, ni busca proactivamente la aportación de los distintos miembros de la empresa ni acepta cuando estos aportan ideas, sugerencias 0 iniciativas.

En el otro extremo se encuentra otro tercio de los encuestados ( $29 \%$ de hombres y $32 \%$ de mujeres), que reportan moverse en un entorno empresarial que es inclusivo y que, por lo tanto, fomenta la igualdad de oportunidades.
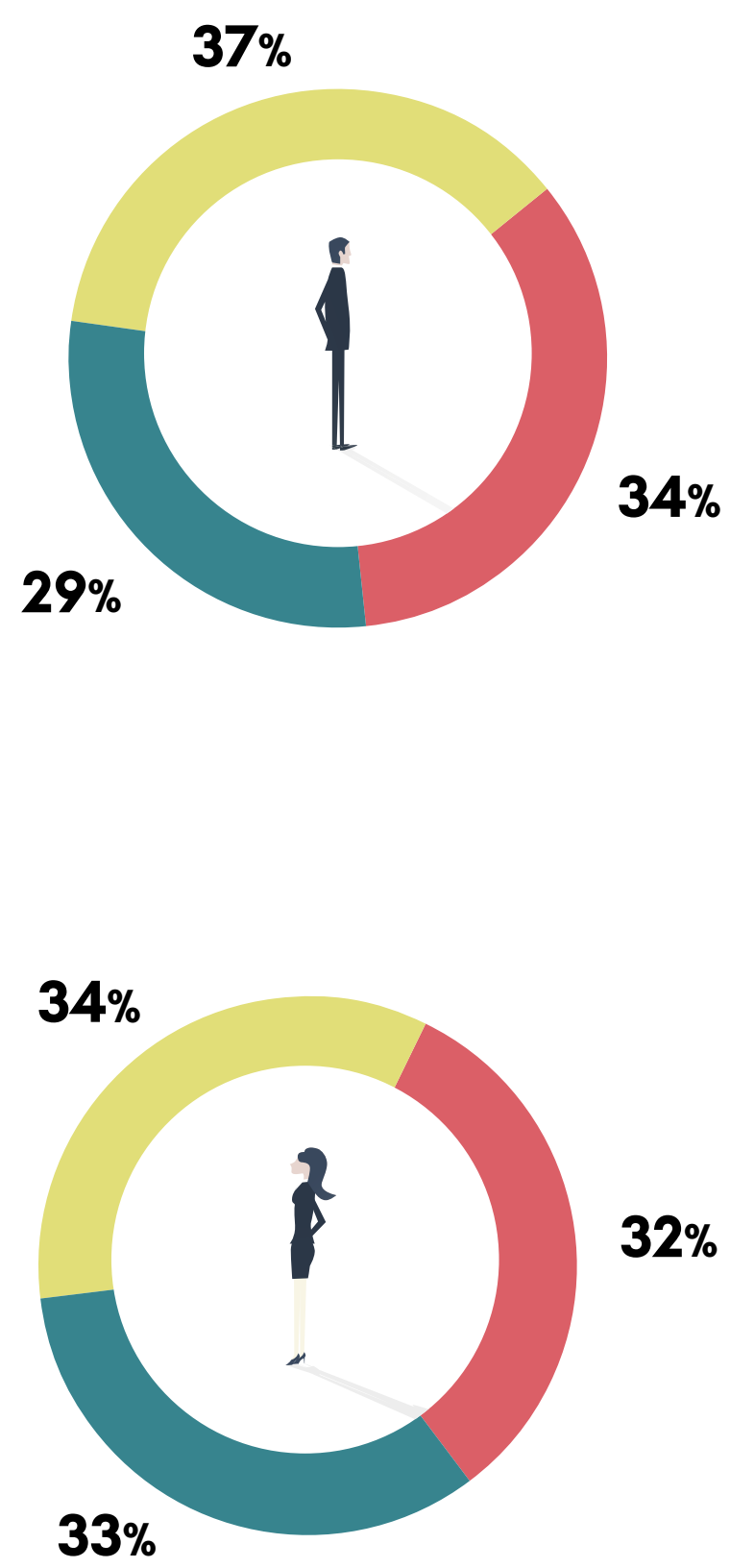

Cultura Inclusiva Neutral Muy discriminante 


\section{Entorno S=HE de igualdad de oportunidades: creencias en el entorno familiar}

Las creencias en el entorno familiar versan sobre quién debería ser el responsable de realizar las tareas de cuidado del hogar, tanto material del espacio físico en el que se cohabita como de las personas que conviven en el núcleo familiar -hijos, dependientes y/o personas mayores.

Un $92 \%$ de las mujeres consideran que dichas tareas deberían ser repartidas equitativamente entre hombres y mujeres. $Y$ del $8 \%$ que piensa que no deberían

\section{$84 \%$ de los} hombres

piensan que el cuidado del hogar y de los hijos debe de ser equitativo con la pareja

\section{$16 \%$} de los dos en la pareja debe de tomar mayor peso en las responsabilidades familiares

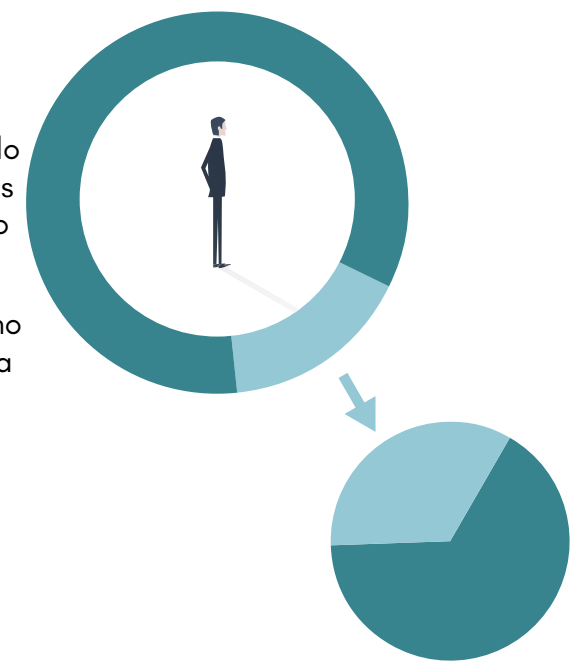

$66 \%$ piensan que son ellos mismas las que deben asumirlo

$\mathbf{3 4} \%$ piensan que uno de los dos en la pareja debe de tomar mayor peso en las responsabilidades familiares repartirse equitativamente, un $79 \%$ afirman ser ellas las deben asumir más peso en las tareas del hogar.

\section{La mayoría de la población piensa que las tareas de cuidado deberían ser asumidas equitativamente por hombres y mujeres}

Un $84 \%$ de los hombres encuestados opinan que el reparto debería ser equitativo. Del 16\% restante, los que afirman que el peso de las tareas no debería ser equitativo, un $66 \%$ piensa que es la mujer la que tendría que tomar el protagonismo; es decir, la que tendría que aumir una mayor carga en dicho cuidado.

$\mathbf{9 2 \%}$ de las mujeres piensan que el cuidado del hogar y de los hijos debe de ser equitativo con la pareja

$8 \%$ de los dos en la pareja debe de tomar mayor peso en las responsabilidades familiares

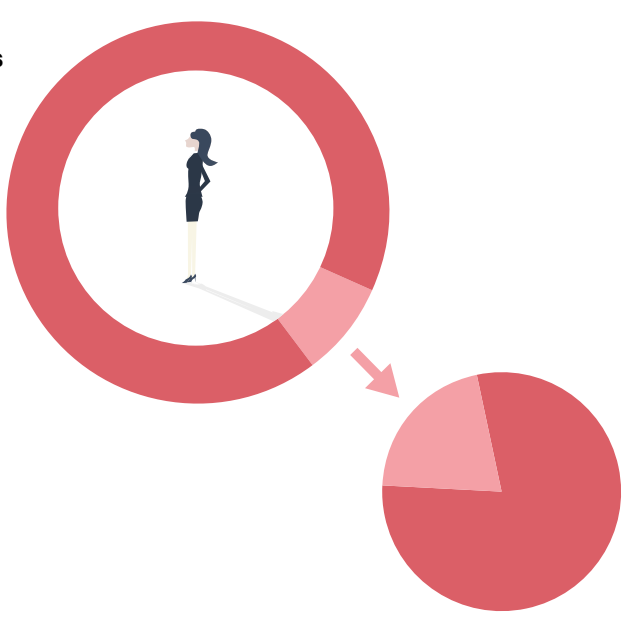

$79 \%$ piensan que son ellas mismas las que deben asumirlo $\mathbf{2 1 \%}$ piensan que uno de los dos en la pareja debe de tomar mayor peso en las responsabilidades familiares 


\section{Entorno S=HE de Igualdad de Oportunidades: creencias personales}

En el modelo $\mathrm{S}=\mathrm{HE}$, las creencias personales se refieren a la automotivación, a la autoevaluación de competencias y al optimismo.

Las creencias personales son muy relevantes. La valoración que una persona hace de sí misma en base a sus pensamientos, sentimientos y experiencias le llevará a proyectar una imagen concreta, a presentarse ante los demás de una determinada forma y a reconocer sus propios aciertos y errores.

Además, la forma en que una persona se valora también estará influida en muchas ocasiones por agentes externos, y puede ir cambiando a lo largo del tiempo.

\section{Si las mujeres llegan a abandonar el mercado de trabajo, o se conforman con posiciones inferiores, no es porque no les importe estar en el mercado laboral o porque no se crean capaces de desarrollar una buena labor profesionall}

Hombres y mujeres están a niveles muy similares en lo que se refiere a la automotivación, autoevaluación de competencias y grado de optimismo. Es decir, si ellas llegan a abandonar el mercado de trabajo o se conforman con posiciones inferiores, no es porque no les importe estar en el mercado laboral o porque no se crean capaces de desarrollar una buena labor profesional.

Específicamente, las mujeres son las que tienen un mayor nivel de automotivación, siendo las que tienen hijos las que muestran un nivel más elevado en esta dimensión frente a las que no los tienen y frente a los hombres (con o sin hijos).

En lo que se refiere a la autoevaluación de competencias, de nuevo las mujeres están ligeramente por encima de los hombres.

\section{Automotivación}

Sin hijos

$\begin{array}{lrcc}\text { Mujer } & 56 \% & 28 \% & 16 \% \\ \text { Hombre } & 58 \% & 13 \% \\ \text { Con hijos } & & \\ \text { Mujer } \quad 64 \% & 28 \% & 10 \% \\ \text { Hombre } \quad 59 \% & 26 \% & 15 \%\end{array}$

Mayores de 40

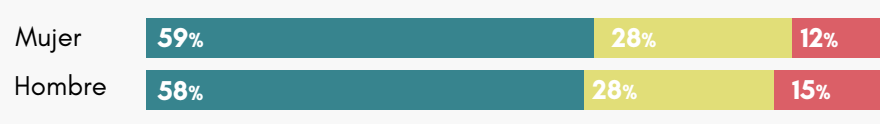

Menores de 40

\begin{tabular}{l|l|l|l} 
Mujer & $62 \%$ & $26 \%$ & $13 \%$ \\
Hombre & $61 \%$ & $25 \%$ & $13 \%$
\end{tabular}

Estudios Superiores

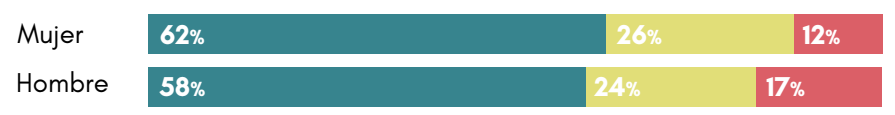

Estudios Medios o Básicos

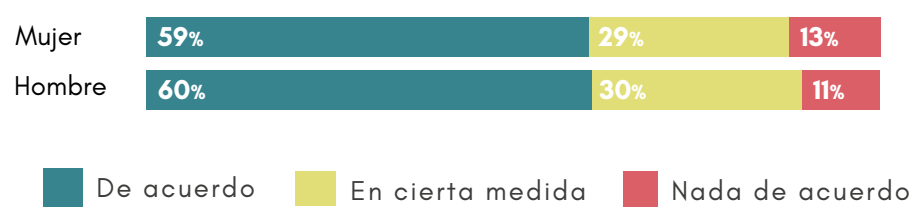


Contrariamente a lo que se dice en muchas ocasiones, las mujeres muestran un mayor nivel de autoestima que los hombres

\section{Autoevaluación de competencias}

Sin hijos

\begin{tabular}{l|l|l|l|} 
Mujer & $91 \%$ & $8 \%$ \\
\hline Hombre & $86 \%$ & $13 \%$ & $1 \%$ \\
\hline
\end{tabular}

Con hijos

\begin{tabular}{l|l|l|l|} 
Mujer & $\mathbf{9 0}$ & $8 \%$ & $\mathbf{2} \%$ \\
\hline Hombre & $\mathbf{8 5} \%$ & $14 \%$ & $1 \%$
\end{tabular}

Mayores de 40

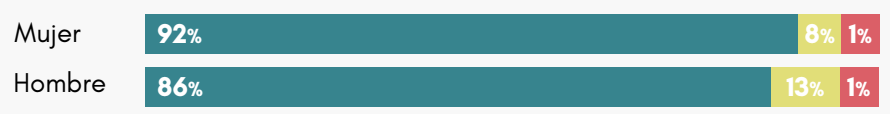

Menores de 40

\begin{tabular}{l|l|l|l|} 
Mujer & $\mathbf{9 0} \%$ & $9 \%$ \\
\hline Hombre & $\mathbf{8 4} \%$ & $15 \%$ & $1 \%$ \\
\hline
\end{tabular}

Estudios Superiores

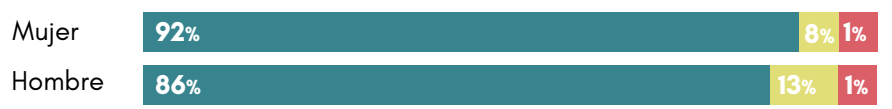

Estudios Medios o Básicos

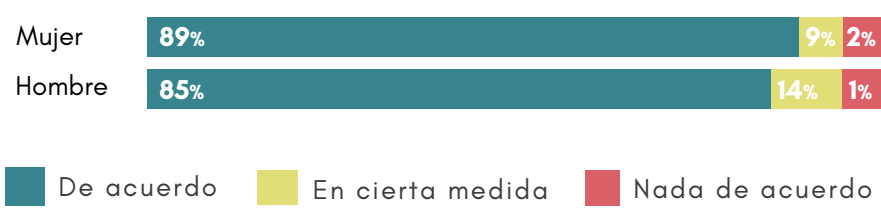

Por último, en relación con el optimismo, vuelven a ser las mujeres con hijos las que muestran un nivel ligeramente superior al de los demás grupos de la muestra (mujeres sin hijos y hombres con o sin hijos).

\section{Optimismo}

Sin hijos

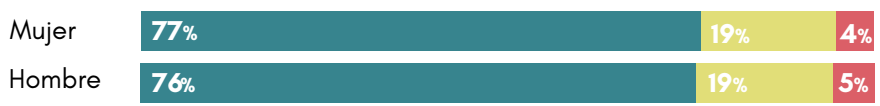

Con hijos

\begin{tabular}{|c|c|}
\hline Mujer & $83 \%$ \\
\hline Hombre & $80 \%$ \\
\hline
\end{tabular}

Mayores de 40

\begin{tabular}{l|l|ll} 
Mujer & $80 \%$ & $17 \%$ & $3 \%$ \\
\hline Hombre & $80 \%$ & $16 \%$ & $4 \%$
\end{tabular}

Menores de 40

\begin{tabular}{|c|c|c|}
\hline Mujer & $81 \%$ & $16 \%$ \\
\hline Hombre & $77 \%$ & $9 \%$ \\
\hline
\end{tabular}

Estudios Superiores

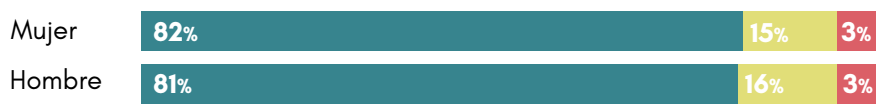

Estudios Medios o Básicos

\begin{tabular}{|c|c|}
\hline Mujer & $78 \%$ \\
\hline Hombre & $76 \%$ \\
\hline Alta & \\
\hline
\end{tabular}




\section{CONSECUENCIAS}

\section{Resultados en la empresa: horas dedicadas al trabajo}

En las empresas puede existir reticencia a crear un entorno de inclusión puesto que existe la percepción general de que hacerlo puede afectar negativamente al número de horas trabajadas, así como al rendimiento de dichas horas.

Sin embargo, nada más lejano a la realidad. El entorno de igualdad de oportunidades conlleva que las personas puedan contribuir con sus ideas y sean valoradas por sus conocimientos, competencias y experiencia. Todo ello se traduce en un mayor grado de aportación a la empresa.

El entorno de igualdad de oportunidades no afecta al número de horas trabajadas ni por hombres ni por mujeres. Es decir, mientras las mujeres mayores de 40 años trabajan 42,5h semanales en entornos $S$ (satisfactorios), en entornos $\mathrm{E}$ (excluyentes) lo hacen $43,2 \mathrm{~h}$ semanales ${ }^{* 2}$. Por otro lado, los hombres mayores de 40 años trabajan 47,5h semanales en entornos $S$ (satisfactorios), y en entornos $E$ (excluyentes) lo hacen 48,6 h semanales ${ }^{*}$.

Sin embargo los resultados son significativamente distintos para las mujeres y los hombres menores de 40 años. Mientras ellas trabajan $55 \mathrm{~h}$ semanales en

*2 Esta diferencia no es estadísticamente significativa entornos S (satisfactorios), en entornos $E$ (excluyentes) lo hacen 46, lh semanales. Esta relación con el entorno es exactamente la contraria para los hombres menores de 40, que trabajan 40,0h semanales cuando están en entornos $S$ (satisfactorios) y $48,6 \mathrm{~h}$ semanales en entornos $E$ (excluyentes).

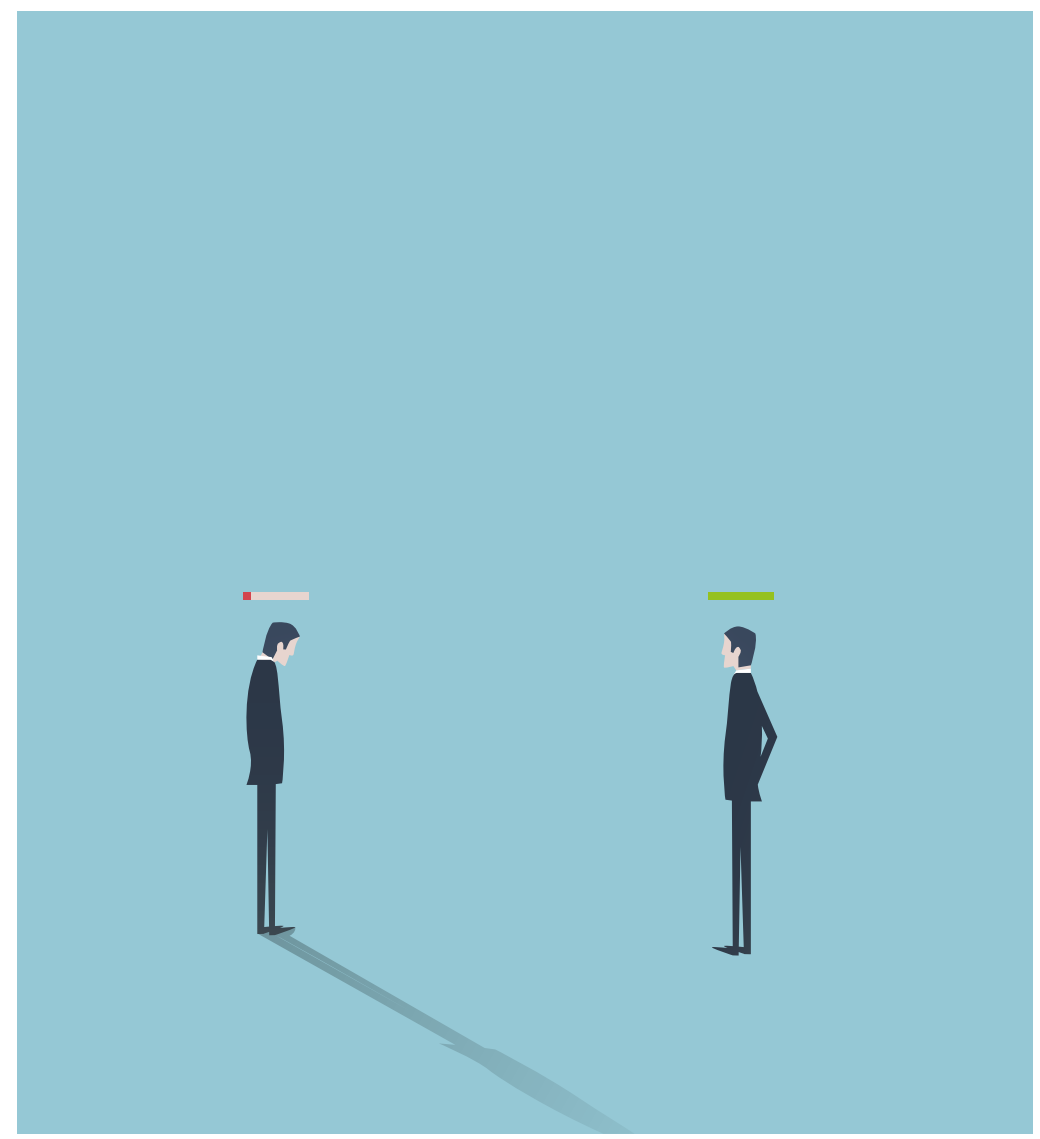


Promedio de horas trabajadas a la semana por los hombres

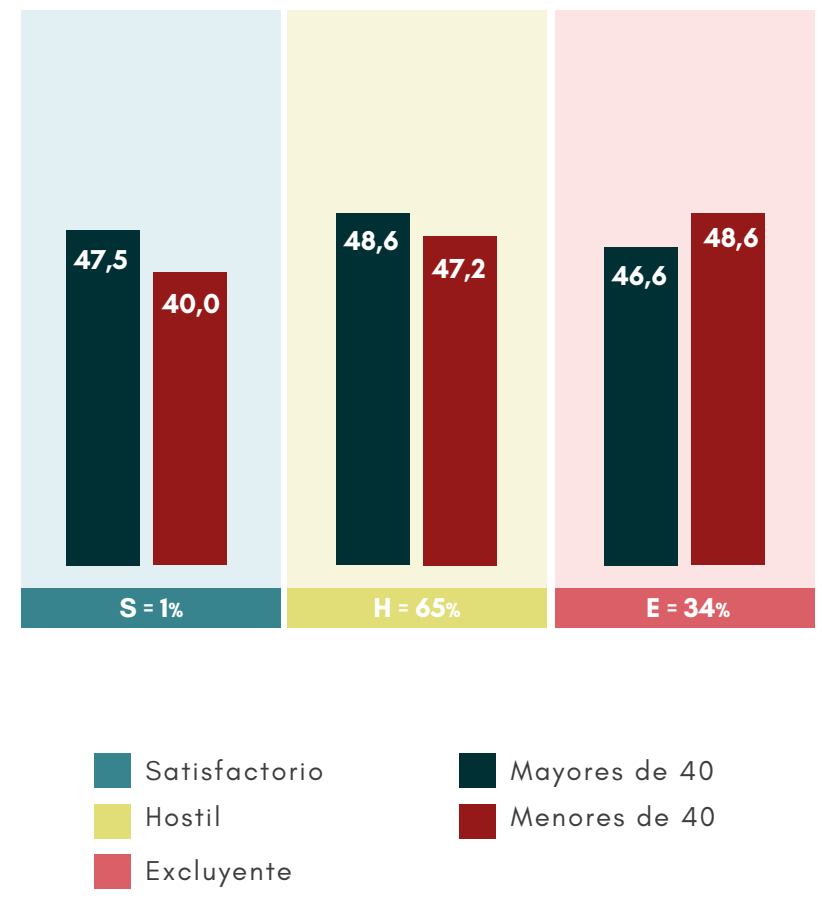

Promedio de horas trabajadas a la semana por las mujeres

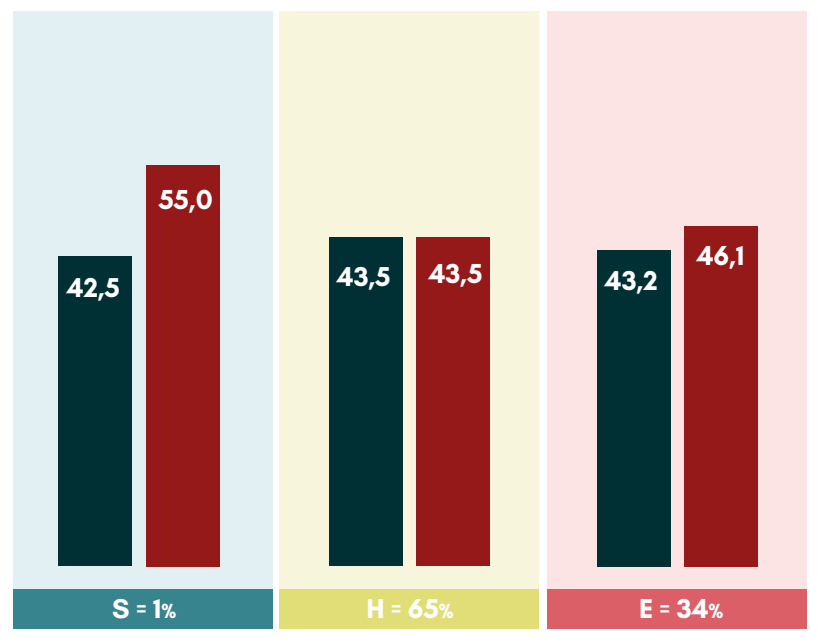

Satisfactorio

Mayores de 40

Hostil

Menores de 40

Excluyente 


\section{El entorno de igualdad de oportunidades} en la familia hace que la mujer dedique más horas al trabajo, pues las responsabilidades no-laborales las comparte equitativamente con su pareja

Las mujeres que tienen un mejor entorno de igualdad de oportunidades en su familia (el $8 \%$ de la población que ha participado en la muestra) son las que dedican mayor tiempo a trabajar; en total, $52,8 \mathrm{~h}$ semanales.

En los hombres sucede justo lo contrario: cuanto peor entorno de igualdad tienen en el hogar (el $6 \%$ de los hombres encuestados vive en entornos $E$-excluyentes), más horas trabajan fuera de casa, llegando a dedicar a su empleo $51,5 \mathrm{~h}$ a la semana.

Una situación lógica, por otro lado, ya que para las mujeres el entorno de igualdad en su hogar significa que reparten equitativamente con sus parejas las tareas de cuidado del hogar, los hijos y las personas dependientes. De esta forma, la mujer puede decidir cuántas horas invierte en su trabajo, y dedicarle el tiempo proporcional a la responsabilidad que tenga o a la presión por los resultados, etc.

Sin embargo, en los hombres sucede todo lo contrario: cuando un hombre está en un entorno de no-igualdad de oportunidades en el que es su cónyuge quien toma las responsabilidades de cuidado, él puede dedicar el tiempo que considere oportuno a labores de su trabajo.

\section{Horas trabajadas por el hombre en el entorno de igualdad de oportunidades en la familia}

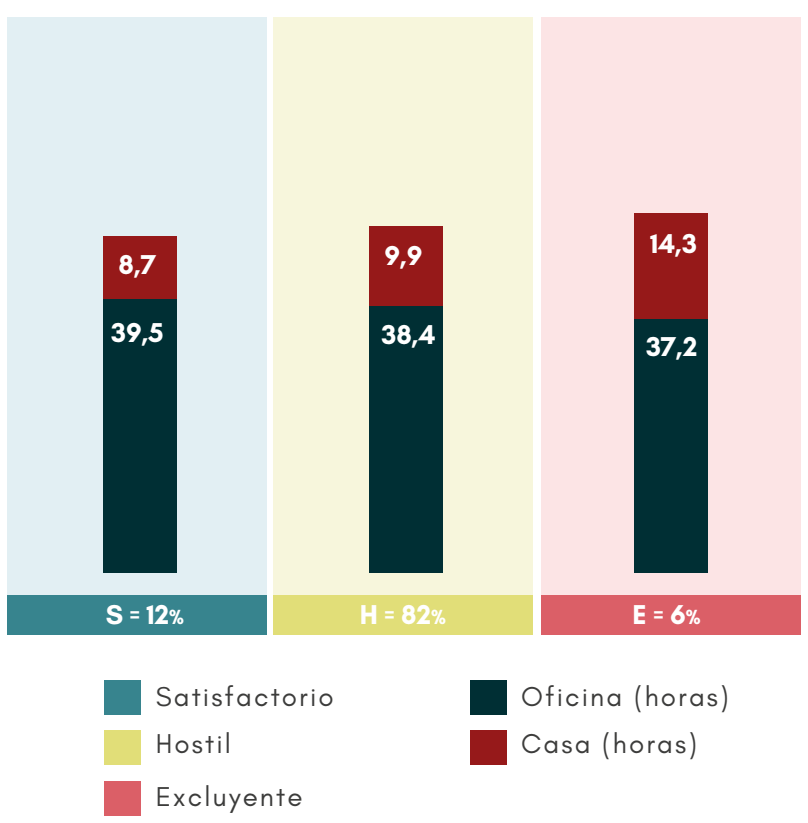

\section{Horas trabajadas por la mujer en el entorno de igualdad de oportunidades en la familia}

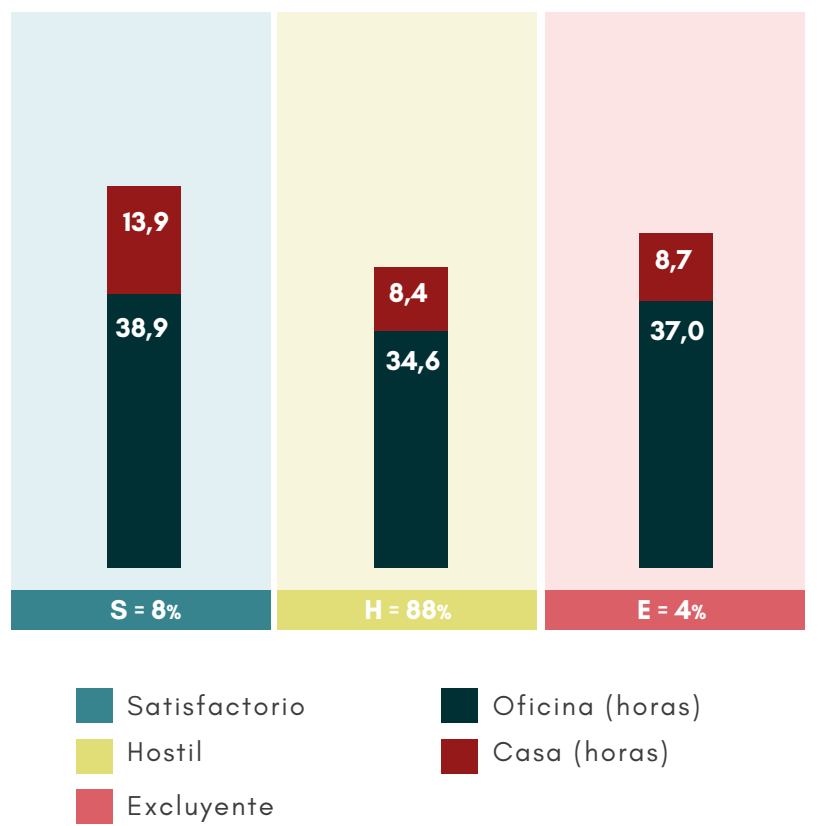




\section{Resultados en la empresa: compromiso con la misión de la empresa}

El compromiso de los trabajadores con la misión de la empresa se refleja en la implicación y el esfuerzo que estos muestran con su empresa. Cuanto mayor es el compromiso con la misión de la organización, más dispuestos estarán los empleados a contribuir personalmente al éxito de la misma.

\section{Los hombres y las mujeres en entornos que proporcionan igualdad de oportunidades muestran un $100 \%$ de compromiso con su organización}

El compromiso con la misión de la organización no se impone, sino que se favorece a través de una serie de prácticas. Y no deja de ser una relación de reciprocidad: en la medida en que la empresa muestra, a través de sus políticas, el liderazgo que ejerce y la cultura empresarial que promueve, que valora al empleado, este a su vez corresponderá a dicho esfuerzo sintiéndose personalmente apelado a contribuir. Es decir, el compromiso es un camino de dos direcciones que transita entre la empresa y trabajador. Es de ida y regreso. A la empresa le conviene el compromiso del trabajador y a éste, ser bien tratado a todos los niveles: económico, relacional y profesional.

Hay una relación clara entre el compromiso de los trabajadores y algunos aspectos de máxima importancia para la empresa, como la eficiencia, la productividad, la atracción del talento, la fidelización o la satisfacción del cliente, entre otras. En definitiva, el compromiso del empleado con la misión de la empresa es de máxima importancia.

\section{Porcentaje de compromiso de hombres y mujeres con la misión de la empresa}

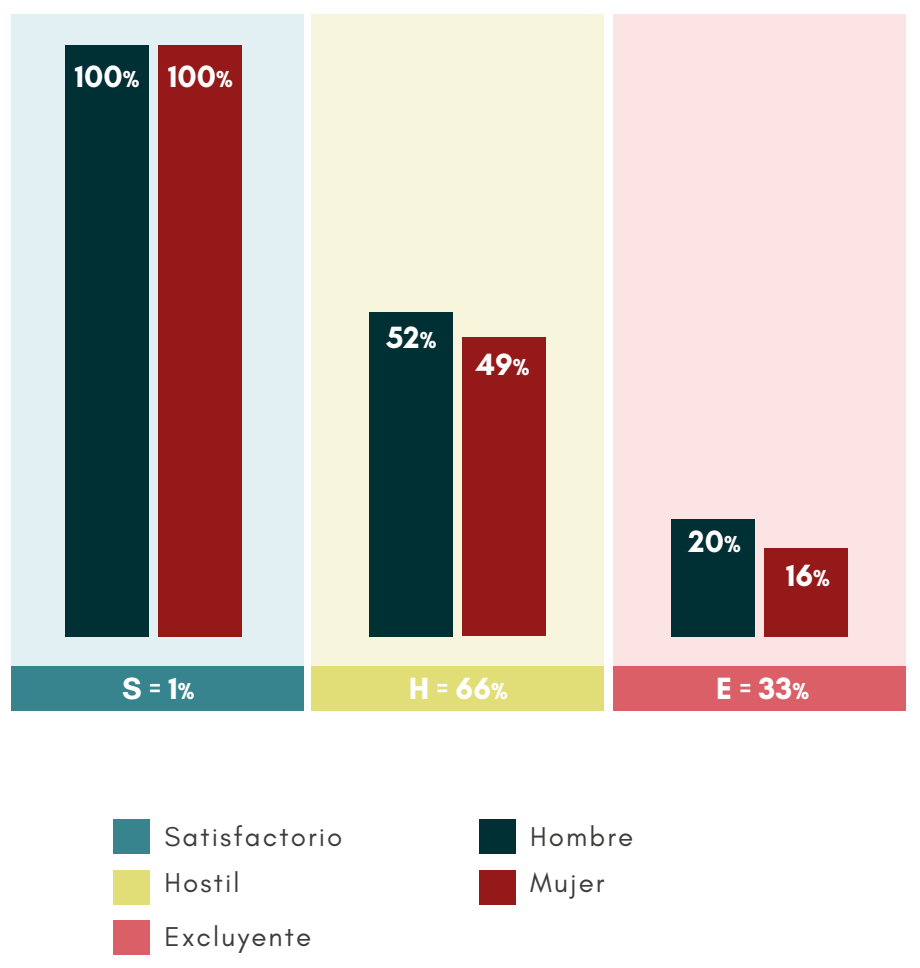




\section{Resultados organizativos: satisfacción en el trabajo}

La satisfacción en el trabajo se puede definir, de manera muy genérica, como una actitud positiva de la persona hacia su trabajo. Como hemos visto en el modelo $\mathrm{S}=\mathrm{HE}$, las empresas, la familia y la propia persona generan un espacio en el que esta es más o menos capaz de ser eficaz en su tarea y desarrollo profesional. Como consecuencia, es más o menos capaz de sentirse satisfecha con su trabajo.

La satisfacción con el trabajo es de mucha relevancia ya que está directamente relacionada con otras consecuencias afectivas y de comportamiento, como el compromiso con la empresa, la atención al cliente, el esfuerzo y el deseo de abandonar la empresa.

\section{El entorno de igualdad de oportunidades afecta en gran medida a la satisfacción de hombres y mujeres con su trabajo}

En este estudio S=HE vemos que hay una alta relación entre el entorno en el que se mueve la persona y su satisfacción con el trabajo que realiza.

El entorno de igualdad de oportunidades afecta en gran medida a la satisfacción de hombres y mujeres con su trabajo. Los hombres y mujeres en entornos $\mathrm{S}$ (satisfactorios) muestran estar $100 \%$ satisfechos con su trabajo. Los hombres y mujeres en el entorno $\mathrm{H}$ (Hostil) dicen tener una gran satisfacción en el $65 \%$ y $64 \%$ de los casos, respectivamente. Los menos satisfechos son los que están en el entorno $E$ (Excluyente), en el que solo el $26 \%$ de hombres y el $30 \%$ de mujeres dicen estar satisfechos con su trabajo.

\section{Hombre}

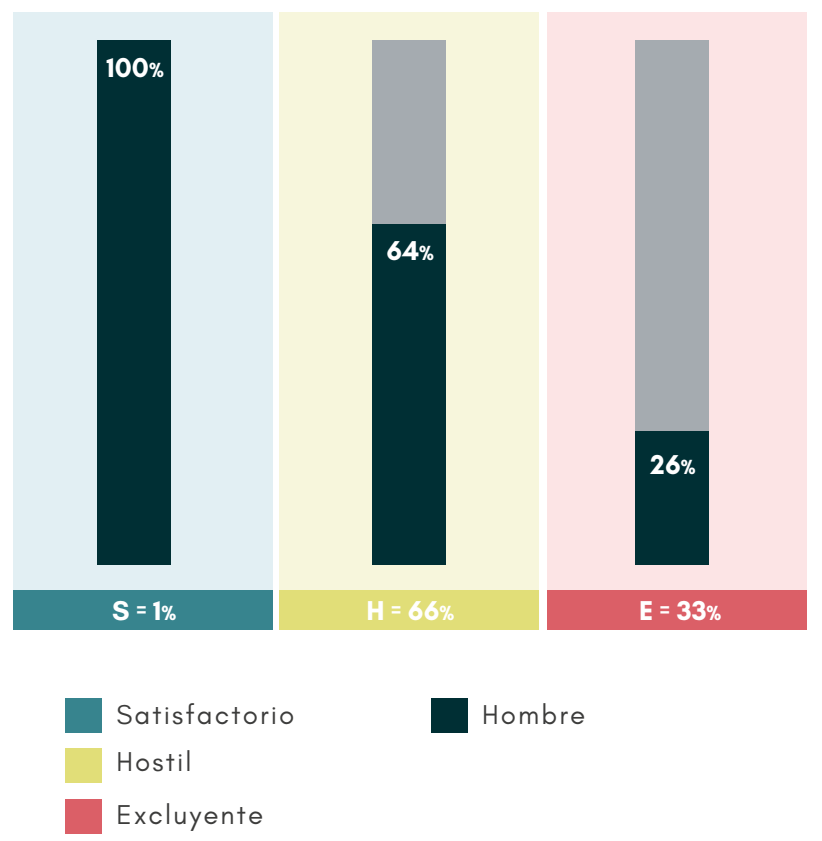

\section{Mujer}
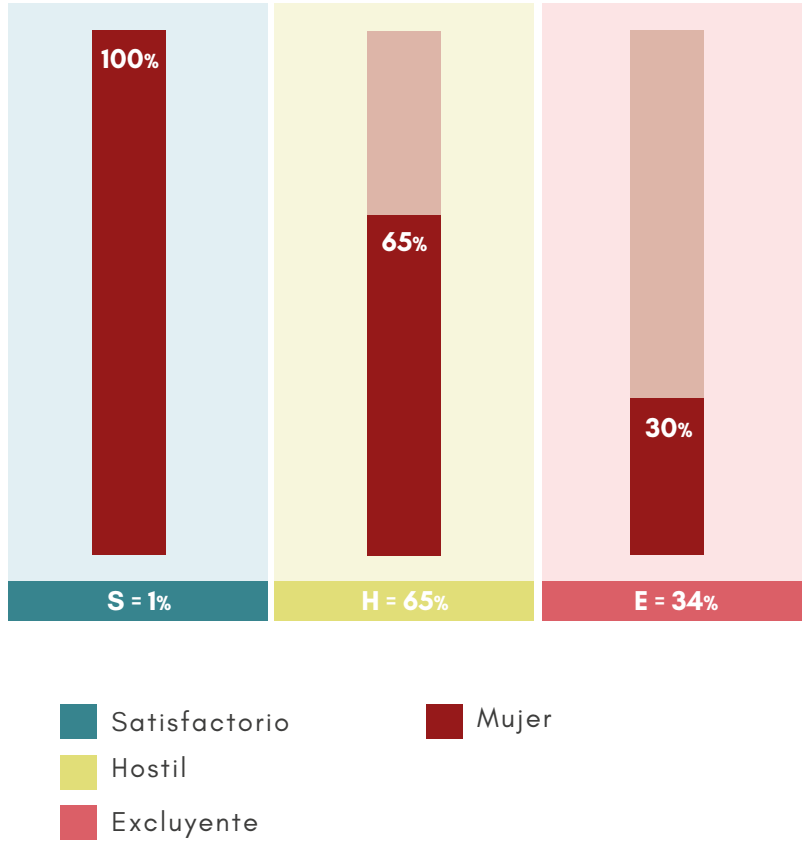


\section{Resultados en la familia: conflictos en la familia debido al trabajo}

El conflicto trabajo-familia es una situación personal en la que las demandas del trabajo o la sobrecarga del mismo dificultan (o incluso hacen imposible) tener una relación satisfactoria con el cónyuge, los hijos $u$ otros familiares dependientes, así como dedicar tiempo a desarrollar otros aspectos relevantes de la vida personal (voluntariado, formación continua, deporte, ocio, etc. $)^{23}$. Esto genera una situación de insatisfacción en la persona que dificulta su desarrollo personal y profesional por estrés, malestar y desaliento.

\section{Cuando el entorno no facilita la igualdad de oportunidades, los conflictos en el hogar debido al trabajo son mayores, tanto para hombres como para mujeres}

El constructo conflicto trabajo-familia ${ }^{24}$ mide la percepción que tiene el empleado de no poder contribuir a la familia porque el trabajo le absorbe un número desproporcionado de horas, mucha energía y toda su capacidad de concentración.

Es lógico, pues, que hayamos encontrado unos resultados tan contundentes en nuestro estudio. El entorno $\mathrm{S}=\mathrm{HE}$ recoge dimensiones del entorno laboral, personal y familiar, y estudia prácticas que nos hacen ser efectivos y equitativos en el reparto de tareas, que facilitan la toma de decisiones correctas y conducen a creencias y valores adecuados a la realidad. Por todo ello, cuando la persona está en un entorno de menor igualdad de oportunidades, sufrirá mayores tensiones y disfrutará de menor apoyo, provocando con ello que su capacidad de disfrute de los eventos familiares o de generar relaciones de calidad y mutualidad, se vea claramente mermada.

\section{Hombre}

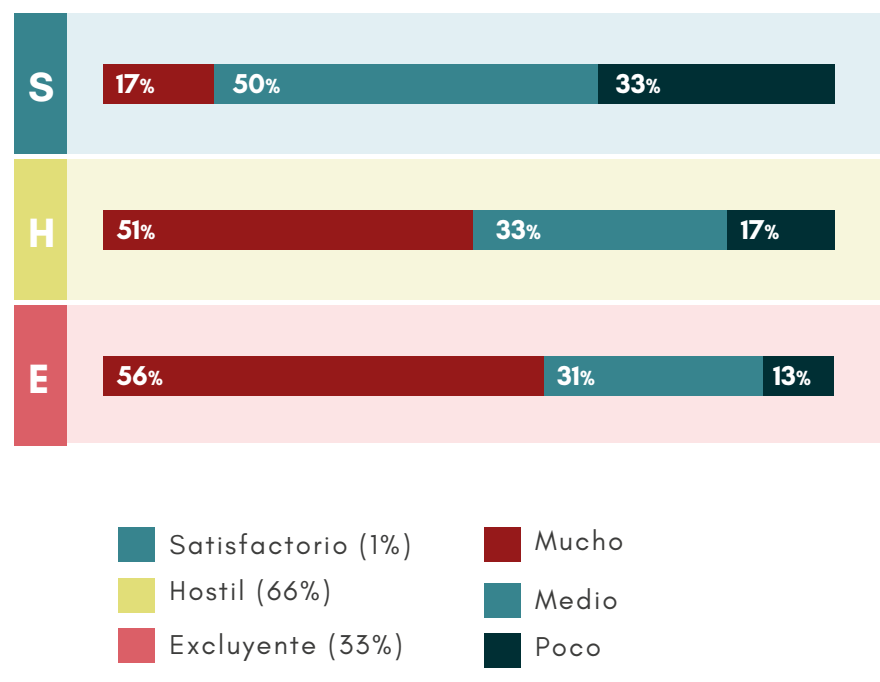

\section{Mujer}

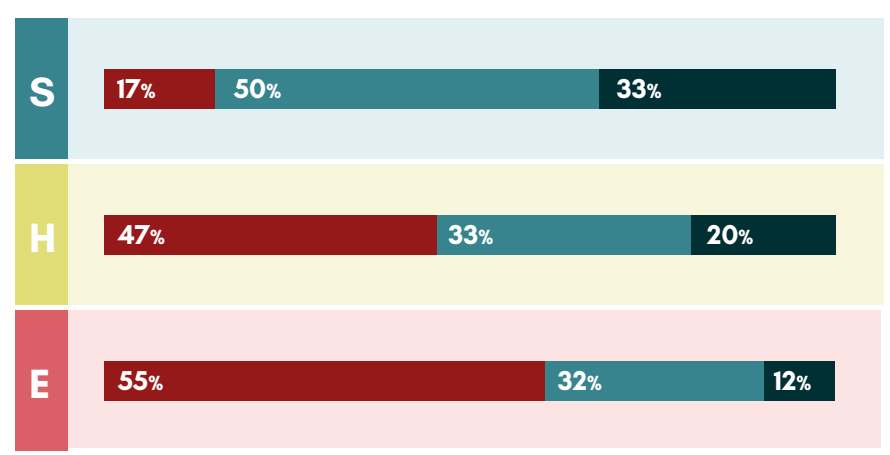

Satisfactorio $(1 \%)$

Hostil (65\%)

Excluyente (34\%)

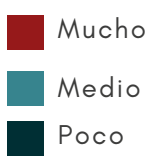




\section{Resultados en la familia: dedicación a la familia}

El tiempo es un recurso escaso de características muy peculiares: no transferible, in-elástico e incierto, entre otras. Por ello en el S=HE queremos saber si la persona dedica a su familia el tiempo que cree que debería.

\section{En el entorno $\mathrm{S}$ las mujeres están muy} satisfechas con el tiempo que dedican a sus familias. Los hombres, en el mismo entorno, afirman sentir menos satisfacción que ellas

Los datos muestran que en los entornos $\mathrm{S}$ (satisfactorio) y $\mathrm{H}$ (Hostil) las mujeres están mucho más satisfechas con las horas que dedican a la familia que los hombres.

Es de enorme relavancia que las persoans dediquen el tiempo necesario a estar con sus familias, ya que es el modo de que repongan fuerzas, ejerzan un rol educativo, cuiden de dependientes y desarrollen competencias. Especificamente, los padres de niños y adolescentes tienen un rol ineludible en la formación de sus hijos, tanto en la aportación a su equilibrio socio-emocional como a sus habilidades sociales y las destrezas básicas de higiene, cuidado personal y rendimiento académico.

El impacto de la igualdad de oportunidades según la hemos definido en el estudio S=HE supera las fronteras de las organizaciones para llegar a las familias y a la sociedad.

La verdadera solidaridad se da en la familia, y solo cuando el propio profesional disfruta de la familia es capaz de vivir la verdadera responsabilidad social y la verdadera profesionalidad en su tarea.
Dedicando tiempo a la familia el profesional aprende que las personas son valiosas en sí mismas. Uno no da por lo que pueda recibir de los demás, sino por lo que pueda aportarles, ya sea conversación, compañía, alegría. Esto nos devuelve a la realidad, porque la realidad es que la alegría surge de dar a los demás de lo propio; en cuyo caso, aunque aparentemente sea contradictorio, en lugar de vaciarse, uno se siente más lleno que nunca.

\section{Tiempo destinado al cuidado de familiares (Entorno S = HE total)}
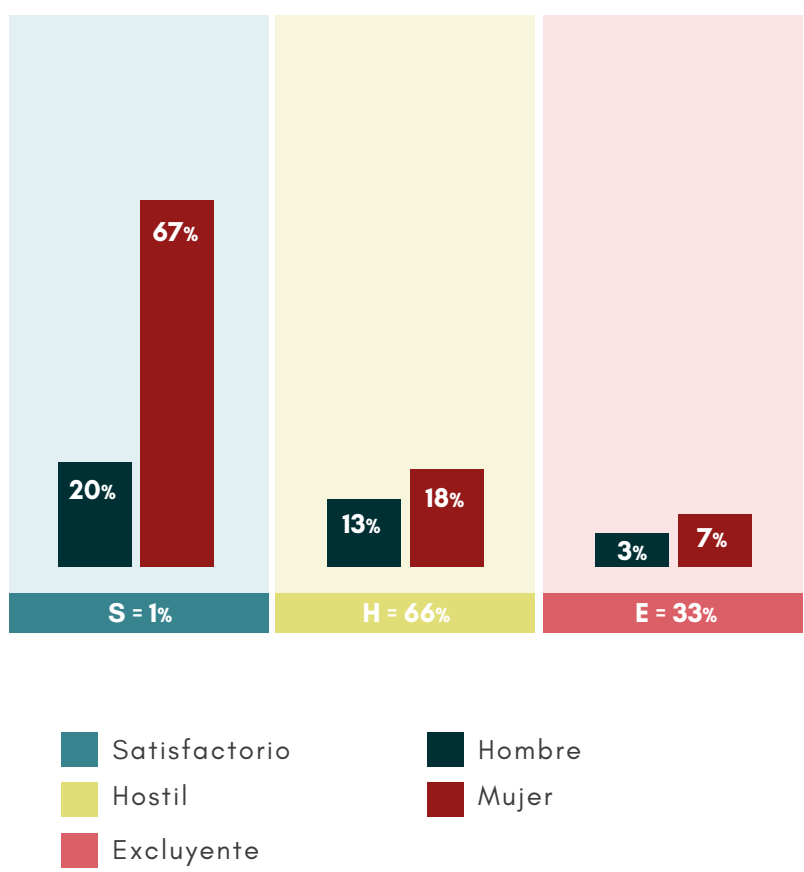


\section{Resultados en la persona: satisfacción en las distintas dimensiones vitales}

El ser humano posee una identidad propia que debe perfeccionarse continuamente. Somos seres inacabados con la necesidad de auto-desarrollarnos para alcanzar la plenitud. Las necesidades básicas, inherentes a la naturaleza humana, son de tres tipos ${ }^{25}$ : materiales, es decir, las que se relacionan con el mundo tangible-sensible; intelectuales, que se relacionan con el aumento del conocimiento operativo; y afectivas, que son aquellas ligadas al logro de relaciones enriquecedoras con otras personas.

Como la persona es además un ser libre, su satisfacción al cubrir esas necesidades es mucho mayor si las alcanza de modo autónomo frente a si las consigue coaccionado por su entorno.

Así pues, la igualdad de oportunidades lleva a la persona a que se sienta y se sepa autónoma. Y es de suma importancia a la hora de disfrutar en el cumplimiento de los deberes laborales, y de las distintas facetas vitales.

Es por ello que en el estudio $\mathrm{S}=\mathrm{HE}$ medimos según una escala ${ }^{26}$ el grado de satisfacción que las personas perciben en los distintos ámbitos vitales, y estudiamos hasta qué punto el entorno en el que desarrollan su trabajo (S-H-E) está relacionado con la satisfacción en esos ámbitos.

A la vista de los datos obtenidos podemos concluir que los entornos de igualdad de oportunidades están fuertemente relacionados con la satisfacción vital de hombres y mujeres, y que el impacto sobre dicha satisfacción es prácticamente igual para ambos.

\section{Hombres}

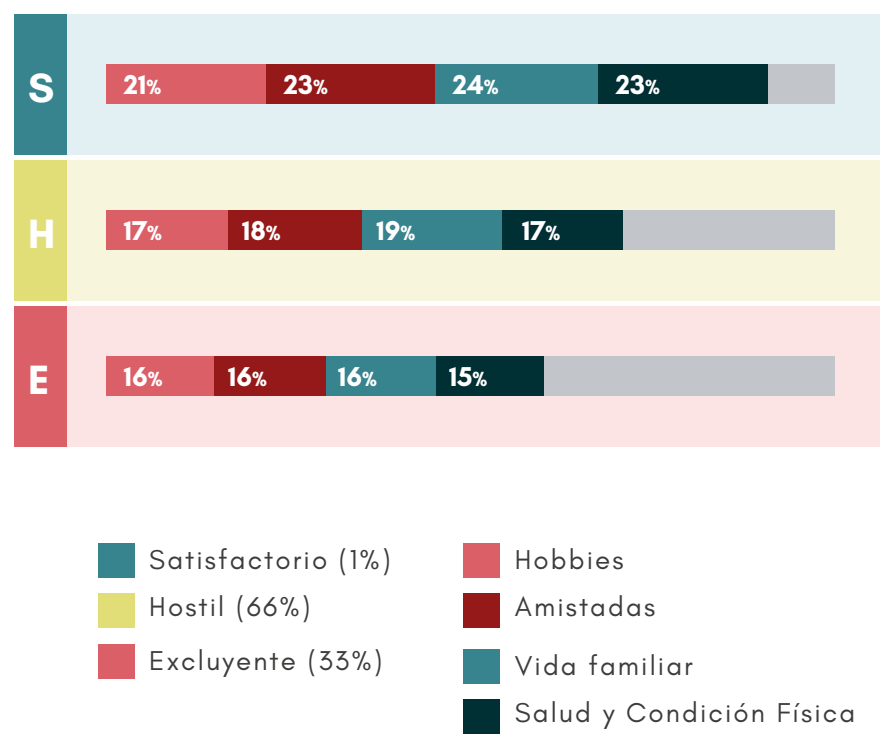

\section{Mujeres}

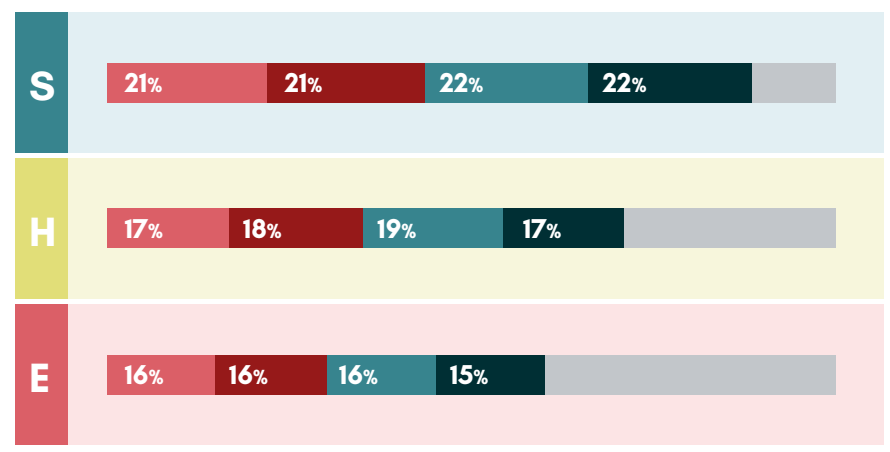

Satisfactorio $(1 \%)$

Hostil (65\%)

Excluyente $(34 \%)$
Hobbies

Amistadas

Vida familiar

Salud y Condición Física 


\section{Resultados en la persona: calidad del sueño}

\section{La calidad del sueño, para hombres y para mujeres, disminuye de modo alarmante cuanto más deteriorado está el entorno respecto a la igualdad de oportunidades}

En concreto, y de máxima importancia en esta investigación, resulta el efecto de la igualdad de oportunidades -o ausencia de ésta- sobre la calidad del sueño. Algunos estudios ${ }^{27}$ de referentes internacionales en neurología muestran que una deficiente calidad del sueño tiene consecuencias en:

- La disminución de la atención durante el día a causa de que la memoria y la habilidad cognitiva se vuelven deficientes, con el consiguiente riesgo de sufrir lesiones ocupacionales (el aumento del riesgo puede ser de hasta un $200 \%$ ).

\section{- El aumento de la presión arterial,} empeoramiento del sistema inmune e incremento del riesgo de ataques cardíacos, de obesidad y de apoplejía, incrementando por tanto el riesgo de mortalidad.

- Una mayor incidencia de depresión y otros trastornos mentales.

- Un incremento de los problemas sociales y de pareja.

Así pues, el impacto negativo que tiene falta de igualdad de oportunidades en la calidad del sueño va mucho más allá de la persona y de la empresa para convertirse en un aspecto de máxima importancia para la sociedad en su conjunto.

Calidad del sueño en el último mes (Entorno S = HE total)

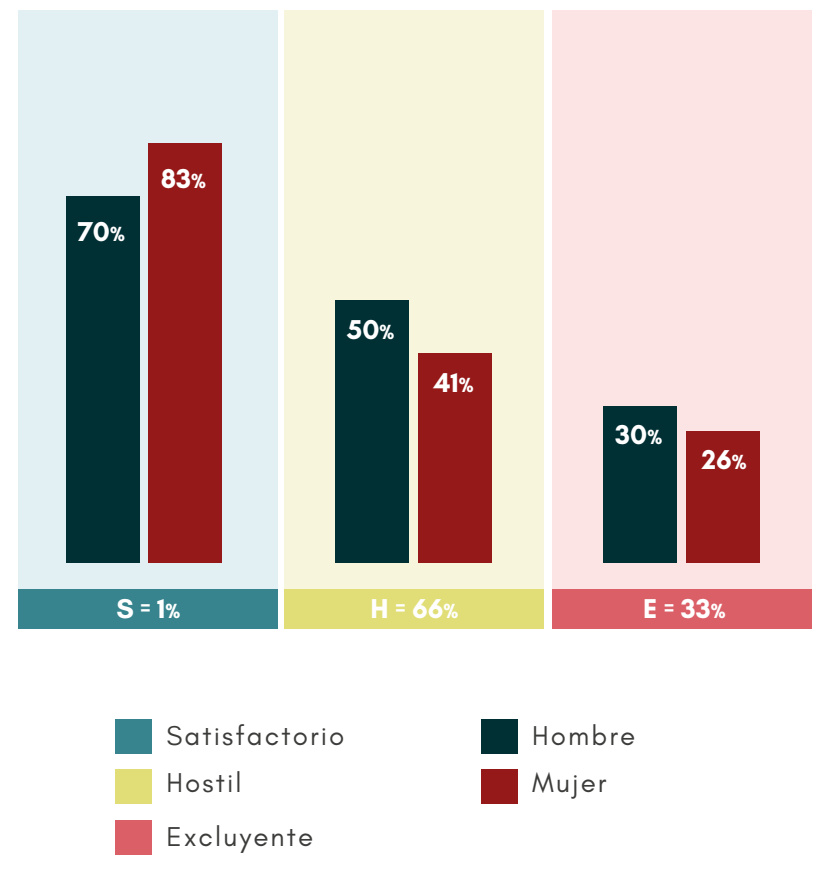


Calidad del sueño en el último mes hombres

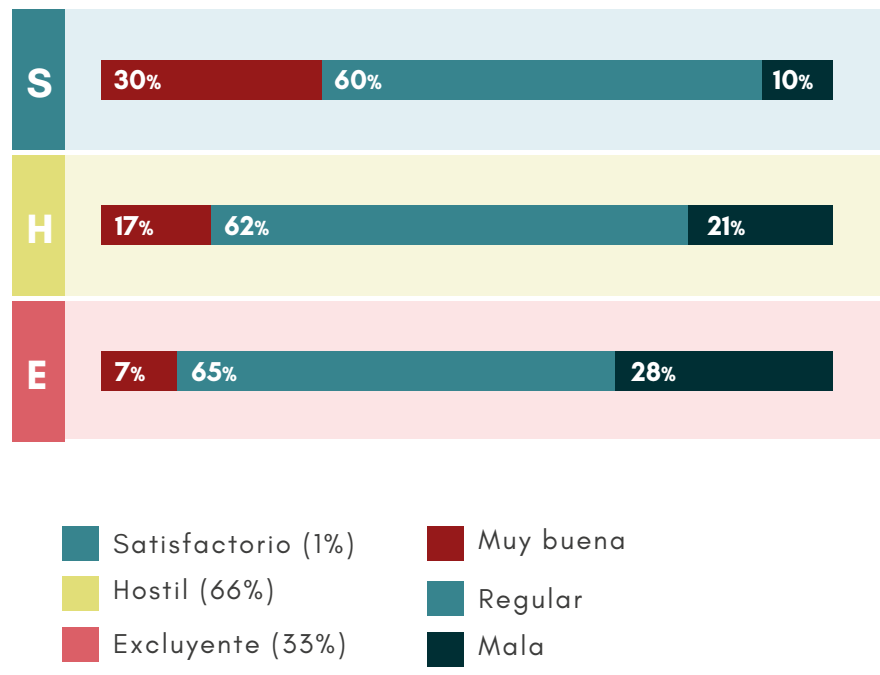

\section{Calidad del sueño en el útlimo mes mujeres}

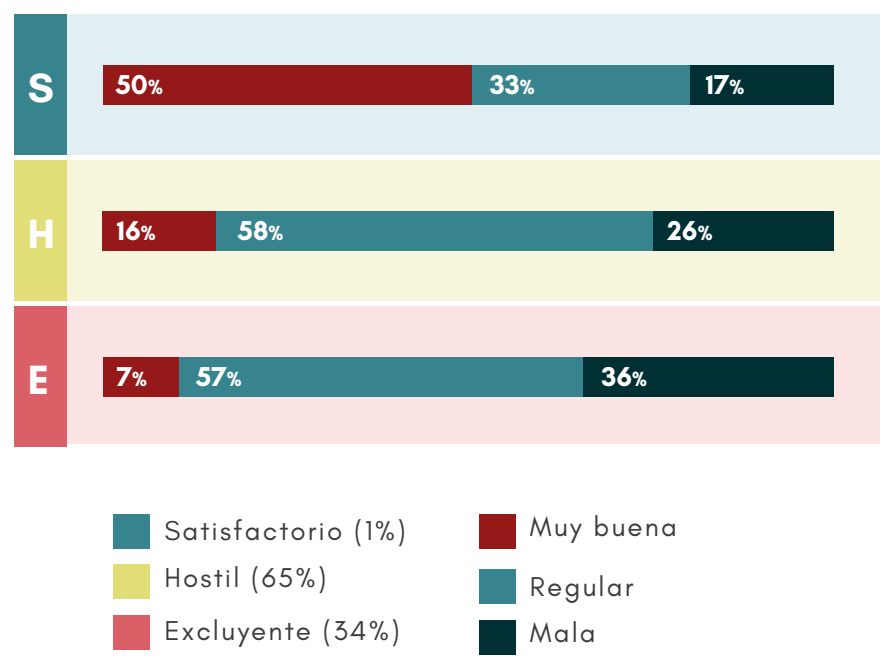

\section{Conflicto hombres}

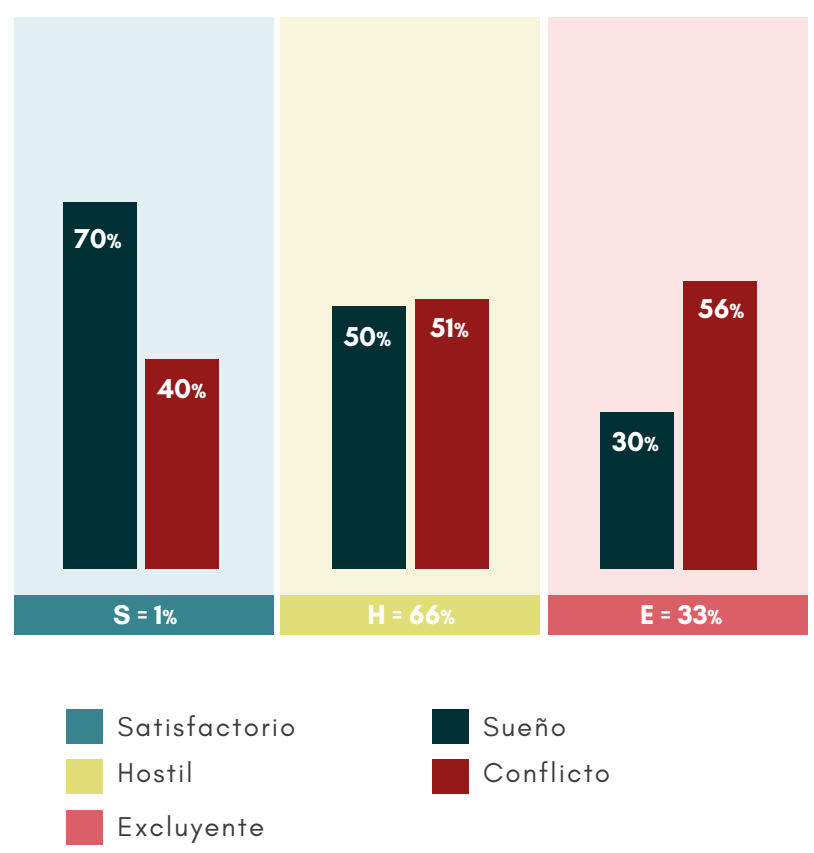

\section{Conflicto mujer}

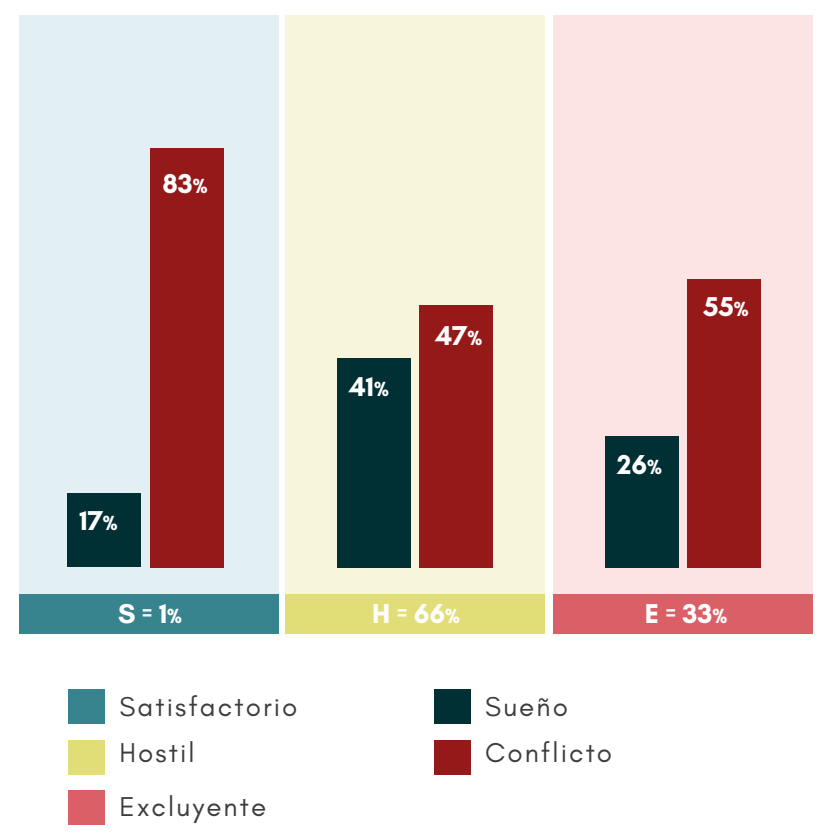




\section{Resultados en la persona: colapso}

Cualquier sociedad del mundo busca una organización y un modo de vida en el que los ciudadanos tengan el mayor bienestar posible. Sin embargo, cada sociedad lo hace del modo que ve más conveniente, con sistemas de gobierno, propuestas políticas y organizaciones sociales que pueden diferir en gran medida entre ellas. Lo que no difiere es la meta: generar calidad de vida.

El concepto de "calidad de vida" es complejo y resultaría difícil llegar a un consenso sobre lo que significa. En este informe, la calidad de vida la medimos con unos parámetros muy sencillos y significativos que, unidos a otros ya reportados (como, por ejemplo, el conflicto trabajo-familia y calidad del sueño) nos ayudan a entender cómo los entornos de igualdad de oportunidades condicionan la salud social de una comunidad o país.

\section{En términos de colapso, las mujeres son las que más sufren las consecuencias de entornos que no fomentan la igualdad de oportunidades}

En este estudio el término "colapso" se refiere a la incapacidad de desarrollar una actividad normal de modo operativo, y se manifiesta en la sensación de no ser capaz de realizar aquello a lo que uno se ha comprometido y que deriva en pensar constantemente en lo que todavía queda por hacer.

El entorno de igualdad de oportunidades repercute sobre el colapso de hombres y mujeres. Sin embargo, son las mujeres las que sufren en mayor medida las consecuencias de entornos que no fomentan la igualdad de oportunidades.

\section{Colapso (Entorno S = HE total)}

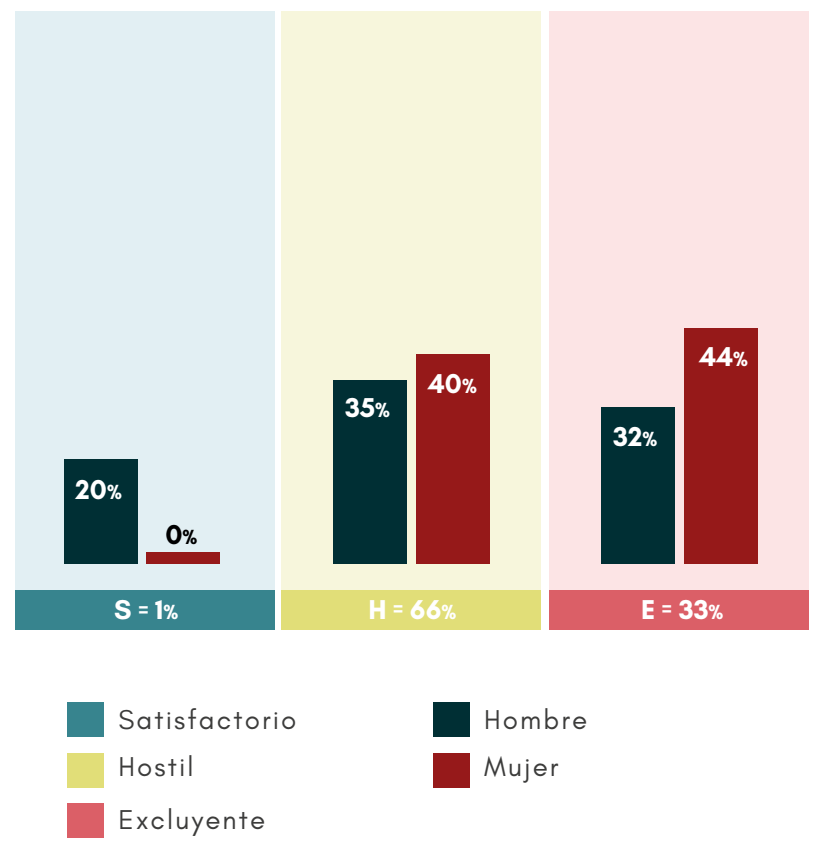


Colapso hombre (Entorno S = HE total)

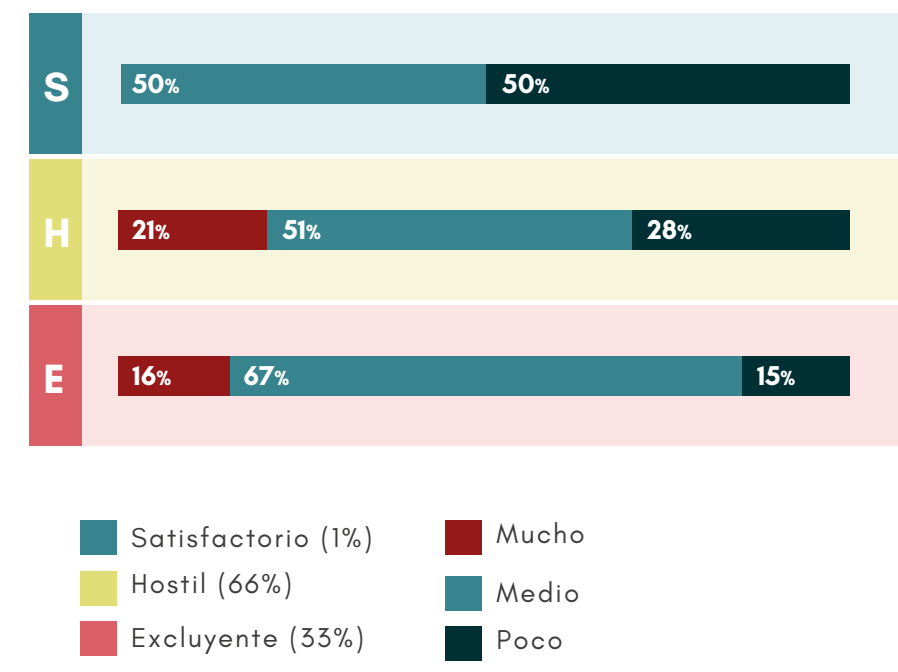

Colapso mujer (Entorno S = HE total)

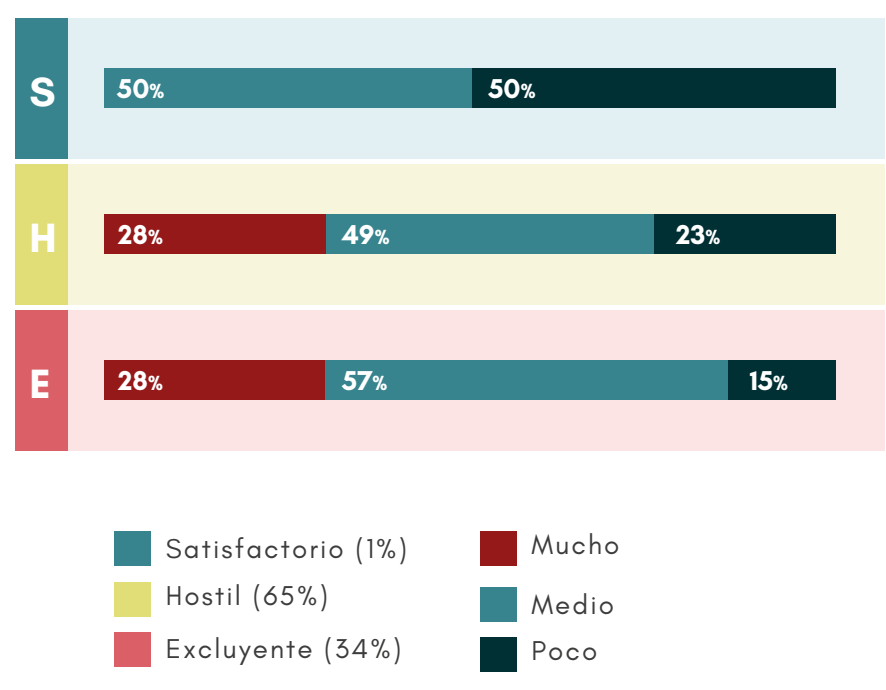




\section{RETOS}

\section{Algunos retos a futuro: estereotipo de trabajador ideal}

Es importante que desaparezca del imaginario colectivo una idea estereotipada sobre la dedicación que requiere ser un trabajador "ideal". El panorama de trabajo actual se caracteriza por ser volátil, incierto, cambiante, acelerado y tecnológico, por lo que el conocimiento, y no la dedicación de tiempo o la disponibilidad para viajar, es ahora lo más relevante, unido a la capacidad de aprender y la voluntad de dar un servicio.

El estereotipo de trabajador ideal se desarrolló a mitad del siglo XX, con la aparición de las grandes corporaciones internacionales. En aquellos momentos era necesario viajar a menudo -puesto que no existían modos eficaces de comunicación remota- y estar disponible constantemente. Pero el entorno ha cambiado radicalmente. Lo que en aquel momento podía ser bueno, e incluso necesario, hoy ya no lo es en modo alguno. Es disruptivo e ineficiente.

En el estudio S=HE medimos hasta qué punto los estereotipos de trabajador ideal siguen aún vigentes. Para hacerlo utilizamos una escala validada para ello ${ }^{28}$ que capta la percepción que se tiene de que para ser un trabajador ideal se debe:
- Estar constantemente disponible para el trabajo cuando a uno le requieren,

- Estar dispuesto a viajar todo lo que sea necesario cuando la empresa lo requiera,

- Estar disponible para cambiar de ciudad si se le requiere, $y$

- Trabajar todas las horas que sean necesarias cada día.

\section{El trabajador ideal debería ser...}

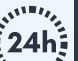

$24 h$

Estar disponible $24 \mathrm{~h}$ en el coso de que se le necesite

Estar dispuesto a viajar si es necesario

\section{Estar dispuesto a} cambiar de ciudad si la empresa lo requiere

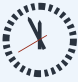
Trabajar cada día todas las horas necesarias para terminar las tareas

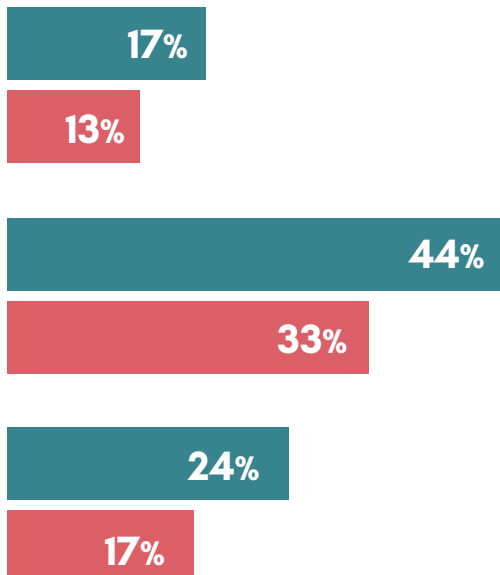

$24 \%$

Hombre Mujer 
La imagen de que el trabajador ideal es aquel que está siempre en disposición de lo que la empresa requiera es aún ampliamente compartida en España, siendo sobre todo los hombres los que están más de acuerdo con ello

Desafortunadamente, los datos de este estudio muestran que más de un tercio de la población está de acuerdo con estas afirmaciones. De modo más exacerbado los hombres. En un $17 \%$ piensan que se debe estar disponible siempre que la empresa lo requiera; en un $44 \%$ piensan que se debe estar dispuesto a viajar siempre que la empresa lo pida; en un $24 \%$ que se debe estar disponible para cambiar de ciudad si a uno le requiere; y en un $39 \%$ que se debe trabajar todas las horas que sean necesarias cada día.

Estas percepciones no son tan mayoritariamente compartidas por las mujeres, que en un $13 \%$ piensan que se debe estar disponible siempre que la empresa lo requiera; en un 33\% piensan que se debe estar dispuesto a viajar siempre que la empresa lo pida; en un $17 \%$ que se debe estar disponible para cambiar de ciudad si a uno le requiere; y en un $32 \%$ que se debe trabajar todas las horas que sean necesarias cada día.

\section{Algunos retos a futuro - Estereotipo de líder ideal}

Es importante que desaparezca del imaginario general una idea estereotipada del líder como alguien dominante y agresivo. El liderazgo es una relación de influencia donde las partes implicadas juegan un papel importante. Liderar ${ }^{29}$ es el arte de movilizar a los demás para alcanzar objetivos compartidos. En consecuencia, en un contexto de mercados complejos y competitivos, el liderazgo es crucial para la sostenibilidad de cualquier actividad económica.

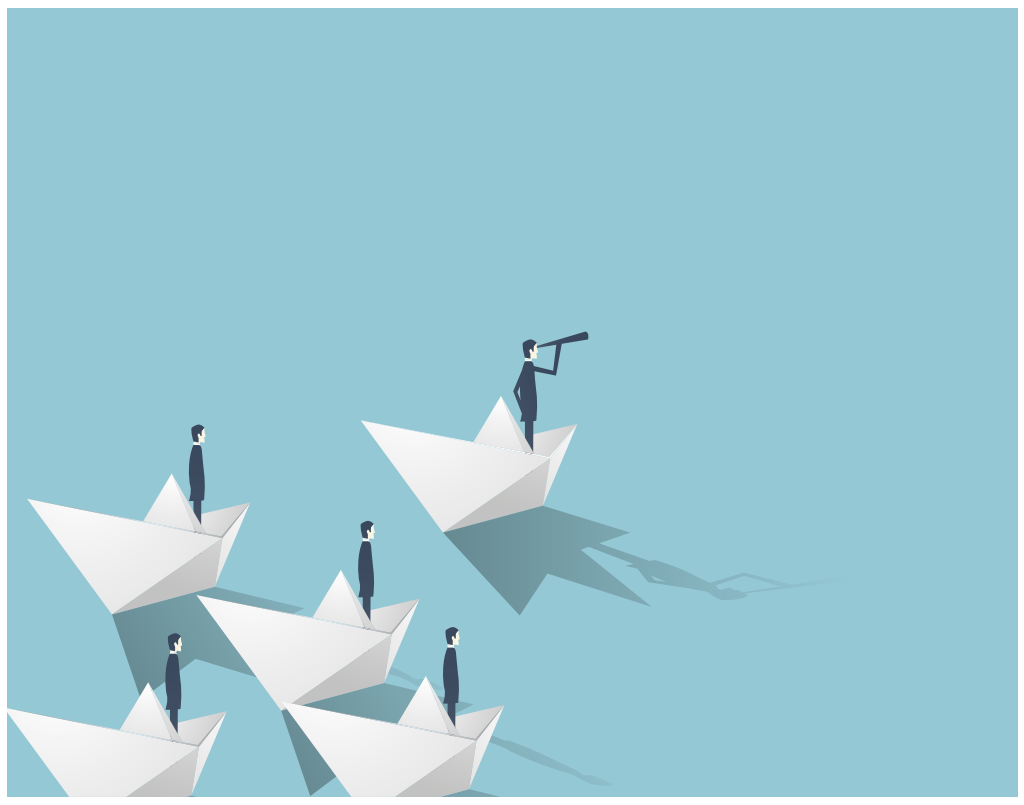


Es más, para contar con líderes capaces de desarrollar la capacidad de liderazgo de los demás, se deberían fomentar las competencias para el liderazgo no solo entre los ejecutivos y directivos, sino también entre los empleados de todos los niveles de una organización.

El verdadero liderazgo es el personal, o lo que es lo mismo, el trascendente ${ }^{30}$. Este tipo de liderazgo se basa en una relación de influencia personal orientada a lograr una misión compartida. Se busca que los empleados se comprometan con una misión que parece convincente tanto para la empresa como para los propios trabajadores ${ }^{31}$.

\section{Características de un buen líder}

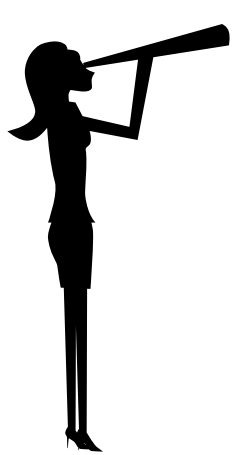

Acogedora

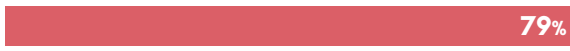

Acogedor

Sensata

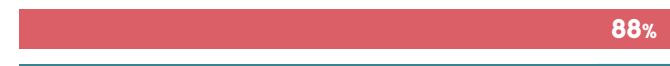

$88 \%$

Trabajadora

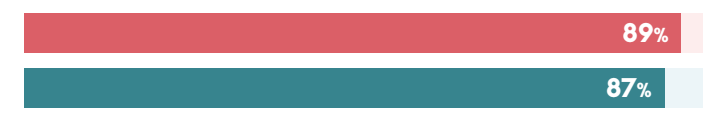

Enérgica

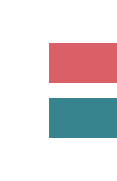

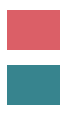

En este caso, los líderes no solo influyen en los demás mediante recompensas y sanciones, sino que también asignan a los empleados tareas atractivas que les permiten aprender y desarrollar sus intereses y aptitudes, además de transmitirles la percepción de que

Resulta indispensable identificar las características arraigadas en el imaginario sobre el líder ideal y evitar aquellas que son contrarias al líder trascendente, el que será realmente eficiente para instaurar un entorno de gualdad de oportunidades.

Agresiva

Sensato

Trabajador

Enérgico

Aresivo

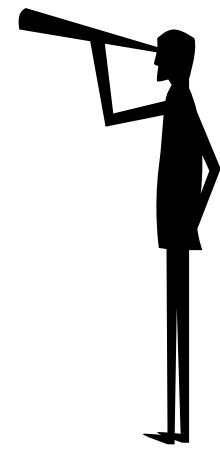

Mujer 


\section{Las empresas y la sociedad necesitan} líderes holísticos que fomentan la eficacia, el aprendizaje personal y colectivo y la generación de unidad

En el estudio S=HE hemos detectado que, afortunadamente, las características que están mayormente ligadas al buen líder son las de: ser acogedor, sensato y trabajador. Todas ellas están en consonancia con la igualdad de oportunidades. Específicamente, las dos primeras, ser acogedor y sensato, son características que habitualmente se habían relacionado con las mujeres ${ }^{32}$. Sin embargo, la buena noticia en el estudio $\mathrm{S}=\mathrm{HE}$ es que a día de hoy en España, tanto hombres como mujeres se definen mayormente como educados y comprensivos, características muy similares a las de ser acogedor y sensato.

Por otro lado, un $42 \%$ de mujeres y un $43 \%$ de hombres creen que el buen líder es aquel que es dominante. Esta característica es antagónica con la igualdad de oportunidades, en la que se trata de crear entornos de contribución y no de imposición.

\section{¿Cómo se definen hombres y mujeres?}

Comprensiva

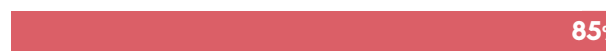

Educada

Dedicada

Fuerte

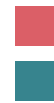

$70 \%$
Comprensivo

Educado

Dedicado
$91 \%$

Fuerte

Dominante

Dominante

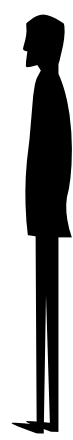

Hombre 


\section{CONCLUSIONES}

\section{El Entorno S=HE y sus consecuencias para hombres y mujeres}

La igualdad de oportunidades para los hombres y las mujeres nace de la premisa de su igual dignidad y su diferencia biológica. También de su singularidad y unicidad. Englobar a todas las mujeres o a todos los hombres en el mismo conjunto es un ejercicio que, aunque en algún caso pueda ser útil, también conduce irremisiblemente a simplificaciones.

Descartar a hombres o a mujeres para alguna posición dentro de la empresa por el mero hecho de ser hombre o mujer es una injusticia y un desacierto. A pesar de ello, en muchas organizaciones es habitual que en la promoción profesional de los empleados se invierta la proporción de mujeres en la plantilla. Es decir, empresas en las que habitualmente se selecciona e integra a un número mayor de mujeres que de varones y en las que, sin embargo, el número de hombres es mucho mayor que el de mujeres en las promociones. $O$ bien, en otras las promociones favorecen desproporcionadamente a los hombres. Como consecuencia, el número de hombres en cargos de responsabilidad suele ser mucho mayor que el número de mujeres.

Como hemos ido desglosando, en el estudio $\mathrm{S}=\mathrm{HE}$ entendemos que esa situación es multi-causada, y que se debe específicamente a los entornos organizativos, familiares y personales en los que hombres y mujeres desarrollan sus tareas.

Idealmente, ni hombres ni mujeres debieran tener una ventaja a la hora de promocionar por el mero hecho de ser hombre y mujer. Lo que debería contar es la competencia para aportar y la motivación a hacerlo.

Resulta dañino, tanto para el resultado de las empresas como para las familias y la sociedad en su conjunto, que los entornos en los que se mueven las personas favorezcan, inadvertidamente o de modo consciente, la promoción de hombres por delante de la de mujeres, o viceversa.

Como hemos visto, la igualdad de oportunidades entre hombres y mujeres tiene muchas consecuencias positivas:

\footnotetext{
- Compromiso con la misión, tanto de hombres como de mujeres. En este punto ambos mejoran su actitud frente a la misión de la empresa; es decir, incrementan su deseo de contribuir a la consecución de la misión de la empresa por el hecho de pensar que es relevante, e independientemente de los resultados externos que eso les comporte (beneficios salariales, etc.).
} 
- Satisfacción en el trabajo; es decir, la actitud positiva de la persona hacia su empresa y la labor que en ella desempeña. La satisfacción con el trabajo es de mucha relevancia ya que está directamente relacionada con otras consecuencias afectivas y de comportamiento, como el compromiso con la empresa, el servicio al cliente o el esfuerzo.

\section{- Disminución del conflicto trabajo-familia; es} decir, de las situaciones en las que las demandas del trabajo o la sobrecarga del mismo dificultan (o incluso hacen imposible) tener una relación satisfactoria con el cónyuge, los hijos u otros familiares dependientes, así como dedicar tiempo a desarrollar otros aspectos relevantes de la vida personal (voluntariado, formación continua, deporte, ocio, etc.).

- Tiempo de dedicación a la familia; es decir, la percepción de que se dedica el tiempo adecuado a lo que la familia requiere. El entorno S=HE de igualdad de oportunidades afecta especialmente a la percepción que tienen las mujeres del tiempo que dedican a su familia. Aunque también afecta a los hombres, el efecto es mucho menor.

\section{- Satisfacción con las distintas áreas de la}

vida; es decir, la satisfacción derivada de las diversas áreas vitales: hobbies, amistades, familia y condición física.

- Calidad del sueño, que depende en gran medida del entorno, y disminuye conforme el entorno es menos favorable. En el caso de las mujeres, en un entorno S (Satisfactorio) la calidad del sueño es mucho mayor que la de los hombres. Sin embargo, cuando el entorno se deteriora, la calidad del sueño de hombres y mujeres empeora en un mismo grado.

- Colapso. El colapso en los hombres, es decir, su percepción de imposibilidad a la hora de desarrollar una actividad normal de modo operativo y manifestada en la sensación de no ser capaz de realizar aquello a lo que uno se ha comprometido, es casi independiente del entorno de igualdad de oportunidades.

Para las mujeres la sensación de colapso depende en gran medida del entorno de igualdad de oportunidades en que se encuentren. Una situación lógica si tenemos en cuenta que son ellas las que asumen una mayor responsabilidad en la realización de las tareas del hogar y del cuidado de los niños y de los mayores (cuando existe la necesidad). 


\section{El Entorno S=HE y la promoción en las empresas: un tema acuciante para las mujeres}

En el estudio S=HE medimos hasta qué punto hombres o mujeres tienen mayor facilidad de promocionar dentro de su empresa por motivo de los entornos en los que desempeñan su trabajo. Lo ideal sería que ni hombres ni mujeres tuviesen mayor facilidad de ascencer por el hecho de ser hombre o mujer.

\section{Las promociones deberían concederse exclusivamente en base a los méritos demostrados en el cumplimiento de responsabilidades}

Las promociones deberían concederse exclusivamente en base a los méritos -que no solo resultadosdemostrados en el cumplimiento de responsabilidades, de la actitud mostrada ante una posible promoción. $Y$ esas características no tienen sexo masculino ni femenino.

Lo deseable sería que en una empresa, cuando le preguntamos a los empleados si "¿es más fácil promocionar a la mujer que al hombre?", la respuesta fuese tajante: "NO". Y cuando le preguntásemos: “¿Es más fácil promocionar al hombre que a la mujer?", la respuesta fuese también "NO".

\section{Los datos del estudio S=HE muestran que las personas no perciben igualdad de oportunidades en las organizaciones. $Y$ esto es negativo tanto para la empresa, como para las familias y la sociedad}

Sin embargo, nos encontramos lejos de esta situación. Los datos nos muestran que un alto porcentaje de hombres, y uno aún mayor de mujeres, piensan que los primeros tienen mayor facilidad a la hora de promocionar que las mujeres.

\section{Un $68 \%$ de las mujeres piensan que en sus empresas se favorece la promoción de los hombres por encima de la de las mujeres}

En el estudio $\mathrm{S}=\mathrm{HE}$, un $68 \%$ de las mujeres, con independencia del tipo de entorno en el que se encuentren, opinan que en sus empresas se favorece la promoción de los hombres por encima de la de las mujeres.

En cuanto a la opinión masculina, el porcentaje de hombres que cree que el entorno facilita más la promoción a los de su género crece cuanto peor es el entorno respecto a la igualdad de oportunidades. Así pues, en un entorno $E$, el peor respecto a la igualdad de oportunidades, el $49 \%$ de los hombres piensan que en su empresa el entorno beneficia a los hombres por encima de las mujeres; en un entorno S (satisfactorio) ese porcentaje cae hasta el $20 \%$.

También nos encontramos con un porcentaje de hombres y mujeres (mayor el de los primeros) que piensan que las mujeres tienen más posibilidades de promocionar por el mero hecho de ser mujeres. Curiosamente, mientras el porcentaje de hombres que creen que las mujeres salen beneficiadas en su empresa aumenta cuanto peor es el entorno, el porcentaje de mujeres que piensan que se beneficia a las mujeres disminuye cuando el entorno empeora. 


\section{Percepción de la ventaja del hombre}

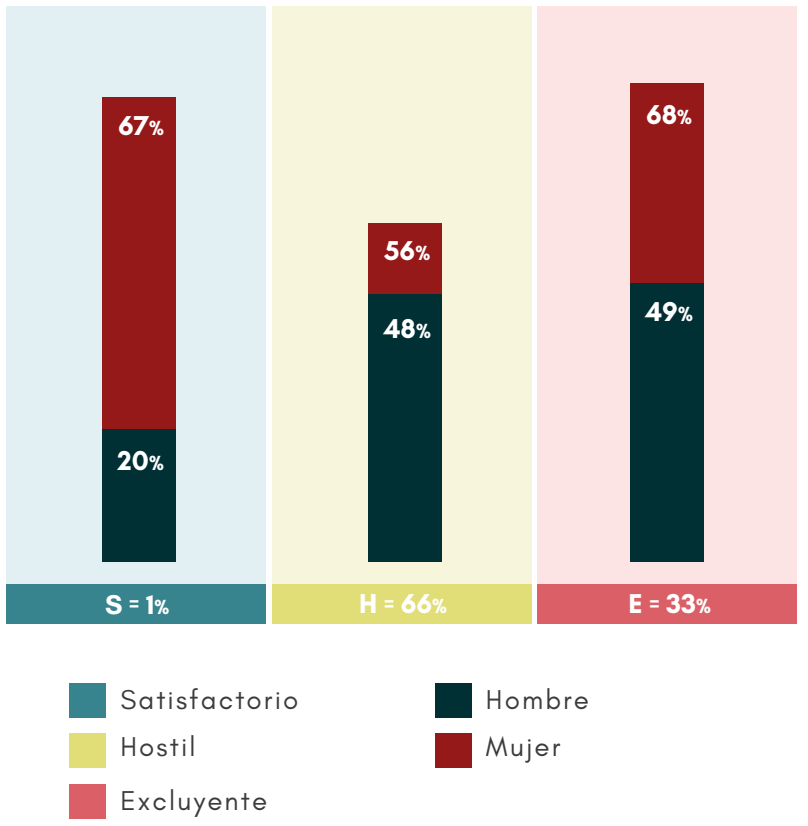

\section{Percepción de la ventaja de la mujer}

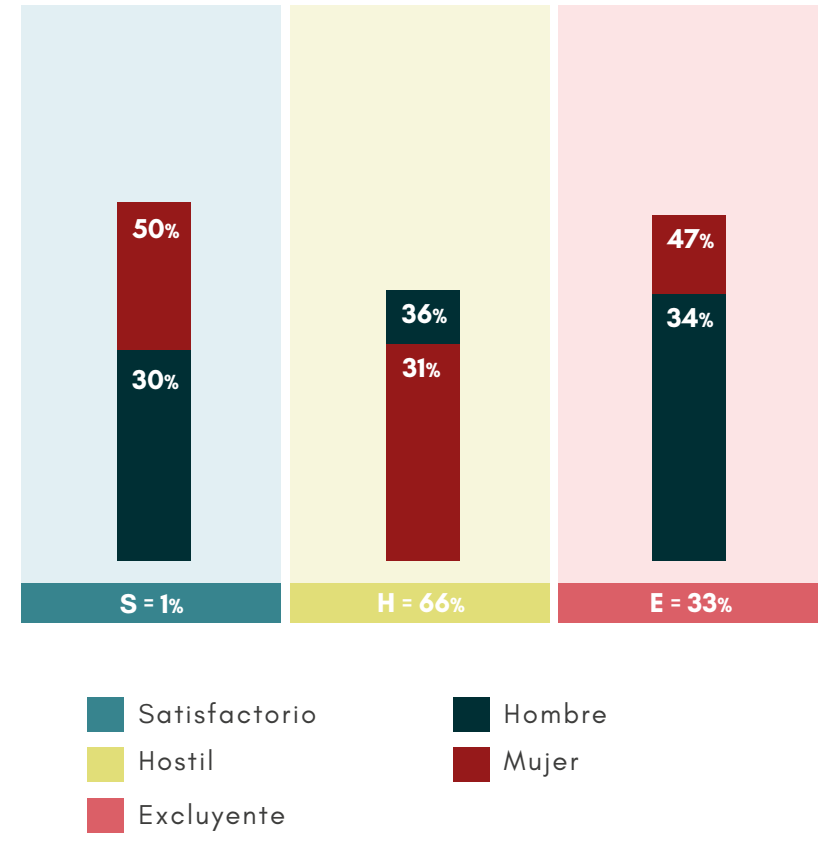

\section{Conclusiones}

Para cualquier ciudadano trabajador, el trato digno y justo es un derecho. Por lo tanto, la igualdad de oportunidades también lo es.

Como hemos repetido innumerables veces a lo largo de este estudio, la igualdad de oportunidades debería ser facilitada por la empresa, pero también por la sociedad, la propia familia y, no menos importante, la propia persona.

$\mathrm{Ni}$ los que toman decisiones en las empresas ni los legisladores ni los miembros de una familia ni trabajador alguno deben descargar la responsabilidad sobre otros. Todos debemos trabajar sinérgicamente en la creación de un entorno de igualdad de oportunidades que favorecerá el desarrollo de la competitividad industrial, de las familias y del país en su conjunto.

Sin embargo, son las mujeres, y por ende los que de ellas dependen, las que más sufren las consecuencias de la falta de entornos de igualdad de oportunidades. Es un derecho de todos, y un deber de todos, seguir trabajando para que estos entornos de igualdad de oportunidades sean la norma y no la excepción. Para que las consecuencias positivas se extiendan y hagan de nuestras empresas, nuestra sociedad y nuestras familias un lugar más humano, más justo y más digno. 


\section{REFERENCIAS}

1 José Manuel Montero y Ana Regil (2015): La tasa de actividad en España: resistencia cíclica, determinantes y perspectivas futuras, Documentos ocasionales n. ${ }^{0} 1502$ [online], Banco de España.

2 Instituto Nacional de Estadística - INE (abril 2017): Encuesta de Población Activa (1T/2017) [online].

3 María Genoveva Millán Vázquez de la Torre, Manuela del Pilar Santos Pita, Leonor María Pérez Naranjo (2015): "Análisis del mercado laboral femenino en España: evolución y factores socioeconómicos determinantes del empleo", Pap. poblac [online]. vol.21, n.84, pp.197-225.

4 Instituto Nacional de Estadística - INE, Nota de prensa: Estadística de estudiantes universitarios. Curso 2014/2015. Ministerio de Educación, Cultura y Deporte.

5 Matilde Alonso Pérez y Elíes Furió Blasco (2010): “La economía española. Del crecimiento a la crisis pasando por la burbuja inmobiliaria", Cahiers de civilisation espagnole contemporaine [online], 6 .

6 Universidad Complutense de Madrid (2013): "Análisis de algunas de las causas últimas de la desigualdad de género en el mercado laboral. Implicaciones para las políticas de empleo". Panorama Laboral 2013 [online]
7 Instituto Nacional de Estadística - INE (2013): Estadísticas de mercado laboral, Brecha salarial de género (no ajustada) en salarios por hora [online].

8 Ref. ídem a núm. 6.

9 Chinchilla N., Jiménez E. y Grau M. (2017): Maternidad y Trayectoria profesional, IESE.

10 Instituto Nacional de Estadística - INE (octubre 2014): Nota de prensa, "Proyección de la Población de España 2014-2064" [online].

$11 \mathrm{Nishii,} \mathrm{L.} \mathrm{H.} \mathrm{(2013).} \mathrm{The} \mathrm{benefits} \mathrm{of} \mathrm{climate} \mathrm{for} \mathrm{inclusion}$ for gender-diverse groups. Academy of Management Journal, 56(6), 1754-1774.

12 Adaptado de Hammer, Kossek, Yragui, Bodner and Hanson (2008): Development and Validation of a Multidimensional Measure of Family Supportive Supervisor Behaviors (FSSB). Journal of Management.

13 Ref. ídem a núm. 11.

14 Bird, G.W., Bird, G.A. and Scruggs, M. (1983): Role Management strategies used by husbands and wives in two-earner households. Home Economics Research Journal, 12; 63-70 
15 Hall, D.T. (1972): A model of coping with role conflict: The role behavior of college educated women.

Administrative Science Quarterly, 17: 471-486

16 Caplan, R. D., R. V. Harrison, and J. R. P. French, Jr. (1980): "Mechanisms of job stress and strain" Duplicated. Ann Arbor: Institute for Social Research, The University of Michigan.

17 Caplan, Robert D., Sidney Cobb, John R. P. French, Jr., R. Van Harrison, and S. Richard Pinneau (1975):

Job Demands and Worker Health. U.S. Department of Health, Education and Welfare, HEW (NIOSH) Publication No. $75-160$

18 Ripley, J. S., Worthington, E. L., Bromley, D., \& Kemper, S. D. (2005): Covenantal and contractual values in marriage: Marital Values Orientation toward Wedlock or Self-actualization (Marital VOWS) Scale. Personal Relationships, 12 (3), 317-336.

19 Chillida, M. y Guerra M.J. (2008): Buenas prácticas para integrar la igualdad de género en las empresas, Fundación Mujeres [online].

20 Bird, G.W., Bird, G.A. and Scruggs, M. (1983): Role Management strategies used by husbands and wives in two-earner households. Home Economics Research Journal, 12; 63-70
21 Ripley, J. S., Worthington, E. L., Bromley, D., \& Kemper, S. D. (2005): Covenantal and contractual values in marriage: Marital Values Orientation toward Wedlock or Self-actualization (Marital VOWS) Scale. Personal Relationships, 12 (3), 317-336.

22 Ref. ídem a núm. 11.

23 Chinchilla y Moragas, 2007; Kelly y otros 2008

24 Matthews R., Kath, L., Barnes-Farrell, J. (2006): A short, valid, predictive measure of work-family conflict: item selection and scale validation, Journal of Occupational Health Psychology, Vol 15 (1) cuestionario.

25 Ferreiro, P., \& Alcázar, M. (2002): Gobierno de Personas en la Empresa. Barcelona: Ariel.

26 Glenn, N. D., \& Weaver, C. N. (1981). The Contribution of Marital Happiness to Global Happiness. Journal of Marriage and Family, 43(1), 161-168

27 Durmer, J.S., \& Dinges D.F. (2005): Neurocognitive consequences of sleep deprivation, Seminars in Neurology, 25, 117-129. 
28 Glaveli, N., Karassavidou, E., \& Zafiropoulos, K. (2013): Relationships among three facets of family-supportive work environments, work-family conflict and job satisfaction: a research in Greece. International Journal of Human Resource Management, 24(20), 3757-3771.

29 Kouzes, J. M., \& Posner, B. Z. (1987): The Leadership Challenge: How to get Extraordinary Things Done in Organizations. San Francisco, CA: Jossey-Bass.

30 Chinchilla, N., \& Moragas, M. (2008). Masters of our destiny: EUNSA.

31 Perez-Lopez, J. A. (1996): Fundamentos de la Dirección de empresas. Madrid, $3 a$ ed. Rialp

32 La escala utilizada para medir las características del líder ideal es la desarrollada por: Epitropaki, $O$. \& Martin, R. (2004). Implicit Leadership Theories in Applied Settings: Factor Structure, Generalizability, and Stability Over Time. Journal of Applied Psychology, 89, 293-310. Se han hecho adaptaciones para acortar el cuestionario. 
